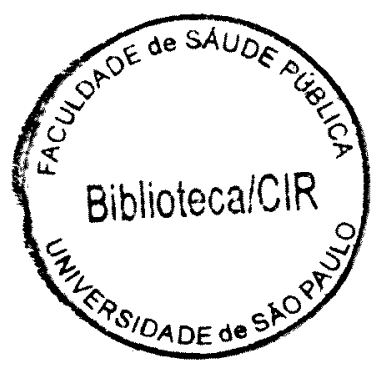

IMPACTO DA ASSISTÊNCIA MÉDICA SOBRE A MORTALIDADE UM ESTUDO DA VARIAÇÃO GEOGRÁFICA DA MORTALIDADE EVITÁVEL NAS CAPITAIS BRASILEIRAS (1979-1992)

PAULO MAURICIO CAMPANHA LOURENÇO

SÃO PAULO

1997 
IMPACTO DA ASSISTÊNCIA MÉDICA SOBRE A MORTALIDADE UM ESTUDO DA VARIAÇÃO GEOGRÁFICA DA MORTALIDADE EVITÁVEL NAS CAPITAIS BRASILEIRAS (1979-1992)

Tese apresentada na Faculdade de Saúde Pública da Universidade de São Paulo pelo Departamento de Epidemiologia para obtenção de Título de Doutor em Saúde Pública.

Autor: Paulo Mauricio Campanha Lourenço

Orientador: Jair Lício Ferreira Santos

São Paulo

1997 


\section{AGRADECIMENTOS}

Sou grato a todos os professores do Departamento de Epidemiologia (FSP/USP), especialmente, aos Professores Titulares Jair Lício Ferreira Santos (orientador), Ruy Larenti (Membro da Comissão Julgadora) e Gilberto Ribeiro Arantes, e ao Professor Associado Augusto Haziak Santo, pela orientação e incentivo, e a todos os funcionários pela gentileza e apoio administrativo, nas diversas etapas de realização deste trabalho.

Agradeço as interessantes críticas e sugestões apresentadas pelos demais membros da Comissão Julgadora: Professora Doutora Mariliza Berti de Azevedo Barros (Departamento de Medicina Social da Faculdade de Ciências Médicas da UNICAMP), Professora Adjunta Maria Cecília de Souza Minayo (Departamento de Ciências Sociais da ENSP) e Professor Titular Laércio Joel Franco (Departamento de Medicina Preventiva da UNIFESP). 


\author{
R E S U M O
}

\title{
Impacto da Assistência Médica Sobre a Mortalidade. Um Estudo da Variação Geográfica da Mortalidade Evitável nas Capitais Brasileiras (1979-1992).
}

Introdução: A distribuição regional e temporal dos óbitos evitáveis, considerados como eventos sentinelas de saúde, têm sido utilizadas como indicador negativo da qualidade dos cuidados de saúde, do nível de saúde da população em geral e do efeito nele provocado por fatores econômicos, políticos e ambientais. Os estudos de análise de tendência temporal, em geral, demonstram que a mortalidade evitável declina mais rapidamente nas últimas décadas que a maioria das outras causas de óbito e sugerem que o declínio está associado à introdução de inovações nos serviços de saúde. Os estudos de variação geográfica demonstram que a mortalidade evitável está associada de modo consistente a fatores socioeconômicos e que a associação com o nível de recursos materiais e humanos de cuidados de saúde é fraca e inconsistente. Nesses estudos, a variação geográfica da mortalidade observada, não parece refletir diferenças de efetividade dos serviços de saúde mas flutuações "espontâneas" na incidência ou severidade dessas condições.

Objetivos: Tendo como premissa que deve ser inversa a relação entre a efetividade da assistência médica e a incidência de óbitos evitáveis por causas indicadoras de cuidados de saúde (CICS), é proposta uma lista de causas de doenças que possuem prevenção e tratamento reconhecidos e cuja ocorrência do óbito pode ser minimizada. Em seguida, é estimada a variação geográfica dos óbitos e do nível de mortalidade nos periodos de 1979-1982 e 1989-1992 e estimado o impacto da assistência médica no declinio da mortalidade por CICS nas capitais brasileiras em 1992.

Metodologia: São construídas vinte e seis bases de dados de área geográfica (25 capitais e o Distrito Federal) contendo todas as causas de óbito classificadas em quatro grupos de análise: Todas as causas (exceto as evitáveis), Todas as causas evitáveis (29 causas básicas), subdividido em (1) Causas indicadoras de políticas sociais e de saúde - CIPSS ( 6 causas básicas) e Causas indicadoras de cuidados 
de saúde - CICS (23 causas básicas), codificadas em três dígitos de acordo com a $9^{\star}$ Classificação Internacional de Doenças de 1975, agregadas anualmente para ambos os sexos em sete grupos etários de 0 a 64 anos de idade abrangendo o período de 1979-1992. As populações das capitais são estimadas a partir dos dados dos Censos Nacionais de 1980 e 1991, ajustadas aritmeticamente para $1^{\circ}$. de julho e calculada a taxa geométrica de crescimento intercensitária. A análise da variação regional dos óbitos, visa esclarecer se ocorre mais variação sistemática entre as áreas do que poderia ser explicado por fatores aleatórios $\left(X^{2}, g 1=k-1=25, p \leq 0,002\right)$ e pela análise exploratória da distribuição de frequência da variância existente. A Razão da Mortalidade Padronizada - RMP (Standardised Mortality Ratio - SMR) é calculada pela divisão da taxa diretamente padronizada em cada área pela taxa de mortalidade da área de referência (conjunto das capitais e Distrito Federal). O nível de significância da divergência com padrão de referência (razão entre óbitos observados e esperados com a padronização) é analisado pelo teste $\mathrm{X}^{2}$ $(\mathrm{gl}=1 ; \mathrm{p} \leq 0,002)$. $\mathrm{O}$ impacto da assistência médica sobre o declínio da mortalidade é estimado pela Razão de Mortalidade Evitável (RME). A RME indica a diferença percentual do nível de mortalidade por CICS observada em 1992 em relação ao que provavelmente ocorreria na ausência da assistência médica $\left(X^{2} ; g l=1 ; p \leq 0,002\right)$. Esse cenário de previsão é simulado pela aplicação do coeficiente de regressão das taxas padronizadas de mortalidade por CIPSS (1979-1992), obtido pela análise de regressão loglinear, na taxa de mortalidade por CICS estimada para 1979 por regressão loglinear.

Resultados: A mortalidade por CICS declina exponencialmente (5,4\% aa.) de 1979 a 1992 e sua distribuição toma-se mais homogênea no conjunto das capitais ao final do período. A intervenção médica, quando medida pela RME, contribui de forma significativa $(p \leq 0,002)$ e abrangente $(85 \%$ das capitais) para este declínio (2,5\% aa. no conjunto, variando de $11,1 \%$ aa. em Fortaleza a $0,3 \%$ aa. em Vitória). A intervenção médica é igualmente efetiva no declínio da mortalidade por CICS na maioria das capitais, seja quando interpretada pela freqüência de resultados significativos alcançados entre capitais de uma mesma macrorregião, exceto para Boa Vista $\left(X^{2}=5,27 \mathrm{p}=0,02165\right)$, onde desempenho é superior ao esperado para as demais capitais da região, seja quando a comparação se faz entre todas as capitais, exceto para Boa Vista $\left(X^{2}=9,84 p=0,00171\right)$ e Goiânia $\left(X^{2}=4,30 p=0,03815\right)$, ou mesmo entre as macrorregiões $\left(X^{2}=3,89 p=0,42163\right)$. Portanto, se há diferença geográfica de efetividade da intervenção médica, ela não pode ser explicada pela proporção de causas de óbito evitável que têm parte importante de seu declínio devido à influência da assistência médica. A intervenção médica é mais freqüentemente efetiva nas capitais com nível de mortalidade por CICS (RMP) superior ao esperado. Esta comparação é tão válida para o período de 1979-1982 $\left(\mathrm{X}^{2}=19,92 \mathrm{p}=0,00001\right)$ quanto para 1989-1992 $\left(\mathrm{X}^{2}=20,52\right.$ 
$\mathrm{p}=0,00001$ ) e torna evidente a importância da intervenção médica para a maior homogeneidade da mortalidade por CICS entre as capitais $(\mathrm{s}=23,34 \mathrm{p}=0,5576$ ), bem como para declínio do nível de mortalidade: das sete capitais com RMP superior a esperada em 1979-1982, apenas Maceió ( $R M P=146$ $\mathrm{p} \leq 0,002)$, João Pessoa $(R M P=156 \mathrm{p} \leq 0,002)$ e Aracaju ( $R M P=153 \mathrm{p} \leq 0,002)$ encontram-se nesta situação em 1989-1992. A intervenção médica não é igualmente efetiva $\left(\mathrm{X}^{2}=70,42 \mathrm{p}=0,0000\right)$ quando seu impacto sobre a mortalidade é interpretado pela frequência de resultados significativos alcançados pelas diversas causas de óbito evitável. O componente mais expressivo da influência da intervenção médica sobre a mortalidade por CICS é sua contribuição para tendência exponencial de declínio da mortalidade por doenças infecciosas intestinais: é a segunda maior taxa de mortalidade estimada em $1992\left(Y^{\prime}=82 / 10^{5}\right)$, a intervenção médica é efetiva em $100 \%$ das capitais e contribui com $83,8 \%$ da taxa de declínio $(12,07 \%$ aa. $)$ desta causa no conjunto das capitais.

Conclusão: As causas de óbito evitável, considerando a influência da intervenção médica na sua taxa de declínio e o nível de mortalidade existente, podem ser classificadas em quatro grupos de acordo com sua contribuição para o declínio global das CICS no conjunto das capitais: (1) Causas que mais contribuem: doenças infecciosas intestinais $\left(X^{2}=33,16 p=0,00000\right)$ e septicemia $\left(X^{2}=6,58 p=0,01033\right)$; (2) Causas que menos contribuem: tumor maligno de útero não especificado $\left(X^{2}=4,63 \quad p=0,03144\right)$, tumor maligno de colo de útero $\left(X^{2}=4,96 \mathrm{p}=0,02591\right)$, doença pulmonar obstrutiva crônica $\left(X^{2}=3,88\right.$ $\mathrm{p}=0,04899)$ e nefrite e nefrose $\left(\mathrm{X}^{2}=5,63 \quad \mathrm{p}=0,01765\right)$; (3) Causas que contribuem o esperado: tuberculose $\left(X^{2}=2,67 \quad \mathrm{p}=0,10253\right)$, diabetes melito $\left(X^{2}=0,5337 \mathrm{p}=0,46506\right)$, meningite $\left(X^{2}=1,49\right.$ $p=0,22250)$, hipertensão arterial $\left(X^{2}=0,0039 \quad p=0,95027\right)$, doença cerebrovascular $\left(X^{2}=0,70\right.$ $\mathrm{p}=0,40267)$, infeç̧̃es respiratórias agudas $\left(X^{2}=0,2059 \mathrm{p}=0,64997\right)$, pneumonia e gripe $\left(X^{2}=2,36\right.$ $\mathrm{p}=0,12473)$, complicações da gravidez, parto e puerpério $\left(X^{2}=3,58 \quad \mathrm{p}=0,05864\right)$ e sintomas, sinais $\mathrm{e}$ afecções mal definidas $\left(\mathrm{X}^{2}=0,055 \mathrm{p}=0,81453\right)$; $\mathrm{e}$ (4) Causas que não contribuem: melanoma maligno de pele, doença de Hodgkin, doença reumática crônica do coração, asma, úlcera gástrica, duodenal e jejunal, apendicite, hérnia abdominal, colelitíase e colecistite. 


\section{Sumnary}

The Impact of Medical Care over Mortality. A Study the Geographical Variation of Avoidable Mortality in the Brazilian Capitals (1979-1992).

Introduction: The distribution in time and space of avoidable mortality, considered as health sentinels events, has been used as a negative indicator of the quality of health care, of the health level of the population in general and of the effect it provoked for economy, politics and the environment factors. Frequently, study on temporal trend indicate that avoidable mortality has declined faster during the last decades than the other causes of death and suggest that such decline is associated with the introduction of innovations in health care. Survey on the geographical variation has show that avoidable mortality is firmly related to socio-economic factors and that the association with the level of material and human supplies is weak and inconsistent. The geographical variation observed in the survey does not seem to reflect differences in the effectiveness of health care but, instead "spontaneous" fluctuations in the incidence or severity of such conditions.

Objectives: Our premise is that is inverse the relationship between the effectiveness of health care and the incidence of death that could be avoided (Health Care Indicators - CICS). Thus, we propose a list of diseases that have recognised prevention and therapy in which the occurrence of death can be minimised. After that, the geographical variation of death and the mortality level in the two periods (1979-1982 and 1989-1992) is estimated, as well as, the impact of medical care in the decline of mortality caused by CICS in the Brazilian capitals in 1992.

Methodology: Twenty-six databases of geographical area were built with all causes of death classified into four analysis groups: all causes (except the avoidable ones), all avoidable causes (twenty-nine basic causes), subdivided into Social and Health Polities Indicators - CIPSS (six basic causes), and Health Care Indicators - CICS (twenty-three basic causes) codified in three digits according to the $9^{\text {th }}$ International Classification of Diseases, put together every year for both sex in seven age groups $(0$ to 64 years) within the period 1979-1992. The population of the capitals is estimated based on 1980 and 1991 National Census arithmetically adjusted to July $1^{\text {st }}$ and calculating the geometric rate of the 
systematic variation among the areas than could be explained by random factors $\left(X^{2}, g l=k-1=25\right.$, $p \leq 0.002)$ and by the exploratory analysis of the frequency distribution of variance. The Standardized Mortality Ratio (RMP) is calculated by the division of the directly standardized in each area by the mortality rate of the reference area (all capitals). The level of significance of divergence (the ratio between the observed death and those expected with standardisation) is analysed by the $\chi^{2}$ Test $(\mathrm{gl}=1$, $p \leq 0.002)$. The impact of medical care over the reduction of mortality is estimated by the Avoidable Mortality Ratio (RME). RME indicates the percentage of difference of mortality level by CICS observed in 1992 and the one which would probably happen without medical care $\left(\chi^{2}, g l=1, p \leq 0.002\right)$. This previewed setting is simulated by the use of the regression coefficient of the standardized ratios of the mortality by CIPSS, which was obtained by the loglinear regression analysis (1979-1992), on the rate of mortality by CICS estimed to $19 \% 9$ by loglinear regression.

Results: CICS mortality declined exponentially (5.4\% per year) from 1979 to 1992 and this distribution is more homogeneous among the capitals at the end of the period. Medical intervention, when measured by RME, contribute significantly ( $\mathrm{p} \leq 0.002)$ and comprehensively ( $85 \%$ of the all capitals) to the result (2.5\% per year, ranging from $11 \%$ in Fortaleza to $0.3 \%$ in Vitoria). Medical intervention is equally effective in the decline of mortality by CICS in most capitals, either when it is interpreted by the frequency of significant results achieved among the capitals of a same macroregion, except for Boa Vista $\left(X^{2}=5.27 \mathrm{p}=0.02165\right)$ where the performance is better than in other capitals of a same region, or when all capitals are compared, exceph, again, for Boa Vista $\left(X^{2}=9.84 \quad \mathrm{p}=0.00171\right)$ and Goiânia $\left(X^{2}=4.30\right.$ $\mathrm{p}=0.03815)$ or even among the macroregion $\left(X^{2}=3.89 \mathrm{p}=0.42163\right)$. Therefore, if there is geographical difference of the effectiveness of medical intervention, it cannot be explained by the proportion of causes of avoidable deaths which have an important part of their decline due to influence of medical care. Medical intervention is more frequently effective in the capitals with a level of mortality by CICS higher than expected. This comparison is valid not only for the period in 1979-1982 $\left(X^{2}=19.92 p=0.00001\right)$, but also for the period in 1989-1992 $\left(\mathrm{X}^{2}=20.52 \mathrm{p}=0.00001\right)$ and it makes clear the importance of medical intervention for a higher homogeneity of mortality by CICS among the capitals ( $\mathrm{s}=23.34$ $\mathrm{p}=0.5576$ ) as well as for the decline of the mortality level: from the seven capitals with SMR higher than expected in 1979-1982, only Maceió ( $R M P=146 \mathrm{p} \leq 0.002$ ), João Pessoa ( $R M P=156 \mathrm{p} \leq 0.002)$ e Aracaju ( $\mathrm{RMP}=153 \mathrm{p} \leq 0.002)$ are in this situation in 1989-1992. Medical intervention is not equally effective $\left(\mathrm{X}^{2}=70.42 \mathrm{p}=0.00000\right)$ when its impact on mortality is interpreted by the frequency of 
significant results achieved by several causes of avoidable death. The most expressive component of the influence of medical intervention over mortality by CICS is its contribution to the exponential tendency of decline of mortality by infectious intestinal diseases: it is the second highest mortality rate estimed in $1992\left(Y^{\prime}=82 / 10^{5}\right)$, medical intervention is effective in all capitals and contributes with $83.8 \%$ of the decline rate (12.07\% per year) of this cause among the capitals.

Conclusion: The causes of avoidable death, considering the influence of medical intervention in its decline rate and the existent mortality level, can be classified in four groups, according to its contribution to global decline of CICS among the capitals: (1) causes which contribute the most: infectious intestinal diseases $\left(X^{2}=33.16 \mathrm{p}=0.00000\right)$ e septicaemia $\left(X^{2}=6.58 \mathrm{p}=0.01033\right)$; (2) causes which contribute the least: malignant neoplasm of uterus $\left(X^{2}=4.63 p=0.03144\right)$, malignant neoplasm of cervix uteri $\left(X^{2}=4.96\right.$ $\mathrm{p}=0.02591)$, chronicle obstructive lung disease $\left(X^{2}=3.88 \mathrm{p}=0.04899\right)$ and nephrites and nephrosis $\left(X^{2}=5.63 p=0.01765\right)$; (3) causes which contributes the expected: tuberculosis $\left(X^{2}=2.67 p=0.10253\right)$, diabetes mellitus $\left(X^{2}=0.5337 \quad p=0.46506\right)$, meningitis $\left(X^{2}=1.49 \quad p=0.22250\right)$, hypertensive disease $\left(X^{2}=0.0039 p=0.95027\right)$, cerebrovascular disease $\left(X^{2}=0.70 \quad p=0.40267\right)$, acute infectious respiratory diseases $\left(X^{2}=0.2059 p=0.64997\right)$, pneumonia and influenza $\left(X^{2}=2.36 p=0.12473\right)$, maternal deaths $\left(X^{2}=3.58 p=0.05864\right)$, indefinite causes $\left(X^{2}=0.055 p=0.81453\right)$; and (4) causes which not contribute: malignant melanoma of skin, Hodgkin's disease, chronicle rheumatic heart disease, asthma, ulcer of stomach, duodenum or illeus, appendicitis, abdominal hernia, colelitiasis and colecistitis. 
Í NDICE

Introdução

$1-6$

Objetivos e Metodologia

$7-12$

Resultados

$13-81$

Conclusões

$82-90$

Bibliografia

$91-94$

Anexo

$95-96$ 
IN T R O DUÇ Ã O 
Introdução

O conceito de mortalidade evitável evoluiu como índice negativo de saúde pública e da efetividade dos serviços de saúde a exemplo de outros indicadores de saúde como a mortalidade infantil e materna. Sendo o objetivo do sistema de saúde a aplicação do conhecimento científico atualizado na resolução de problemas reais, quando há indicação que uma determinada patologia é evitável por intervenção médica ou sanitária e na realidade ocorre o oposto, parece ser necessário estabelecer a qualidade dos serviços prestados. Consequentemente, certas causas de óbito são definidas como indicadoras da mortalidade evitável supondo que medidas preventivas ou terapêuticas podem influenciar sua incidência. Deste modo, o estudo da mortalidade evitável torna-se um instrumento útil para o planejamento regional de saúde pois serve aos propósitos de descrever e monitorar o estado de saúde, de aprimorar a avaliação dos serviços, de explorar a confiabilidade de sistemas de vigilância epidemiológica que identificam problemas especificos de saúde. O comportamento inesperado das taxas de óbitos por essas causas podem indicar a existência de problemas regionais e motivar estudos mais detalhados sobre a qualidade do serviço de saúde ou sobre o curso de eventos que precedem e determinam a ocorrência de óbitos potencialmente evitáveis.

Tendo como premissa que deve ser inversa a relação entre a qualidade e/ou efetividade dos cuidados de saúde e a incidência de mortes evitáveis, Rutstein ${ }^{23}$ propõe uma ampla lista de causas de doenças que possuem profilaxia e terapia reconhecida e cuja ocorrência do óbito pode ser minimizada. Pressupõe-se que quanto menor a ocorrência de tais doenças, incapacidades e mortes prematuras delas decorrentes no sistema de atenção à saúde, mais eficaz seria o serviço prestado. A distribuição regional e temporal dos óbitos evitáveis, considerados como eventos sentinelas de saúde, tem sido utilizada como um indicador negativo da qualidade dos cuidados de saúde, do nivel de saúde da população em geral e do efeito nele provocado por fatores econômicos, políticos e ambientais, bem como para avaliar a qualidade dos serviços médicos prestados dentro e fora de hospitais.

A seleção de causas de óbitos no primeiro estudo publicado por Charlton ${ }^{4}$, inspirada na lista de eventos sentinelas de saúde de Rutstein, é utilizada em todos os estudos revisados por Mackenbach et $\mathrm{al}^{\text {1s }}$. Em estudos mais recentes, várias causas de óbitos evitáveis foram acrescentadas, inclusive algumas causas evitáveis por prevenção primária, tais como, acidentes de tráfego, cirrose hepática e câncer de pulmão. 
Quadro 1. Seleção de causas de óbito publicada por Charlton

Doença hipertensiva

Tumor de colo uterino

Pneumonia e bronquite

Tuberculose (exceto silicotuberculose)

Asma

Doença reumática crônica do coração

Doença respiratória aguda

Infeç̧ão bacteriana

Doença de Hodgkin

Diversos estudos foram realizados com o objetivo de investigar se as taxas de mortalidade por condições evitáveis por intervenção médica poderiam ser interpretadas como indicadores da efetividade dos serviģos de saúde. Esses estudos têm relacionado condiç̃es clínicas e cirúrgicas para as quais há um certo consenso que os óbitos em determinados grupos etários são evitáveis por intervenção médica. As condições consideradas evitáveis, selecionadas a partir da lista original de Rutstein, omitem causas infrequientes, ou por indisponibilidade de dados, ou por discordância quanto a existéncia de evidência significativa do aumento da efetividade do ato médico concomitante à alta taxa de sobrevida como, por exemplo, o tratamento do câncer de tireóide.

Estudos sobre mortalidade evitável e serviços de saúde realizados por equipes de diversos países da Comunidade Européia originaram um atlas com informaçð̃es sociodemográficas, periodicamente publicado desde 1988. Pesquisadores de outros países europeus, do Canadá, da Nova Zelândia e Lituânia publicaram estudos que descrevem a variaçăo da mortalidade evitável no tempo (associada a introdução de inovaçōes médicas) e no espaço (decorrente do nível de variáveis socioeconômicas). 
Quadro 2. Causas de óbito evitável utilizadas em alguns estudos mais recentes

Úlcera gástrica e duodenal

Gripe

Infeç̧ões de ouvido

Doença cardíaca congênita

Tumor do testículo

Mortalidade infantil

Tumor maligno de traquéia, brônquio e pulmão

Acidentes com veículos a motor

Diabetes mellitus

Obstrução intestinal
Hiperplasia prostática

Endocardite

Sífilis

Nefrite e nefrose

Acidente de tráfego

Todas as doenças respiratórias

Cirrose do figado

Enterite e outras doenças diarreicas

Epilepsia

Tumor de laringe

Todas as demais doenças infecciosas e parasitárias, incluindo otite média, mastoidite, infeçððes da pele, osteomielite e periostite

Bócio, tireotoxicose, avitaminoses e deficiências nutricionais

Análises de dois tipos têm sido publicadas: análise de tendência temporal ( 9 estudos), que relaciona o declínio da mortalidade evitável a inovações de intervenção médica; análise de variação geográfica (10 estudos), na qual a mortalidade evitável é relacionada a disponibilidade de recursos de saúde e a outros fatores socioeconômicos.

Os métodos estatísticos mais frequientes empregados nos estudos de análise temporal são os procedimentos de padronização de taxas para remoção da influência de diferenças na estrutura etária entre populações e os procedimentos de regressão linear para estimativa de tendências.

Nos estudos de variação geográfica, a Razão de Mortalidade Padronizada - RMP (Standardized Mortality Ratio) é a medida mais utilizada, algumas vezes ajustada por transformações logarítmicas. Na análise estatística da relação entre mortalidade evitável e variáveis de serviços de saúde, são empregadas regressões lineares múltiplas, e fatores sociodemográficos são utilizados como variáveis de controle. 
Quadro 3. Características básicas dos estudos de tendência temporal

$\begin{array}{llll}\text { Primeiro } & \text { País } & \text { Causas } & \begin{array}{l}\text { Método } \\ \text { Autor }\end{array} \\ \text { de análise }\end{array}$

\begin{tabular}{|c|c|c|c|c|}
\hline $\mathrm{Gil}^{9}$ & Espanha & $1960-1984$ & 13 & Padronização de taxas \\
\hline Charlton ${ }^{5}$ & Internacional $^{*}$ & $1950-1980$ & 13 & Padronização de taxas \\
\hline Gaizauskiene $^{8}$ & Lituânia & $1970-1990$ & 14 & $\begin{array}{l}\text { Padronização de taxas } \\
\text { Regressão linear }\end{array}$ \\
\hline Mackenbach $^{13}$ & Holanda & $1950-1984$ & 35 & Regressão loglinear \\
\hline Malcon $^{18}$ & Nova Zelândia & $1968-1987$ & 15 & $\begin{array}{l}\text { Padronização de taxas } \\
\text { Regressão linear } \\
\text { Regressão não-linear } \\
\text { Regressão loglinear }\end{array}$ \\
\hline Poikolainen $^{21}$ & Finlândia & $1969-1981$ & 22 & $\begin{array}{l}\text { Padronização de taxas } \\
\text { Regressão loglinear }\end{array}$ \\
\hline Xavier $^{24}$ & Espanha & $1975-1990$ & 21 & $\begin{array}{l}\text { Padronização de taxas } \\
\text { Regressão linear } \\
\text { Regressão não-linear }\end{array}$ \\
\hline Westerling $^{25}$ & Suécia & $1974-1985$ & 21 & $\begin{array}{l}\text { Padronização de taxas } \\
\text { Regressão linear }\end{array}$ \\
\hline Westcrling $^{26}$ & Suécia & $1974-1985$ & 22 & $\begin{array}{l}\text { Padronização de taxas } \\
\text { Regressão linear } \\
\text { Regressão não-linear }\end{array}$ \\
\hline
\end{tabular}

"Paises comparados: Inglaterra, País de Gales, Estados Unidos, França, Japão, Itália c Sućcia 
Quadro 4. Características básicas dos estudos de variação geográfica

\begin{tabular}{|c|c|c|c|c|c|}
\hline \multirow{2}{*}{$\begin{array}{l}\text { Primeiro } \\
\text { autor }\end{array}$} & \multirow{2}{*}{$\begin{array}{l}\text { País, } \\
\text { número } \\
\text { de regiões }\end{array}$} & \multirow[b]{2}{*}{ Periodo } & \multirow{2}{*}{$\begin{array}{l}\text { Número } \\
\text { de causas } \\
\text { de óbito }\end{array}$} & \multicolumn{2}{|c|}{ Variável independente } \\
\hline & & & & Cuidados de saúde & Outras \\
\hline Bauer $^{2}$ & $\begin{array}{l}\text { Inglaterra e } \\
\text { País de Gales, } \\
98 \text { regiões }\end{array}$ & $1974-1978$ & 13 & $\cdots$ & $\begin{array}{r}\text { Morbidade } \\
\text { Socioeconômicas }\end{array}$ \\
\hline Carr-Hill ${ }^{3}$ & $\begin{array}{l}\text { Inglaterra e } \\
\text { País de Gales, } \\
15 \text { regiões }\end{array}$ & $1976-1983$ & 4 & Gastos & Socioeconômicas \\
\hline Charlton $^{6}$ & $\begin{array}{l}\text { Inglaterra e } \\
\text { País de Gales, } \\
98 \text { regiões }\end{array}$ & $1974-1978$ & 15 & --- & Socioeconômicas \\
\hline Humblet $^{12}$ & $\begin{array}{l}\text { Bélgica } \\
43 \text { regiões }\end{array}$ & $1974-1978$ & 10 & Demanda & Socioeconômicas \\
\hline Mackenbach $^{14}$ & $\begin{array}{l}\text { Holanda } \\
28 \text { regiões }\end{array}$ & $\begin{array}{l}1950-1954 \\
1960-1964 \\
1970-1974 \\
1980-1984\end{array}$ & 14 & $\begin{array}{l}\text { Recursos } \\
\text { humanos } \\
\text { e materiais }\end{array}$ & Socioeconômicas \\
\hline Mackenbach $^{16}$ & $\begin{array}{l}\text { Inglaterra e } \\
\text { País de Gales } \\
\text { Holanda } \\
41 \text { regiớes }\end{array}$ & $\begin{array}{l}1931-1961 \\
1961-1981 \\
1950-1954 \\
1960-1964 \\
1970-1974 \\
1980-1984\end{array}$ & 16 & --- & Socioeconômicas \\
\hline Mackenbach $^{17}$ & $\begin{array}{l}\text { Holanda } \\
39 \text { regiões }\end{array}$ & $1969-1984$ & 7 & $\begin{array}{l}\text { Recursos } \\
\text { humanos e materiais }\end{array}$ & Socioeconômicas \\
\hline Pampalon ${ }^{20}$ & $\begin{array}{l}\text { Canadá (Quebec) } \\
16 \text { regiões }\end{array}$ & $\begin{array}{l}1969-1973 \\
1982-1990\end{array}$ & 13 & $\begin{array}{l}\text { Recursos } \\
\text { humanos e materiais }\end{array}$ & Socioeconômicas \\
\hline Poikolainen $^{22}$ & $\begin{array}{l}\text { Internacional } \\
25 \text { paises }\end{array}$ & $1975-1978$ & 57 & $\begin{array}{l}\text { Recursos } \\
\text { humanos e materiais }\end{array}$ & Socioeconômicas \\
\hline Westerling $^{28}$ & $\begin{array}{l}\text { Suécia } \\
26 \text { regiões }\end{array}$ & $1987-1990$ & 5 & Hospital & Socioeconômicas \\
\hline
\end{tabular}


Quadro 5. Características de oferta de serviços médicos e variáveis socioeconômicas

Número de clínicos gerais por 100.000 habitantes

Número de leitos hospitalares por 1.000 habitantes

Percentagem de leitos públicos em hospitais universitários

Percentagem de leitos públicos em pequenos hospitais ( $<200$ leitos)

Taxa bruta de imigração por 1.000 habitantes

Grau de urbanização (em relação a população residente em cidades de até 100.000 habitantes)

Fonte: Mackenbach ${ }^{14}$ (modificado)

Os estudos de análise de tendência temporal, em geral, demonstram que a mortalidade evitável declina mais rapidamente nas últimas décadas que a maiorias das outras causas de óbito e sugerem que o declínio está associado à introdução de inovações nos serviços de saủde. Os estudos de variação geográfica demonstram que a mortalidade evitável está associada de modo consistente a fatr,res socioeconômicos e que a associação com o nível de recursos materiais e humanos de cuidados de saúde é fraca e inconsistente. Machenbach $^{15}$ afirma que os niveis remanescentes de mortalidade evitável nos países industrializados resultam, pelo menos em parte, da efetividade dos serviços de saúde. Contudo, a variação geográfica da mortalidade não parece refletir diferenças de efetividade dos serviços de saúde mas flutuações "espontâneas" na incidência ${ }^{2}$ ou severidade dessas condições. É possível que a variação geográfica da mortalidade evitável possa refletir diferenças de efetividade dos serviços de saúde e, especialmente, a efetividade da intervenção médica, se forem consideradas outras circunstâncias além do nível de recursos disponíveis, mais relacionadas a maneira como está organizada a oferta e o acesso aos serviços de saúde e a outras circunstâncias socioeconômicas. 
OB JETIVOS

$\mathrm{E}$

METODOLOGIA 


\section{Objetivos}

Estimar a variação geográfica da mortalidade evitável no período de 1979 a 1992 e o impacto da assistência médica no declínio da mortalidade evitável nas capitais brasileiras em 1992.

\section{Metodologia}

1. Dados de mortalidade c dados censitários

Os dados anuais de mortalidade são do Sistema Integrado de Mortalidade para período de 1979 a 1992 relativos às capitais e Distrito Federal*. São construidas vinte e seis bases de dados de área geográfica (25 capitais e o Distrito Federal) contendo todas as causas de óbito classificadas em quatro grupos de análise: Todas as causas (exceto as evitáveis), Todas as causas evitáveis (29 causas básicas), subdividido em (1) Causas indicadoras de politicas sociais e de saúde - CIPSS ( 6 causas básicas) e Causas indicadoras de cuidados de saúde - CICS (23 causas básicas), codificadas em três dígitos de acordo com a $9^{\mathrm{a}}$ Classificação Internacional de Doenças de 1975, agregadas anualmente para ambos os sexos em sete grupos etários (0-4, 5-14, 15-24, 25-34, 35-44, 45-54, 55-64) abrangendo o periodo de 1979-1992.

As populações das capitais são estimadas a partir dos dados dos Censos Nacionais de 1980 e 1991 , ajustadas aritmeticamente para $1^{\circ}$. de julho e calculada a taxa geométrica de crescimento intercensitária.

No processo de seleção das causas evitáveis de óbito são utilizadas as listas Rutstein ${ }^{23}$, Charlton et at $t^{4}$ e, principalmente, de Holland ${ }^{11}$ com as modificações a seguir. As causas coqueluche (CID 033), tétano (CID 037), sarampo (CID 055), tumor maligno de corpo de útero (CID 182), osteomielite (CID 730) pela freqüência muito baixa (geralmente nula) em vários anos em várias áreas geográficas, não são estudadas. As causas septicemia (CD 038), tumor maligno de esôfago (CID 150), melanoma maligno de pelc (CID 162), deficiências nutricionais (CID 260-269), úlcera gástrica, jejunal e duodenal (CD 531-534), meningite

\footnotetext{
'Palmas, capital do Estado de Tocantins criado em 1986, não foi incluida no estudo.
} 
(CID 320-322), nefrite e nefrose (CID 580-589), sintomas, sinais e afeç̧ões mal definidas (CID 780-799) e homicidios e outras formas de violência (CID E960-E969), são incluídas no estudo.

Quadro 6. Causas de óbito evitável selecionadas e grupos etários

CID Causas de óbito evitável selecionadas

Grupo etário (anos)

Causas Indicadoras de Políticas Sociais e de Saúde (CIPSS) ～0-64

150 Tumor maligno do esôfago

$5-64$

162 Tumor maligno da traquéia, brônquio e pulmão

$5-64$

260-269

Deficiências nutricionais

$0-4$

571

Doença crônica do fígado e cirrose

$15-64$

$\begin{array}{llr}\text { E810-E819 Acidente de trânsito com veículo a motor } & 0-64\end{array}$

E960-E969 Homicídio e outras violências

$0-64$

Causas Indicadoras de Cuidados de Saúde (CICS) $\quad$ 0-64

001-009

Doenças infecciosas intestinais

$0-4$

010-018

Tuberculose

5-64

038

Septicemia

$0-4$

172

Melanoma maligno da pele

$0-64$

179

Tumor maligno do útero não especificado

$15-64$

180

201

Tumor maligno do colo do útero

$15-64$

Doença de Hodgkin

$5-64$

250

Diabetes mellitus

$15-64$

320-322

Meningite bacteriana

Doença reumática crônica do coração

$5-44$

401-405

Hipertensão arterial

$35-64$

430-436

Doença cerebrovascular

$35-64$

460-466

Infeç̧ões respiratórias agudas

$0-4$

Pneumonia e gripe

$0-64$

491-492

Doença pulmonar obstrutiva crônica

35-64

Asma

$5-44$

Úlcera gástrica, duodenal, jejunal

$15-64$

Apendicite

$5-64$

$\begin{array}{llr}550-553 & \text { Hérnia da cavidade abdominal } & 0-64 \\ 574-575 & \text { Colelitiase e colecistite } & 5-64\end{array}$

580-589 Nefrite e nefrose $\quad 0-64$

630-639 Complicação da gravidez, parto e puerpério $\quad$ 15-64

780-799 Sintomas, sinais e afecções mal definidas

$0-64$ 
A mortalidade perinatal não é estudada por não estar disponível os dados de nascidos-vivos para diversas capitais. Além do cólera (CID 001), como na seleção de Holland, são incluidas todas as causas de doenças infecciosas intestinais (CID 001-009). O tumor maligno de útero não especificado (CID 179) e de colo de útero (CID 180), além de serem mantidos, são analisados separadamente. As doenças respiratórias são agregadas em quatro grupos de causas: infeç̧ões respiratórias agudas de vias aéreas superiores (CID 460-469), pneumonia e gripe (CID 480-487), doenças pulmonares obstrutivas crônicas (CID 491-492) e asma (CID 493). As doenças cardiovasculares são estudadas em dois grupos: Hipertensão arterial (CD401405) e doença cerebrovascular (CID 430-436).

Desenho de Estudo

É um estudo de avaliação do impacto da intervenção médica sobre a tendência temporal das taxas de mortalidade por região geográfica (capital) utilizando dados agregados de óbitos por causas evitáveis selecionadas. A análise ecológica possibilita fazer inferências sobre o impacto das intervenções médicas sobre as taxas de mortalidade, como propõe Morgensten $^{19}$ para a avaliação da efetividade de uma intervenção a nível da população.

Uma estimativa do efeito da intervenção médica sobre o declínio da mortalidade evitável regional é proposta a partir do cálculo da Razão de Mortalidade Evitável (RME). Tendo como objetivo comparar taxas observadas e esperadas, semelhante a Razão de Mortalidade Padronizada (Standardised Mortality Ratio - SMR), a RME é a razão entre a taxa padronizada de mortalidade evitável por CICS, estimada para 1992 pelo modelo de regressão loglinear (taxa observada), e a taxa esperada para 1992, quando aplicado o coeficiente de regressão $(b)$ implícito na curva de tendência exponencial ajustada da taxa padronizada de mortalidade por CIPSS à taxa de mortalidade por CICS estimada para 1979.

Esta hipótese de trabalho tem como pressupostos que: (1) todos os óbitos devidos a causas consideradas evitáveis por cuidados de saúde (CICS) poderiam ter sido evitados por intervenção médica adequada; (2) o declínio da mortalidade por CIPSS reflete a influência dos fatores de prevenção primária de caráter socioeconômico, independentes da ação médica; (3) na ausência da intervenção médica, o declínio da mortalidade evitável por CICS deve ser igual ao declínio da mortalidade evitável por CIPSS; (4) as taxas de declínio (coeficientes de regressão, b) mantêm-se constantes durante o periodo de estudo 
(4) as taxas de declínio (coeficientes de regressão, b) mantêm-se constantes durante o período de estudo (1979-1992); (5) a variação temporal e regional da aplicação de técnicas de classificação das causas nas declarações de óbitos, não influenciam a mensuração do nível da mortalidade.

A análise de regressão linear dos logaritmos naturais das taxas padronizadas, executada pelo programa estatístico Statgraphics 5.1, é utilizada para descrever a tendência exponencial da mortalidade evitável por CICS e CIPSS porque reduzem o efeito aleatório, importante nos eventos raros, e evitam as estimativas negativas. O teste $t$ de Student (bicaudal) foi utilizado para determinar a significância estatística da tendência, com nivel estabelecido para $\mathrm{p} \leq 0,002$ para evitar a ocorrência de resultados falsos positivos (nível de significância é igual a 0,05 dividido por 26 , o número de regiões geográficas).

O método de padronização de taxas utilizado foi o direto:

$$
p^{\prime}=\Sigma N_{i} p_{i} / \Sigma N_{i}
$$

p': taxa de mortalidade padronizada

$\mathrm{N}_{\mathrm{i}}$ : população de referência por grupo etário

$\mathrm{p}_{\mathrm{i}}$ : taxa de mortalidade por grupo etário

A população de referência $\left(\mathrm{N}_{\mathrm{i}}\right)$ corresponde a soma das populações médias estimadas das capitais para o período de 1979-1992.

A Razão da Mortalidade Padronizada - RMP (Standardised Mortality Ratio - SMR) é calculada pela divisão da taxa diretamente padronizada em cada área pela taxa de mortalidade da área de referência (conjunto das capitais e Distrito Federal). O nível de significância da divergência com padrão de referência (razão entre óbitos observados e esperados com a padronização) é analisado pelo teste $\chi^{2}$ (grau de liberdade $\mathrm{gl}=1$ ). A análise é considerada adequada se o número esperado de óbitos for ao menos cinco em $80 \%$ das regiões. O método de correção de Yate foi empregado'.

$$
\chi^{2}=(O-E)^{2} / E
$$


A análise da variaçăo regional do número de óbitos visa csclarecer sc ocorrc mais variação cntre as áreas do que poderia ser explicado por fatores aleatórios e qual o tamanho da variação sistemática (nãoalcatória) existente. A estimativa da variância pode scr considerada como uma medida da variabilidade entre um grupo de pequenas áreas e pode comparar as diversas ocorrências de óbitos para demonstrar se há mais variabilidade em um local do que em outro. É necessário estabelecer quanta variação pode ser esperada sob a hipótese nula de que todas as áreas têm frequência de óbitos similares e que a variação obscrvada é devida ao acaso?.

No estudo da homogeneidade da distribuição dos óbitos entre as vinte e seis áreas geográficas, a variância observada é decomposta em seus componentes sistemático e aleatório. Visando diminuir as flutuaç̃̃es na frequência de óbitos são empregados os valores médios dos periodos de 1979 a 1982 e de 1989 a 1992. A variância observada é calculada dividindo o valor do $\chi^{2}$ pelo número total de óbitos pela condição específica (total de óbitos esperados) que por definição é proporcional à população da área geográfica $^{27,29}$ :

$$
\sum_{i=1}^{k} \frac{\left(o_{i j}-e_{i j}\right)^{2} / e_{i j}}{n_{j}}
$$

Quando a hipótese nula é verdadeira, isto é, quando não há variação sistemática significativa, toda variação observada é resultado da variação aleatória. Assumindo a hipótese nula, a expressão matemática da distribuição $\chi^{2}$ é o grau de liberdade $(k-1)$ da distribuição. Assim, o componente aleatório da variância é definido como:

$\mathrm{gl} / \mathrm{n}=(\mathrm{k}-1) / \mathrm{n}$

O componente sistemático, que não sofre a influência da variabilidade interna de cada região geográfica e que quando possui valor elevado indica grandes diferenças entre as regiões, é obtido pela diferença entre a variância observada e a variância aleatória, sendo calculado por

$$
\sum_{i=1}^{k} \frac{\left(o_{i j}-e_{i j}\right)^{2} / e_{i j}}{n_{j}}-\frac{(k-1)}{n_{j}}
$$


onde $o_{\mathbb{V}}$ representa $o$ número observado de óbitos $e e_{\mathrm{j}}$ o número esperado de óbitos em cada região de acordo com a população de referência (conjunto das capitais e Distrito Federal); $n_{\mathfrak{J}}$ corresponde ao total observado de óbitos pela condição em estudo.

A hipótese nula, isto é, que não há variação sistemática significativa na freqüência de óbitos entre as regiões, foi testada pelo teste do $\chi^{2}$ com 25 graus de liberdade $(k-1)$, com a correção de Yate (o que possibilitou aplicar o teste mesmo com número esperado inferior a 5$)^{7}$. Se a hipótese nula não pode ser rejeitada, então não há excesso de variabilidade entre as regiões ou os dados disponiveis não são adequados para evidenciar uma variação significativa existente. A presença de variação regional significativa na mortalidade pode ser considerada como um sinal de alerta e ponto de partida para o planejamento e avaliação de programas preventivos e terapêuticos. A variância é também de interesse, mesmo quando não significativa, quando a variabilidade dos óbitos está concentrada em áreas específicas ${ }^{10}$, o que é demonstrado pela análise da distribuição de freqüência da variância dos óbitos por CICS nas capitais. 
RESULT ADOS 


\section{Resultados}

\section{Análise da Distribuição dos Óbitos no Conjunto das Capitais}

Não há variação sistemática significativa na distribuição dos óbitos para a quase totalidade das causas estudadas no conjunto das capitais (Tabela 2). Quando consideradas em conjunto, esta conclusão é válida tanto para as causas de óbito evitável $\left(\sigma_{79 / 82}^{2}=33,90 \mathrm{p}=0,1100 ; \sigma_{89 / 92}^{2}=22,71 \mathrm{p}=0,5945\right)$ quanto para as demais causas $\left(\sigma_{79 / 82}^{2}=33,13 p=0,2200 ; \sigma_{89 / 92}^{2}=19,89 p=0,7524\right)$. Entre as causas de bbito evitável selecionadas, as CIPSS $\left(\sigma_{79 / 82}^{2}=30,06 p=0,22200, \sigma_{89 / 22}^{2}=21,54 p=0,6624\right)$ apresentam menor variaçăo que as $\operatorname{CICS}\left(\sigma_{79 / 82}^{2}=34,76 \mathrm{p}=0,0927, \sigma_{89 / 92}^{2}=23,34 \mathrm{p}=0,5576\right)$, porém ambas sem significância estatística. No perído de 1989-1992 a distribuição dos óbitos torna-se ainda mais homogênea em todos os grandes grupos, com declínio da variância sistemática de todas as causas evitáveis $(-33 \%)$, das CIPSS (-28\%) e CICS (-33\%)e das demais causas de óbitos $(-34 \%)$,.

No grupo das CIPSS, os óbitos por tumor maligno de esôfago têm a distribuição mais homogênea $\left(\sigma_{79 / 82}^{2}=22,67 p=0,5395 ; \sigma_{89 / 92}^{2}=16,49 p=0,8994\right)$ e os óbitos por acidente de trânsito com veículos a motor a distribuição mais heterogênea no periodo de 1979-1982 $\left(\sigma_{79 / 122}^{2}=36,25 p=0,0678 ; \sigma_{89 / 22}^{2}=24,96\right.$ $\mathrm{p}=0,4648$ ) no conjunto das capitais. As deficiências nutricionais têm a distribuição mais desigual dos óbitos $\left(\sigma_{79 / 82}^{2}=28,97 \mathrm{p}=0,2651 ; \sigma_{89 / 92}^{2}=26,44 \mathrm{p}=0,3846\right)$ no periodo de 1989-1992 e é a causa de óbito com o menor declínio na variância sistemática (-9\%) nesse grupo.

As CICS que apresentam distribuição desigual com significância estatística são o melanoma maligno de pele $\left(\sigma_{79 / 82}^{2}=107,06 \mathrm{p}=0,0000 ; \sigma_{89 / 82}^{2}=63,94 \mathrm{p}=0,0000\right)$, o tumor maligno de útero não especificado $\left(\sigma_{79 / 82}^{2}=114,43 \mathrm{p}=0,0000 ; \sigma_{89 / 92}^{2}=66,33 \mathrm{p}=0,0000\right)$, o tumor maligno de colo de útero $\left(\sigma_{79 / 82}^{2}=62,67\right.$ $\mathrm{p}=0,0000)$, as complicações da gravidez, parto e puerpério $\left(\sigma_{79 / 82}^{2}=53,91 \mathrm{p}=0,0007\right)$ e os sintomas, sinais e afeç̧ões mal definidas $\left(\sigma_{79 / 22}^{2}=53,77 \mathrm{p}=0,0007\right)$. No período de 1979-1982, as doenças infecciosas intestinais $\left(\sigma^{2}=37,78 \mathrm{p}=0,0486\right)$, a tuberculose $\left(\sigma^{2}=40,49 \mathrm{p}=0,0260\right)$ e a hérnia abdominal $\left(\sigma^{2}=39,35\right.$ $\mathrm{p}=0,0339$ ) também têm elevada variância sistemática. A doença reumática crônica do coração e as infeções respiratórias agudas apresentam variância sistemática crescente (31\% e 9\%, respectivamente) no período estudado. Todas as demais CICS têm distribuição mais homogênea no final em relação ao período inicial, tendo a variância sistemática reduzido de $-1 \%$ (septicemia) a $-55 \%$ (tuberculose e complicaçðes da gravidez, parto e puerpério). 
Tabela 1. Variância sistemática das causas específicas de óbitos no conjunto das capitais e Distrito Federal.

\begin{tabular}{|c|c|c|c|c|c|c|}
\hline \multirow[b]{2}{*}{ Cid9 } & \multirow[b]{2}{*}{ Causa } & \multicolumn{2}{|c|}{$1979-1982$} & \multicolumn{2}{|c|}{ 1989-1992 } & \multirow{2}{*}{$\begin{array}{l}\text { Diferengs } \\
\text { entre os } \\
\text { Periodos } \\
(\%)\end{array}$} \\
\hline & & variäncia & $\mathbf{p}$ & variância & $\mathrm{p}$ & \\
\hline & Todas as causas (exceto as evitaveis) & 30.13 & 0.2196 & 19.89 & 0.7524 & -34 \\
\hline & Todas as causas evitáveis & 33.90 & 0.1100 & 22.71 & 0.5945 & -33 \\
\hline & Cansas indicadoras de politicas sociais e de saúde & 30.06 & 0.2220 & 21.54 & 0.6624 & -28 \\
\hline 150 & Tumor maligno do es 6 fago & 22.67 & 0.5395 & 16.49 & 0.8994 & -27 \\
\hline 162 & Tumor maligno da traquéia, brônquio e pulmão & 26.21 & 0.3963 & 19.33 & 0.7809 & -26 \\
\hline $260-269$ & Deficiências nutricionais & 28.97 & 0.2651 & 26.44 & 0.3846 & -9 \\
\hline 571 & Doença crónica do flgado e cirrose & 32.42 & 0.1461 & 19.14 & 0.7904 & -41 \\
\hline E810-E819 & Acidente de transito com veiculo a motor & 36.25 & 0.0678 & 24.96 & 0.4648 & -31 \\
\hline \multirow[t]{2}{*}{ E960-E969 } & Homicidio e outras violências & 28.42 & 0.2887 & 20.09 & 0.7419 & -29 \\
\hline & Causas indicadoras de cuidados de saúde & 34.76 & 0.0927 & 23.34 & 0.5576 & -33 \\
\hline $001-009$ & Doenças infecciosas intestinais & 37.78 & 0.0486 & 29.82 & 0.2310 & -21 \\
\hline $010-018$ & Tuberculose & 40.49 & 0.0260 & 18.11 & 0.8376 & -55 \\
\hline 038 & Septicemia & 25.29 & 0.4463 & 24.94 & 0.4659 & -1 \\
\hline 172 & Melanoma maligno da pele & 107.06 & 0.0000 & 63.94 & 0.0000 & -40 \\
\hline 179 & Tumor maligno do útero nåo especificado & 144.43 & 0.0000 & 66.33 & 0.0000 & -54 \\
\hline 180 & Tumor maligno do colo do útero & 62.67 & 0.0000 & 36.79 & 0.0604 & -41 \\
\hline 201 & Doença de Hodgkin & 26.24 & 0.3949 & 20.57 & 0.7164 & -22 \\
\hline 250 & Diabetes mellitus & 25.09 & 0.4573 & 20.43 & 0.7240 & -19 \\
\hline $320-322$ & Meningite & 22.19 & 0.6246 & 21.79 & 0.6481 & -2 \\
\hline 393-398 & Doença reumática crônica do coraçấo & 23.62 & 0.5413 & 30.95 & 0.1906 & 31 \\
\hline $401-405$ & Hipertensð̃o arterial & 32.79 & 0.1363 & 18.83 & 0.8054 & -43 \\
\hline $430-436$ & Doença cerebrovascular & 31.19 & 0.1828 & 20.08 & 0.7427 & -36 \\
\hline $460-466$ & Infecçðes respiratórias agudas & 15.67 & 0.9244 & 17.03 & 0.8809 & 9 \\
\hline $480-487$ & Pneum onia e gripe & 22.57 & 0.6025 & 17.94 & 0.8450 & -21 \\
\hline $490-492$ & Doença pulmonar obstrutiva crônica & 36.50 & 0.0644 & 19.27 & 0.7840 & -47 \\
\hline 493 & Asma & 32.43 & 0.0703 & 16.17 & 0.8478 & -50 \\
\hline $531-534$ & Úlcera gastrica, duodenal, jejunal & 35.47 & 0.0801 & 19.48 & 0.7734 & -45 \\
\hline $540-543$ & Apendicite & 35.74 & 0.0756 & 19.54 & 0.7705 & -45 \\
\hline $550-553$ & Hérnia da cavidade abdominal & 39.35 & 0.0339 & 21.22 & 0.6804 & -46 \\
\hline $574-575$ & Colelitlase e colecistite & 29.79 & 0.2323 & 21.96 & 0.6379 & -26 \\
\hline $580-589$ & Nefrite e nefrose & 37.91 & 0.0472 & 25.21 & 0.4508 & -34 \\
\hline $630-639$ & Complicaçào da gravidez, parto e puerpério & 53.91 & 0.0007 & 24.42 & 0.4953 & -55 \\
\hline 780-799 & Sintomas, sinais e afeçres mal definidas & 53.77 & 0.0007 & 27.00 & 0.3559 & -50 \\
\hline
\end{tabular}




\section{Análise da Distribuição dos Óbitos nas Capitais}

Não há variância sistemática significativa nos grupos de causas de óbito estudados, ou seja, não foi possível refutar a hipótese que a distribuição dos óbitos observados não difere do esperado sob a distribuição de Poison no conjunto das capitais. Conseqüentemente, conclui-se que há uma considerável homogeneidade na distribuição dos óbitos entre as capitais e que as diferenças existentes tendem a diminuir no periodo estudado. Contudo, resta demonstrar quão homogêneas são as distribuições de frequêência da variância observada e quanto contribuem para a variância sistemática do conjunto das capitais.

A distribuição de frequência da variância observada dos óbitos nas capitais indica a diminuição dos valores de todas as medidas de posição, dispersão e simetria empregadas para a comparação dos períodos estudados, da maioria dos grupos de causas de óbito considerados (Anexo 1). A exceção fica por conta dos óbitos por CIPSS, com discreto aumento de assimetria positiva. Estes resultados reforçam as conclusões iniciais da análise da variância sistemática do conjunto das capitais de crescente homogeneidade de distribuição dos óbitos pelas capitais. Os histogramas de caixa ("box"), apresentados a partir da página seguinte (Quadro 7), tomam evidente o desempenho desfavorável da mortalidade em Fortaleza e São Luiz em todos os grupos de causas de óbito em 1979-1982 e a evolução favorável obtida no período de 19891992. Mostram também que os valores da variância dos óbitos por CIPSS são extremos em Porto Velho e Boa Vista e por CICS em Manaus, em relação aos das demais capitais no período de 1989-1992.

Geralmente, a variância elevada em um grupo de causas de óbito na capital é acompanhada por valores elevados em outros grupos de causa de óbito na mesma capital, quando ć considerado o valor do quartil superior da distribuição de freqüência das variâncias observadas das capitais (Quadro 8). Os exemplos mais destacados são Fortaleza, São Luiz, Maceió, Porto Velho, Boa Vista, Aracaju, Manaus e João Pessoa. 


\section{Quadro 7. Histogramas da distribuição de frequeência dos óbitos nas capitais}

Analise de variancia da mortalidade

Todis as causas (exceto as evitaveis)

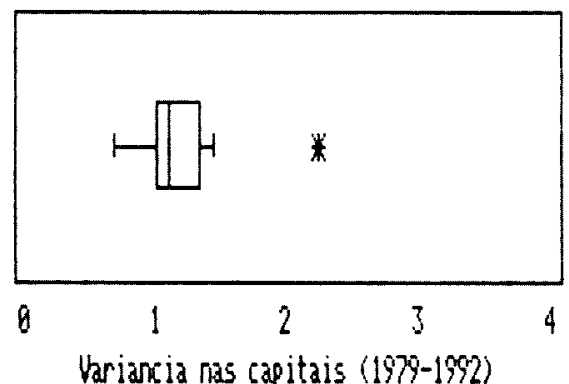

* Sao Luiz

Variancia nas capitais (1979-1972)

Analise de variancià da mortalidade Todas as causas evitaveis

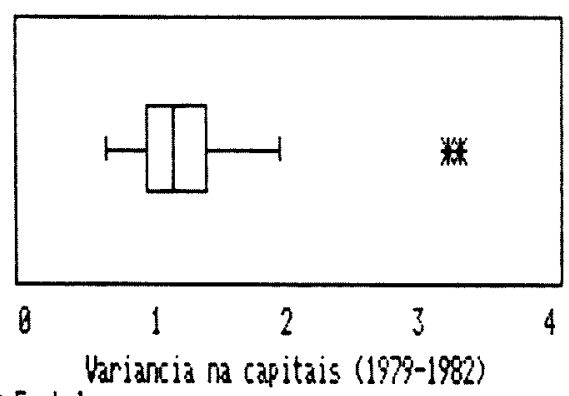

¿ Sao Luiz xortaleza

Analise de variarcia da onortalidade Causas indicadoras politicas soc e saude

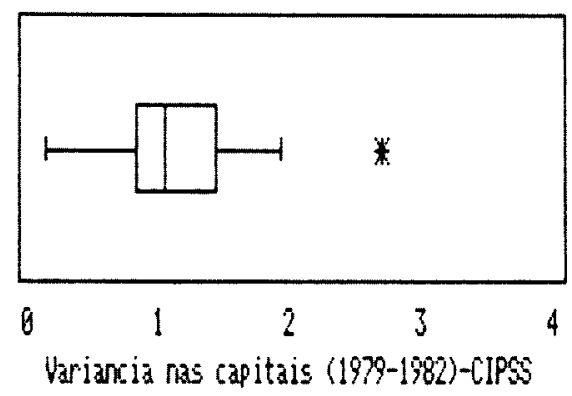

x so Luiz

Analise de variancia da acrtalidade Causas indicadoras de cuidados de sauds

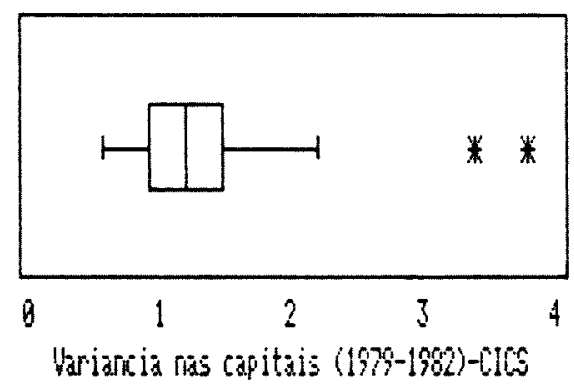

* Fortaleza x Sao Luiz
Fralise de variancia da mortalidade Todas as causas (exceto is evitaveis)

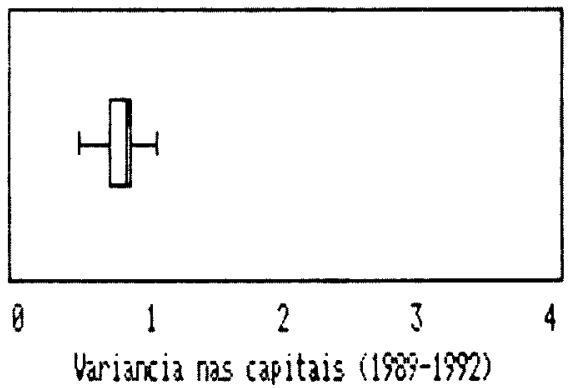

finalise de variancia da arrtalidade Touds as causas evitaveis

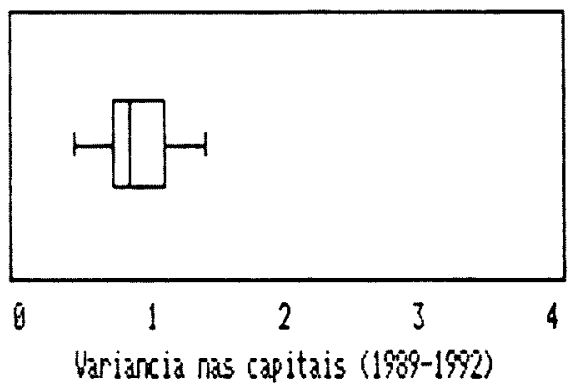

Analise de variancia da mortalidade Cause indicadoras politicas soc e saude

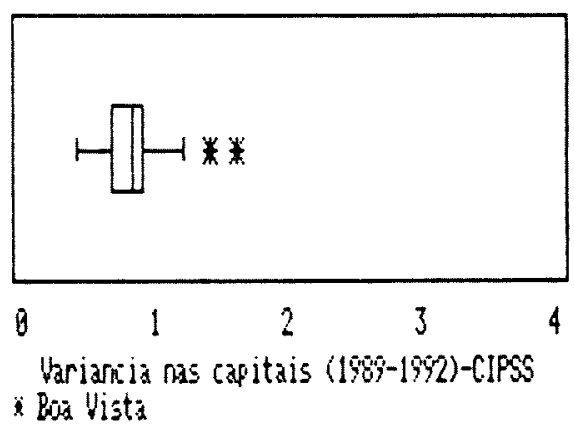

Arralise de variancia da mortalidade causas indicadoras de cuidados de saude

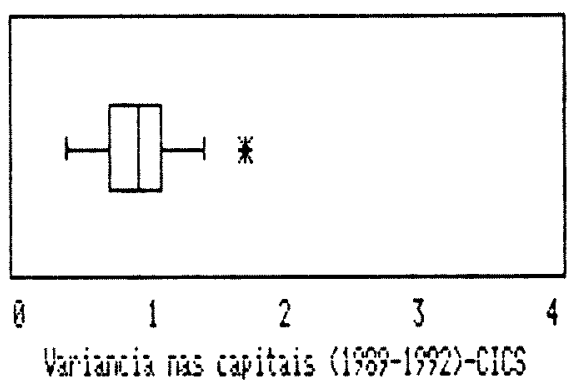


Arralise de variancia da mortalidade Thencas infecciosas intestinais

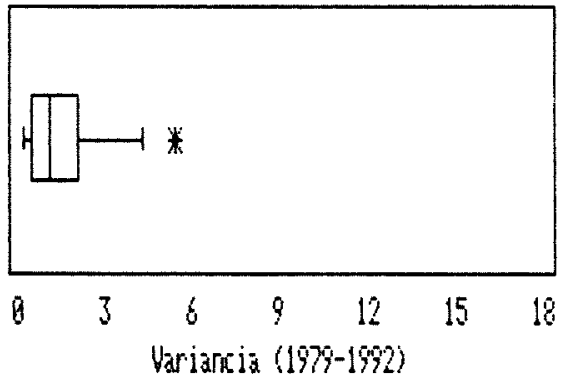

* Sal Luiz

Analise de variancia da mortalidade Tuberculose

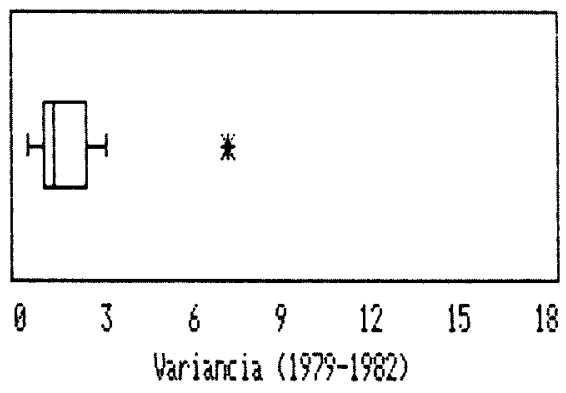

x Sia Luiz

Analise de variancia da mortalidade Septicenia.

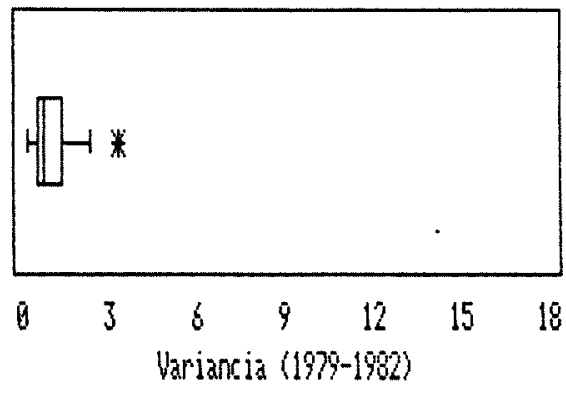

i Fưrtaleza

Arralise de variancia da mortalidade Melanoma maligno de pele

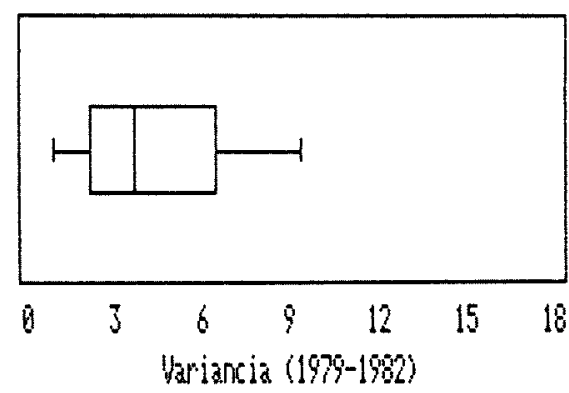

Arálise de variancia da mortalidade Iloercas infecciosas intestinais

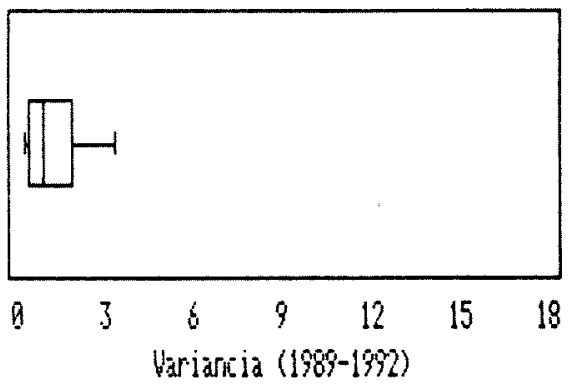

Arralise de variancia da arotalidade Tuberculose

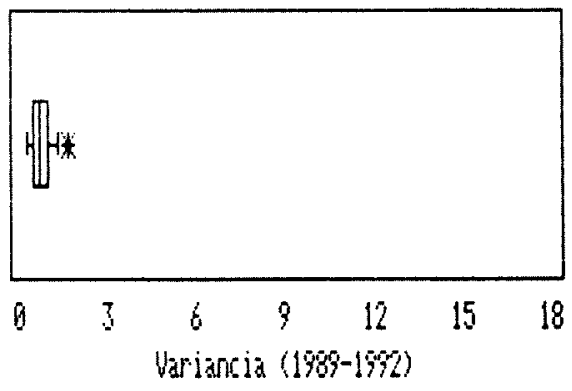

x heotife

Aralise de variancia da mortalidade Septiceaia

a Haceio a fio banco

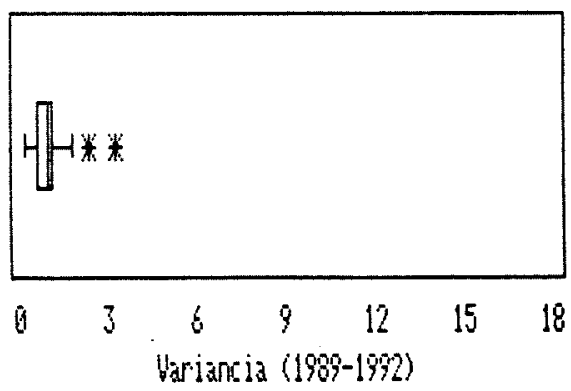

Aralise de variancia da artalidade Melanoma asligno de pele

* Jour Pesoa

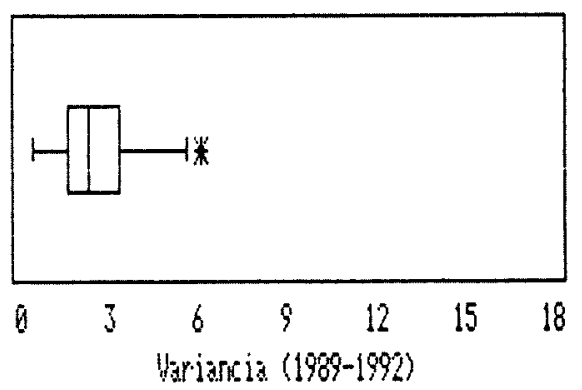


Aralise de variancia da mortalidade Tunor maliono de utero rao especiticado

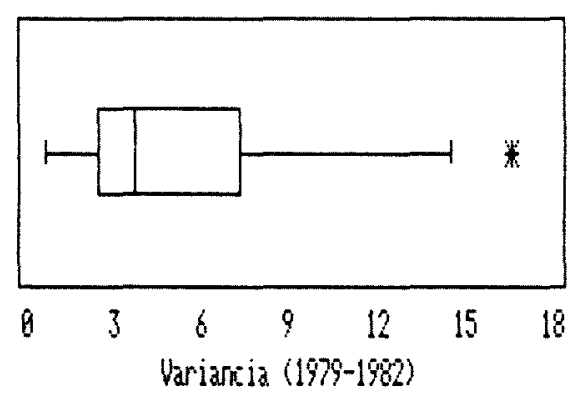

$x$ Mlanaus

Arnalise de variancia da mortalidade Tuaror maligno de colo de utero

* Salvador X Sau Luiz

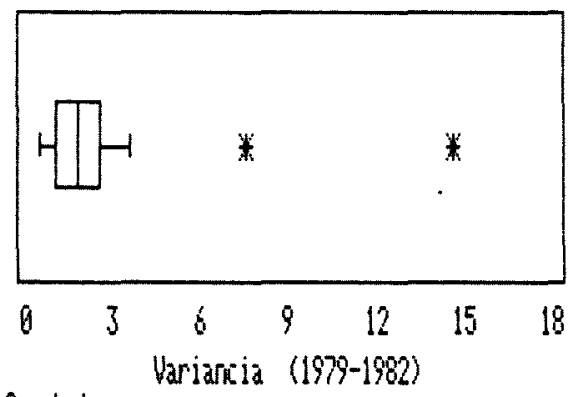

Analise de variancia da martalidade Doenca de Hodgkin

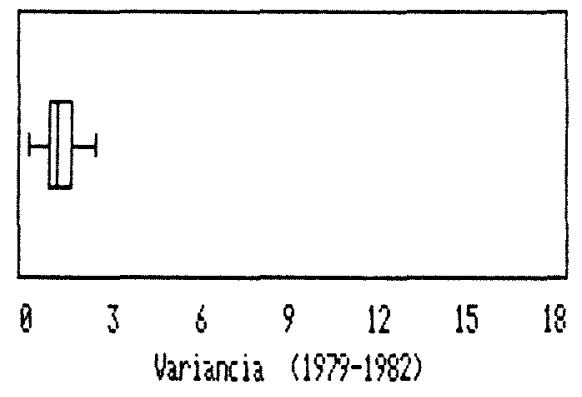

Analise de variania da mơtalidade Diabste melito

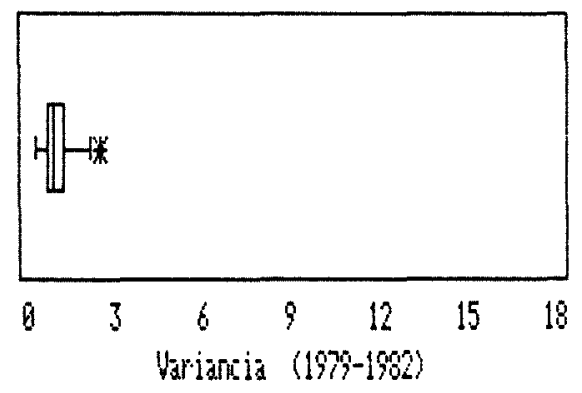

Analise de variancia da mortalidade Tunor miligno de utero mo especificado

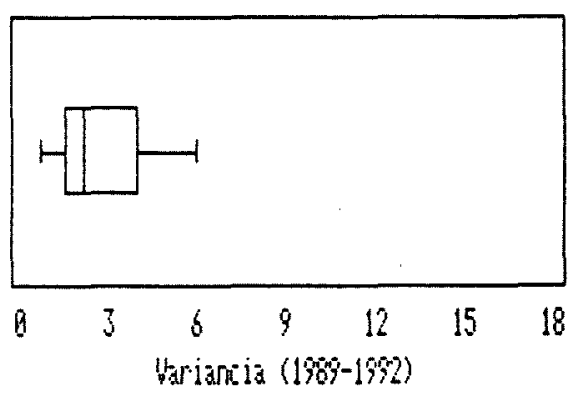

Fralise de variaricia da aortalidade Tumor anligno de colo de utero

* Macapa Sa Luiz Ealuador

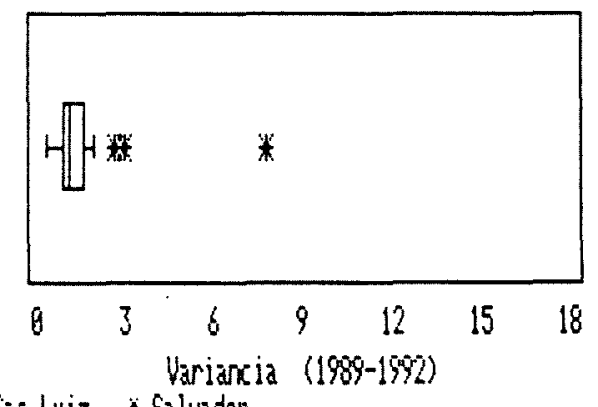

Aralise de variancia da mortalidade Ihena de Hadgkin

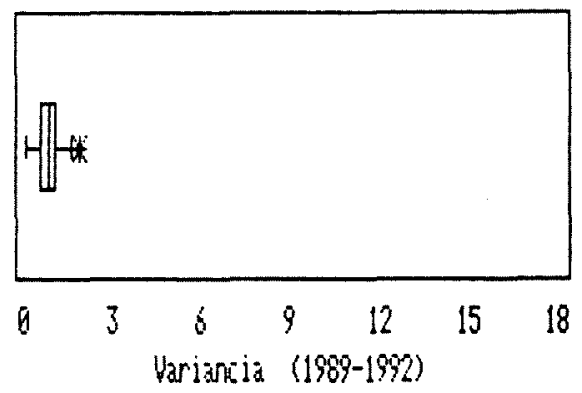

What

Rnalise de variancia da nortalidade Diabete melito

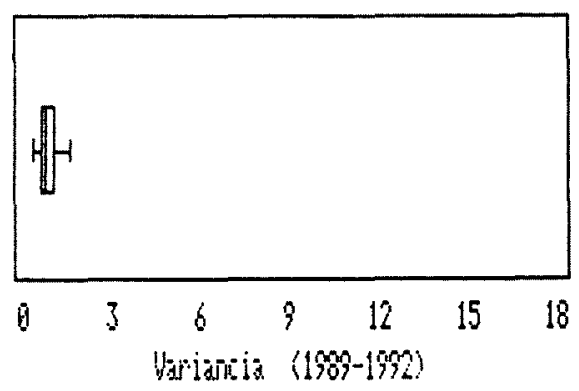

* Sao Luiz 
Analise de variancia da oortalidade Meninaite

Fortaleza

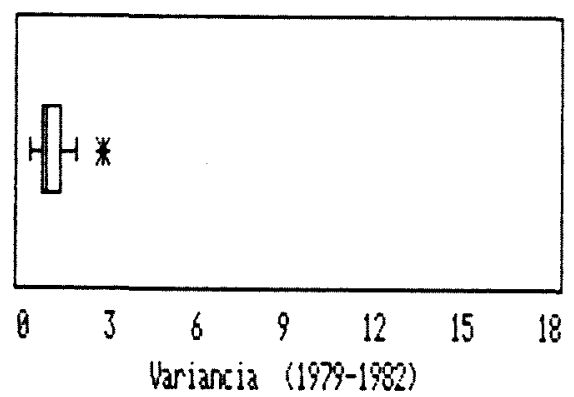

Aralise de wariancia da mortalidade Iberica reumatica cronica do coracao

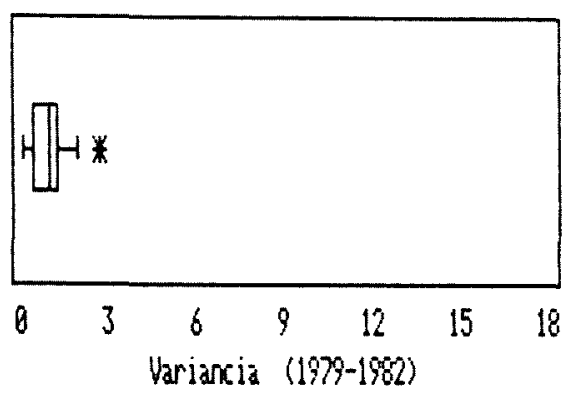

* Curitiba

Analise de variancia da bortalidade Hipertensao arterial

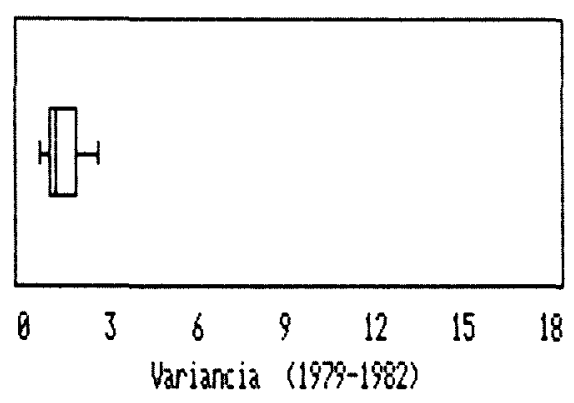

Analise de variarcia da mortalidade loenca cerebrowascular

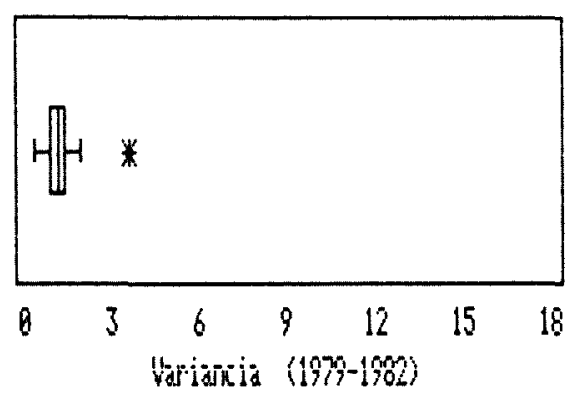

Analise de variarcia da mortalidade Menimgite

* Vitoria

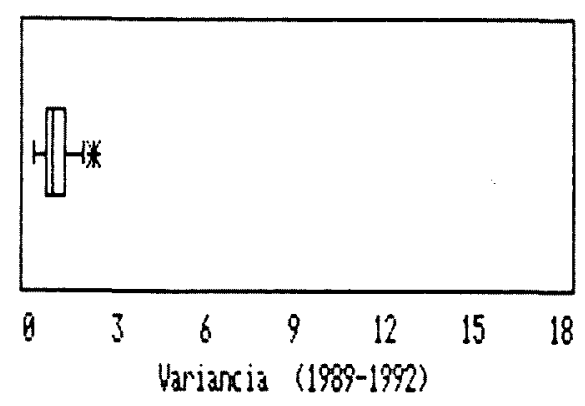

Analise de variancià da mortalidade Ioenca reumatica cronica do coracao

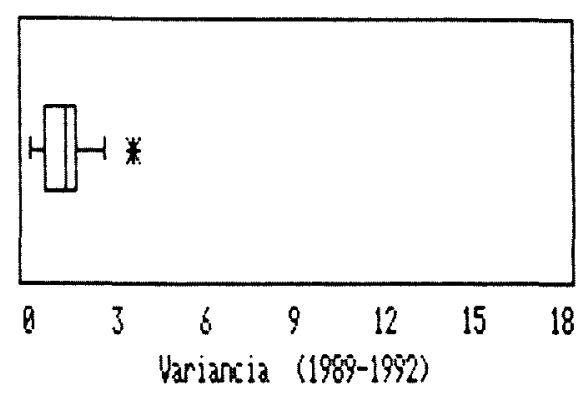

* Curitita

Analise de variancia da mortalidade Hipertensao arterial

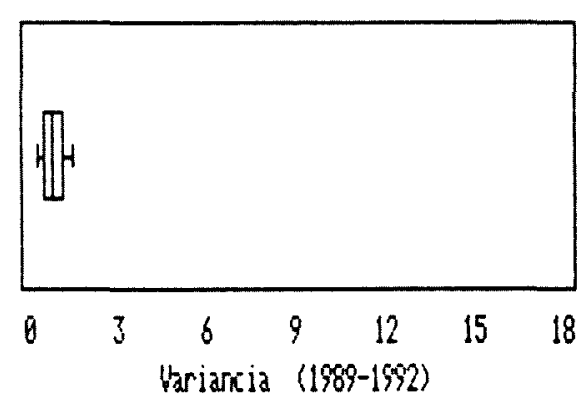

Analise de variancia da mortalidade Dherca ceretronascular

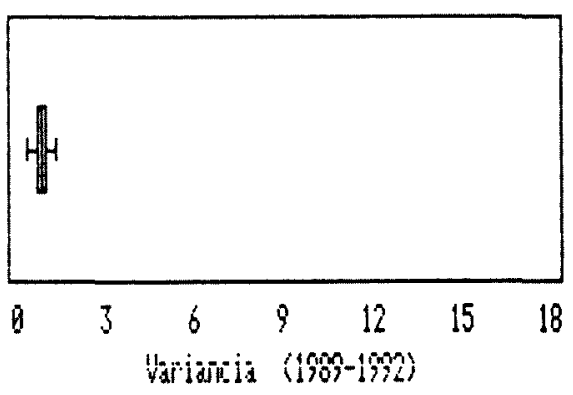

* Sao Luiz 
Arnalise de variancia da wortalidade Inteccoes respiratorias agudas

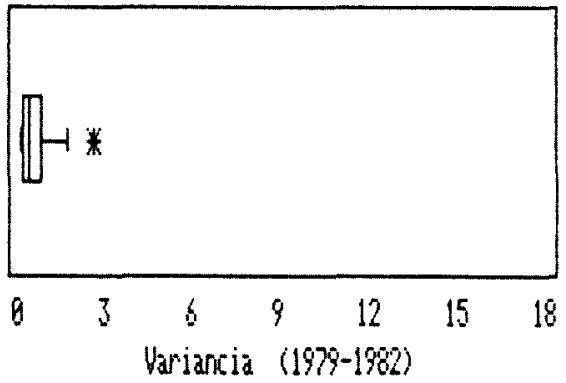

* Sao Luiz Variancia $(1979-1982)$

Aralise de variancia da mortalidade Pneumonia e gripe

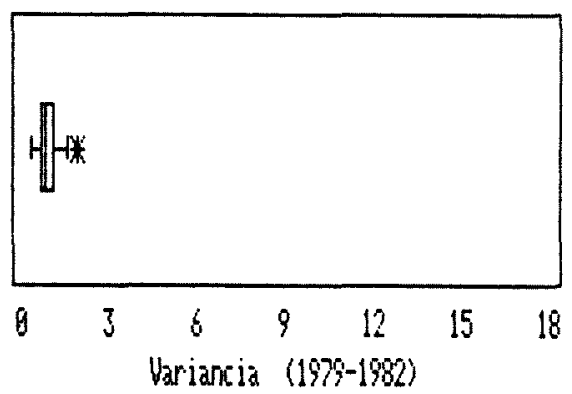

x. Belo Horizonte

Aralise de variancia da nortalidade Inenca pulamar obstrutiva cronica

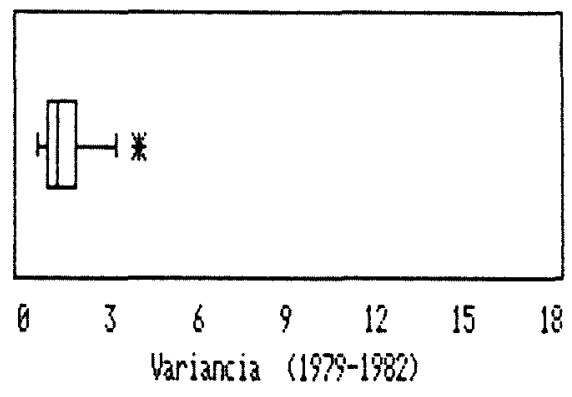

* Joso Pessoa

Analise de variancia da mortalidade Asma

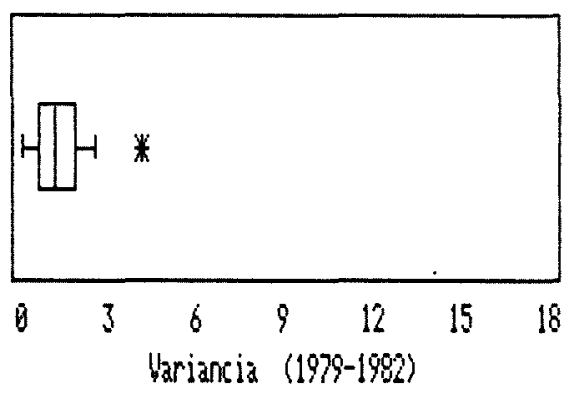

Aralise de variania da uartalidade Infeccoes respiraterias agudas

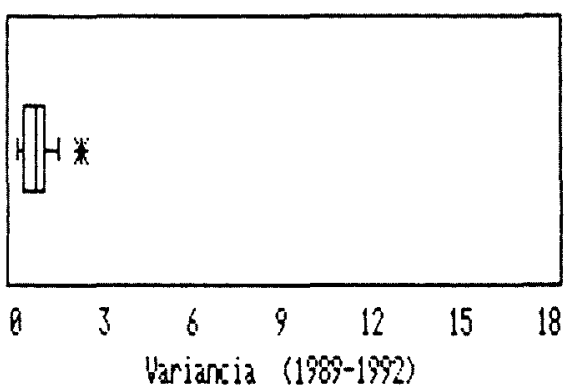

a Fio brano

Pralise de variancia da mortalidade Preumonia e gripe

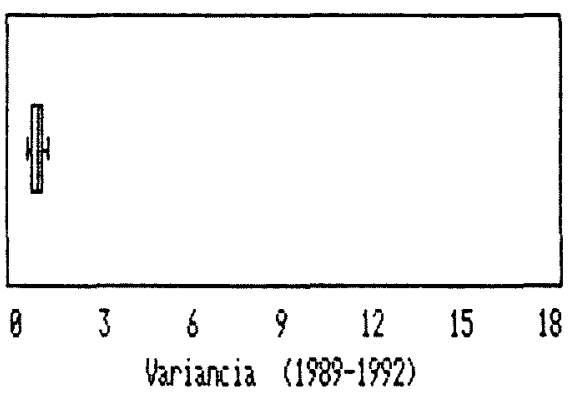

Analise de variancia da mortalidade Ihenca pulanar obstrutiva cronica

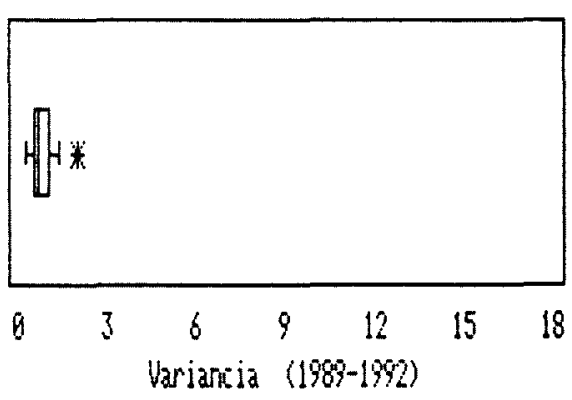

3 Curitiba

Analise de variancia od mortalidade $\hat{H} \in \mathrm{A}$ a

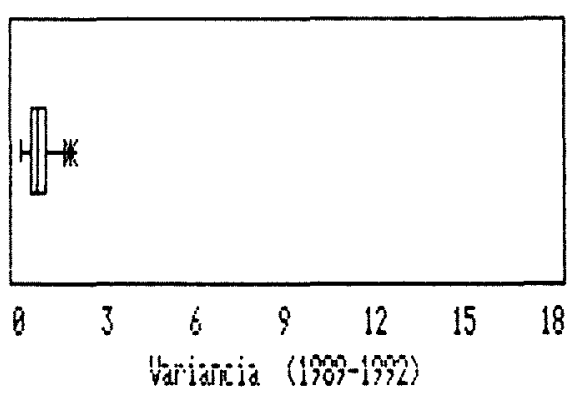


Analise de variancia da mortalidade Ulcera gastrica duodenal e iejuna!

* Porto Velto $x$ Sa Luiz

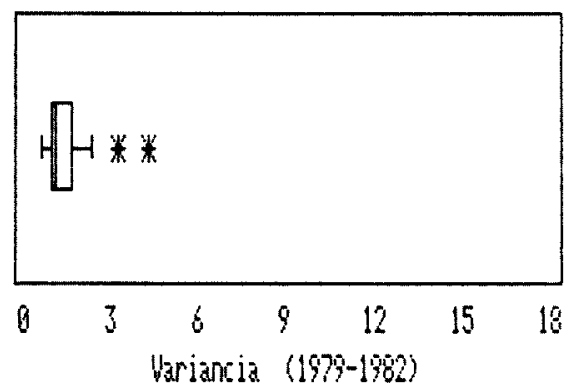

Analise de variancia da mortalidade Apendicite

* Sao Luiz * Belen

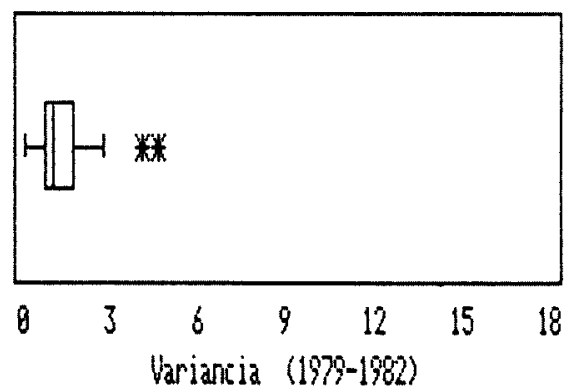

Arnalise de variancia da mortalidade Hernia abjominal

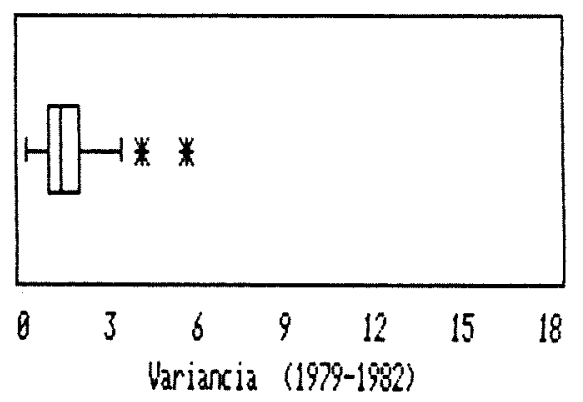

x Belen x Macapa Variancia (1979-1982)

Arralise de variancia da mortalidade Colecistite e colelitiase

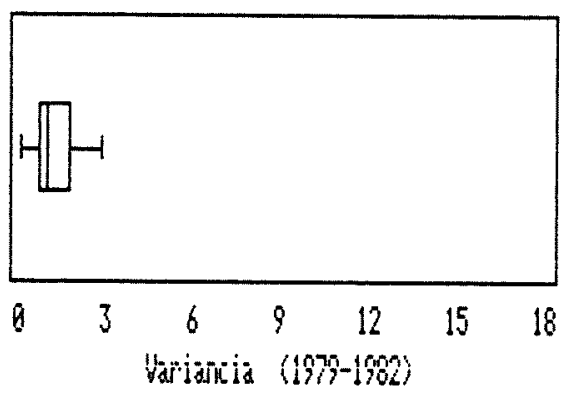

Arralise de variarcia da mortalidade Uliera gastrica, duodenal e jejunal

* Sao Luiz

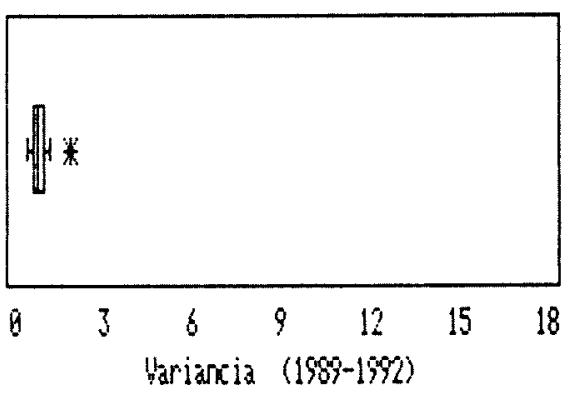

Fnalise de variancia da mortalidade Apendicite

* Sa Luiz

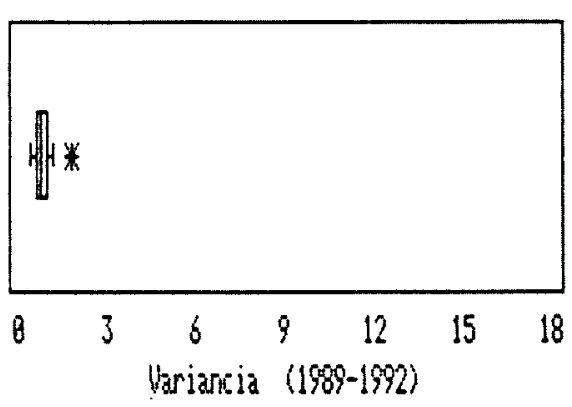

Arralise de variancia da mortalidade Hernia abdominal

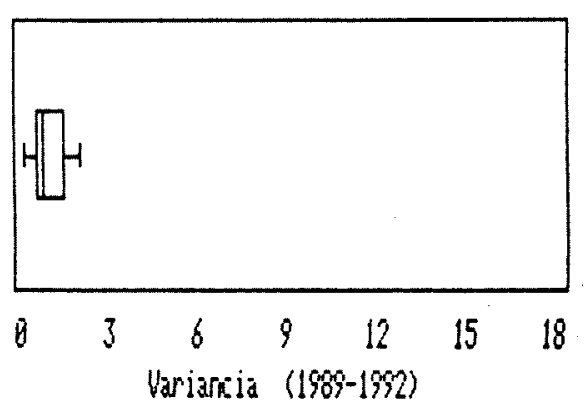

firalise de variancia da martalidade Colecistite e colelitiase

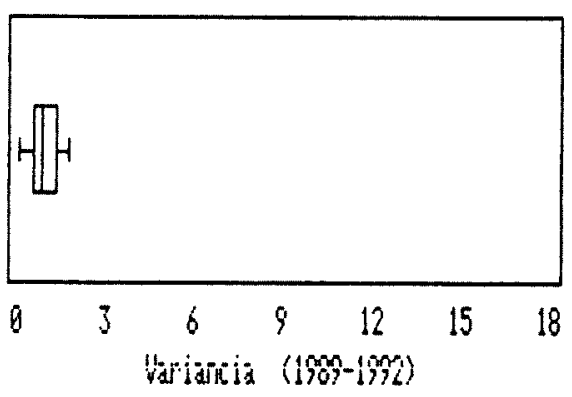


Analise de variarcia da mortalidade Nefrite e nefrose

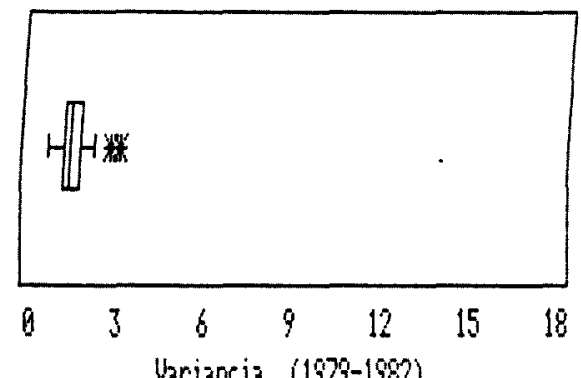

* Belen * Sá Luiz

Analise de variancia da mortalidade Complicagao da gravidez,parto,puepperio

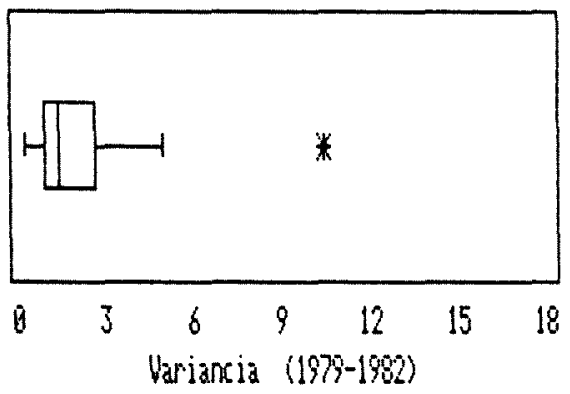

* Sao Luiz

Analise de variancia da nortalidade Causas mal detinidas

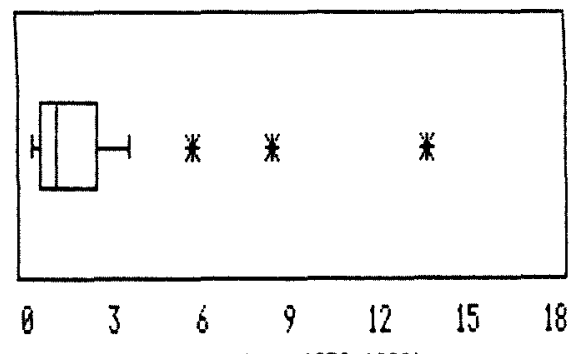
Variancia $(1979-1982)$

tuiaba xoan Pessoa xortaleza
Analise de bariancia da mortalidade Metrite e retrouse

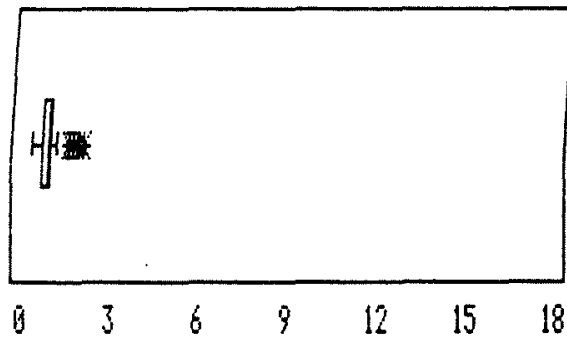
Variancia $(1989-1992)$

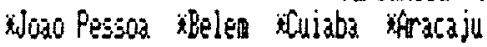

Añilise de variania da mortalidade Complicago da gravidez, parto,puerperio

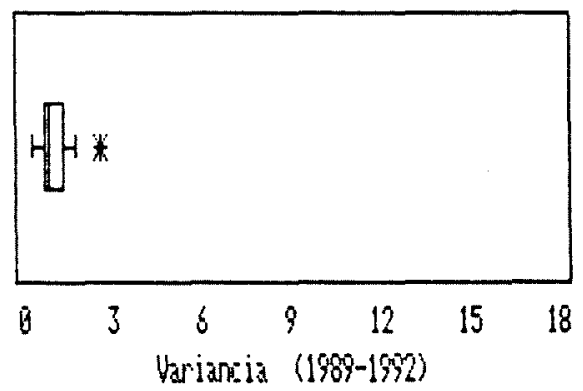

* SoL Luiz

Arralise de variancia da mortalidade Causas al dotinidas

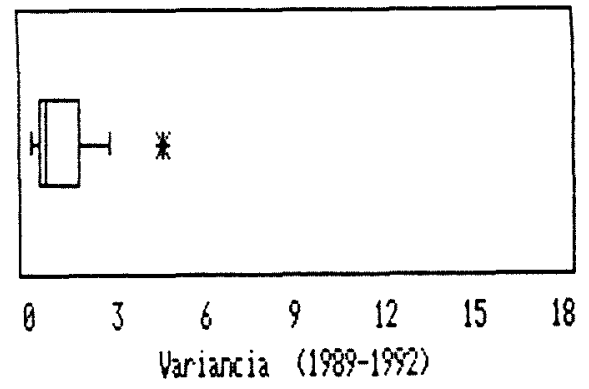

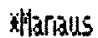


Quadro 8. Capitais com variância observada a partir do quartil superior da distribuição de frequêencia

\section{Rio Branco}

Maceió

Manaus

Salvador

Fortaleza

Brasilia

Vitória

\section{Goiânia}

São Luís

Belo Horizonte

Campo Grande

Cuiabá

Belém

João Pessoa

Curitiba

Recife

Terezina

Rio de Janeiro

Natal

Porto Velho

Boa Vista

Porto Alegre

Florianópolis

Aracaju

São Paulo $\mathbf{x} \quad \mathbf{x}$

X

$\mathbf{x}$

$\mathrm{x}$

$\begin{array}{llll}\mathbf{x} & \mathbf{x} & \mathbf{x}\end{array}$

$\mathbf{X}$

$\mathbf{x}$

$\begin{array}{lllll}\mathbf{x} & \mathbf{x} & \mathbf{x} & \mathbf{x} & \\ \mathbf{x} & & \mathrm{x} & & \mathbf{x} \\ & & & & \mathrm{x}\end{array}$

$\mathbf{x}$

$\mathrm{x}$

$\mathrm{x}$

$\mathbf{x}$

$\mathrm{x}$

$\mathbf{x}$

$\mathrm{x}$

$\mathbf{x}$

$\mathbf{x}$

$\mathbf{x}$

$\mathbf{x}$

$\mathbf{x}$

$\mathbf{x} \quad \mathrm{x}$

$\mathrm{x}$

$\mathbf{x}$

$\mathbf{x}$

$\mathbf{x} \quad \mathbf{x}$

$\mathbf{x}$

$\begin{array}{lll}\mathbf{x} & \mathrm{x} & \mathbf{x} \\ \mathrm{x} & \mathrm{x} & \mathbf{x}\end{array}$

$\begin{array}{lll}\mathbf{x} & \mathrm{x} & \mathrm{x} \\ \mathrm{x} & & \mathrm{x}\end{array}$

$\mathbf{x}$

$\mathbf{x}$

$\mathbf{x}$

$\mathbf{x}$

$\mathbf{x}$

$\mathbf{X}$

'TC: Todas as causas (exceto as evitáveis); quartil superior ${ }_{1979-1982}=1,3292$ quartil superior ${ }_{1989-1992}=0,8425$

${ }^{2} \mathrm{TE}$ : Todas as causas evitáveis; quartil superior ${ }_{1979-1982}=1,3835$ quartil superior ${ }_{1989-1992}=1,0752$

${ }^{3}$ CIPSS: Causas indicadoras de políticas sociais e de saúde; quartil superior ${ }_{1979-1982}=1,4291$ quartil superior ${ }_{1969-1992}=0,8979$

${ }^{4} \mathrm{CICS}$ : Causas indicadoras de cuidados de saúde; quartil superior ${ }_{1979-1982}=1,4752$ quartil superior ${ }_{1989.1992}=1,0446$ 
3. Análise da Tendência de Declínio da Mortalidade no Conjunto das Capitais

A mortalidade por causas evitáveis e pelas demais causas de óbito declina no periodo estudado (Tabela 2). A análise de tendência pelo modelo de regressão loglinear resulta em coeficientes negativos para o conjunto das causas evitáveis selecionadas $(b=-0,038 \quad \mathrm{p}=0,0000)$, bem como para as demais causas de óbito $(b=-0,024 \mathrm{p}=0,0000)$. Quando comparadas, a velocidade de declínio da taxa de mortalidade por CICS (5,4\% aa.) é 2,2 vezes a velocidade de declínio da taxa de mortalidade pelas demais causas $(2,4 \%$ aa.). A taxa de mortalidade por CIPSS decresce $0,04 \%$ aa. e não apresenta tendência de declínio exponencial $(B=-0,004 \mathrm{p}=0,3251)$.

A taxa de mortalidade por 100 mil pessoas para o grupo etário de 0 a 64 anos ajustada por idade estimada por regressão loglinear declina para todas as causas evitáveis $\left(Y_{1979}^{\prime}=306,51 Y_{1992}^{\prime}=186,20\right)$, para CIPSS $\left(\mathrm{Y}_{1979}^{\prime}=77,58 \quad \mathrm{Y}^{\prime}{ }_{1992}=73,67\right)$, para $\operatorname{CICS}\left(\mathrm{Y}_{1979}^{\prime}=230,86 \mathrm{Y}_{1992}^{\prime}=114,03\right)$ e para as demais causas $\left(\mathrm{Y}^{\prime}{ }_{1979}=279,85 \mathrm{Y}^{\prime}{ }_{1992}=204,51\right)$.

A mortalidade por CIPSS não apresenta tendência exponencial de declínio significativa $(b=-0,004$ $\mathrm{p}=0,3251$ ) devido a evolução diferenciada das diversas causas de óbito do grupo. A mortalidade por deficiências nutricionais experimenta a segunda maior taxa de declínio dentre todas as causas de óbito ( $13 \%$ aa.), enquanto que há crescimento exponencial dos óbitos por homicídio e outras violências $(b=0,04$ $\mathrm{p}=0,0001)$.

Há declínio exponencial da taxa de mortalidade por CICS para quase a totalidade das causas de óbito, exceto para diabetes melito $(b=-0,003 \quad p=0,2698)$, hérnia da cavidade abdominal $(b=-0,028$ $p=0,0361)$, colecistite e colelitíase $(b=-0,017 p=-0,1100)$, e causas mal definidas $(b=-0,011 p=-0,3823)$. As exceções são: o melanoma maligno de pele $(b=0,001 p=0,9033)$, com taxa de mortalidade estacionária, e apendicite $(b=0,09 p=0,0056)$ que apresenta tendência exponencial de crescimento não significativa ( $>0,0020)$. A tendência de declínio exponencial é significativa para as demais causas de óbitos (CICS) e as doenças infecciosas intestinais $(b=-0,14 p=0,0000)$ e infeç̧ões respiratórias agudas $(b=-0,13 p=0,0003)$ apresentam as maiores taxas de declínio registradas no conjunto das capitais $(-14 \%$ e $-13 \%$ aa., respectivamente). 
Tabela 2. Análise de regressão loglinear da mortalidade no conjunto das capitais, 1979-1992

\begin{tabular}{|c|c|c|c|c|}
\hline Cid 9 & Causa de óbito & $\begin{array}{l}\text { Coeficiente } \\
\text { de regressão }\end{array}$ & $Y^{\prime}{ }_{1979}$ & $Y^{\prime}{ }_{1992}$ \\
\hline \multicolumn{2}{|c|}{ Todas as causas (exceto as evitáveis) } & $-0,024^{* * *}$ & 279,85 & 204,51 \\
\hline \multicolumn{2}{|c|}{ Todas as causas evitáveis } & $-0,038^{* * *}$ & 306,51 & 186,20 \\
\hline \multicolumn{2}{|r|}{ - Causas indicadoras de politicas sociais e de saúde } & $-0,004$ & 77,58 & 73,67 \\
\hline 150 & Tumor maligno do esôfago & $-0,025^{* * *}$ & 2,69 & 1,94 \\
\hline 162 & Tumor maligno da traquéia, brônquio e pulmão & $-0,011^{* * *}$ & 7,40 & 6,41 \\
\hline $260-269$ & Deficiências nutricionais & $-0,125^{* * *}$ & 117,50 & 23,00 \\
\hline 571 & Doença crônica do figado e cirrose & $-0,015^{* *}$ & 18,69 & 15,45 \\
\hline E810-819 & Acidente de trânsito (veiculo a motor) & $-0,010$ & 26,03 & 22,76 \\
\hline E960-969 & Homicídio e outras violências & $0,040^{* * *}$ & 17,84 & 30,22 \\
\hline \multicolumn{2}{|c|}{ - Causas indicadoras de cuidados de saúde } & $-0,054^{* * *}$ & 230,86 & 114,03 \\
\hline $001-009$ & Doenças infecciosas intestinais & $-0,144^{* * *}$ & 536,84 & 82,49 \\
\hline $010-018$ & Tuberculose & $-0,052^{* * *}$ & 9,68 & 4,90 \\
\hline 038 & Septicemia & $-0,066^{* * *}$ & 48,86 & 20,74 \\
\hline 172 & Melanoma maligno da pele & 0,001 & 0,44 & 0,44 \\
\hline 179 & Tumor maligno do útero não especificado & $-0,027^{* \bullet \bullet}$ & 2,29 & 1,61 \\
\hline 180 & Tumor maligno do colo do útero & $-0,022^{* * *}$ & 4,79 & 3,61 \\
\hline 201 & Doença de Hodgkin & $-0,030^{* * *}$ & 0,70 & 0,47 \\
\hline 250 & Diabetes melito & $-0,003$ & 12,56 & 12,02 \\
\hline $320-322$ & Meningite & $-0,079^{* * *}$ & 36,27 & 12,98 \\
\hline $393-398$ & Doença reumática crônica do coração & $-0,052^{* * *}$ & 1,67 & 0,84 \\
\hline $401-405$ & Hipertensão arterial & $-0,031^{* * *}$ & 34,42 & 23,13 \\
\hline $430-436$ & Doença cerebrovascular & $-0,022^{* * *}$ & 119,77 & 89,66 \\
\hline $460-466$ & Infecções respiratórias agudas & $-0,131^{* * *}$ & 20,78 & 3,80 \\
\hline $480-487$ & Pneumonia e gripe & $-0,067^{* * *}$ & 43,97 & 18,47 \\
\hline $491-492$ & Doença pulmonar obstrutiva crônica & $-0,073^{* * *}$ & 8,55 & 3,31 \\
\hline 493 & Asma & $-0,034^{* * *}$ & 0,70 & 0,45 \\
\hline $531-534$ & Úlcera gástrica, duodenal, jejunal & $-0,042^{* * *}$ & 2,68 & 1,56 \\
\hline $540-543$ & Apendicite & $0,095^{* *}$ & 0,39 & 1,35 \\
\hline $550-553$ & Hérnia da cavidade abdominal & $-0,028^{*}$ & 0,36 & 0,25 \\
\hline $574-575$ & Colelitiase e colecistite & $-0,017$ & 0,61 & 0,49 \\
\hline $580-589$ & Nefrite e nefrose & $-0,035^{* * *}$ & 5,82 & 3,68 \\
\hline $630-639$ & Complicação da gravidez, parto e puerpério & $-0,080^{* * *}$ & 4,05 & 1,44 \\
\hline $780-799$ & Sintomas, sinais e afecções mal definidas & $-0,011$ & 25,20 & 21,87 \\
\hline
\end{tabular}

$p \leq 0,05 \quad-p \leq 0,01 \quad-p \leq 0,002 \quad$ em branco: $p>0,05$ 
4. Análise da Tendência de Declínio da Mortalidade nas Capitais

4.1. Declínio da mortalidade por todas as causas (exceto as causas evitáveis)

A Razão de Mortalidade Padronizada (RMP) indica que há diminuição no nível de mortalidade por todas as causas (exceto as evitáveis) durante o período de estudo, pois as sete capitais que apresentam nível de mortalidade superior ao esperado (p $\leq 0,002)$ no periodo de 1979-1982 evoluem para o nível esperado em 1989-1992: Porto Velho (RMP=94 $p=0,4175)$, Cuiabá ( $R M P=95 \quad p=0,4475)$ e São Luiz (RMP=96 $\mathrm{p}=0,5817)$, e Fortaleza ( $R M P=71 \mathrm{p}=0,0000$ ) evolui para um nível inferior ao esperado (Tabela 3).

A maior homogeneidade da distribuição dos óbitos entre as capitais acompanha o declínio da taxa de mortalidade a partir do final da década de 1970, durante a década de 1980 e início da década de 1990 . Este fato é demonstrado na análise de regressão loglinear da taxa de mortalidade por todas as causas (excluídas as causas evitáveis): vinte capitais apresentam tendência exponencial de declínio. Contudo, seis capitais parecem contrastar desta tendência geral observada (declínio de $2,4 \%$ aa.), por não apresentarem declínio exponencial: apresentam coeficiente de regressão negativo estatisticamente não-significativo $(p>0,002)$ : Rio Branco $(b=-0,009 p=0,4027)$, Macapá $(b=-0,006 p=0,6503)$, Vitória $(b=-0,029 p=0,0135)$, Rio de Janeiro $(b=-0,005 p=0,3211)$, Boa Vista $(b=-0,027 p=0,0567)$ e Aracaju $(b=-0,021 p=0,1349)$. Nestas capitais durante o período estudado, a taxa de mortalidade por todas as causas (excluídas as causas evitáveis) permanece estacionária.

\subsection{Declínio da mortalidade por causas evitáveis}

No período de 1979-1982, nove capitais têm taxa de mortalidade por causas evitáveis superior à esperada, com destaque para Fortaleza $(R M P=292 p=0,0000)$ e São Luiz $(R M P=274 p=0,0000)$. No período seguinte, sete capitais encontram-se nesta situação, dentre as quais estão Vitória $\left(\mathrm{RMP}_{79 /{ }^{2}}=85\right.$ $\left.\mathrm{p}=0,010 ; \quad \mathrm{RMP}_{80 / 92}=122 \mathrm{p}=0,003\right)$ e Recife $\left(\mathrm{RMP}_{79 / 82}=109 \mathrm{p}=0,155 ; \mathrm{RMP}_{89 / 92}=129 \mathrm{p}=0,0000\right)$ com evolução desfavorável (Tabela 4).

As causas evitáveis declinam 3,8\% aa. no conjunto das capitais entre 1979 e 1992 . Apesar da análise de regressão da taxa de mortalidade por causas evitáveis produzir coeficientes negativos para todas as capitais, a tendência de declínio é insignificante $(p>0,002)$ em nove delas: Rio Branco, Manaus, Brasília, 
Vitória, Campo Grande, Rio de Janeiro, Porto Velho, Boa Vista e Porto Alegre. Nestas capitais, a taxa de mortalidade por causas evitáveis permanece estacionária durante todo o periodo estudado (Tabela 4).

Tabela 3. Coeficiente de regressão loglinear e taxa de mortalidade* por todas as causas (exceto as evitáveis) padronizada por idade e razão de mortalidade padronizada para as capitais brasileiras

\begin{tabular}{|c|c|c|c|c|c|c|c|c|}
\hline \multirow[b]{2}{*}{ Capital } & \multirow[b]{2}{*}{$\mathbf{b}$} & \multirow[b]{2}{*}{$\mathbf{p}$} & \multicolumn{3}{|c|}{$1979 / 1982$} & \multicolumn{3}{|c|}{$1989 / 1992$} \\
\hline & & & Taxa & $\mathrm{RMP}$ & $\mathbf{p}$ & Taxa & RMP & p \\
\hline Rio Branco & $-0,0192$ & 0,0427 & 168,1 & 63 & 0,0000 & 140,9 & 67 & 0,0000 \\
\hline Maceió & $-0,0234$ & 0,0004 & 251,4 & 94 & 0,3205 & 197,1 & 94 & 0,3791 \\
\hline Macapá & $-0,0060$ & 0,6503 & 226,4 & 84 & 0,0118 & 191,3 & 91 & 0,1998 \\
\hline Manaus & $-0,0356$ & 0,0000 & 252,3 & 94 & 0,3487 & 176,0 & 84 & 0,0194 \\
\hline Salvador & $-0,0208$ & 0,0008 & 288,6 & 108 & 0,2242 & 232,8 & 111 & 0,1303 \\
\hline Fortaleza & $-0,0812$ & 0,0000 & 335,4 & 125 & 0,0000 & 149,2 & 71 & 0,0000 \\
\hline Brasilia & $-0,0300$ & 0,0000 & 235,0 & 88 & 0,0460 & 175,8 & 84 & 0,0186 \\
\hline Vitónia & $-0,0292$ & 0,0135 & 251,3 & 94 & 0,3160 & 190,4 & 91 & 0,1793 \\
\hline Goiânia & $-0,0429$ & 0,0001 & 275,3 & 103 & 0,6852 & 174,7 & 83 & 0,0152 \\
\hline São Luís & $-0,0937$ & 0,0000 & 505,2 & 188 & 0,0000 & 201,9 & 96 & 0,5817 \\
\hline Belo Horizonte & $-0,0361$ & 0,0000 & 334,6 & 125 & 0,0001 & 231,4 & 110 & 0,1573 \\
\hline Campo Grande & $-0,0292$ & 0,0000 & 274,6 & 102 & 0,7194 & 202,2 & 96 & 0,5943 \\
\hline Cuiabá & $-0,0422$ & 0,0003 & 321,2 & 120 & 0,0013 & 198,9 & 95 & 0,4475 \\
\hline Belém & $-0,0475$ & 0,0000 & 278,7 & 104 & 0,5421 & 171,7 & 82 & 0,0085 \\
\hline João Pessoa & $-0,0241$ & 0,0001 & 205,2 & 77 & 0,0001 & 160,3 & 76 & 0,0006 \\
\hline Curitiba & $-0,0403$ & 0,0000 & 314,5 & 117 & 0,0051 & 210,4 & 100 & 0,9743 \\
\hline Recife & $-0,0166$ & 0,0007 & 265,3 & 98 & 0,7175 & 224,7 & 105 & 0,4727 \\
\hline Terezina & $-0,0403$ & 0,0001 & 235,6 & 88 & 0,0503 & 164,1 & 78 & 0,0016 \\
\hline Rio de Janeiro & $-0,0050$ & 0,3211 & 226,9 & 85 & 0,0127 & 236,7 & 112 & 0,0755 \\
\hline Natal & $-0,0335$ & 0,0003 & 193,3 & 72 & 0,0000 & 139,0 & 66 & 0,0000 \\
\hline Porto Velho & $-0,0517$ & 0,0010 & 322,9 & 120 & 0,0009 & 198,1 & 94 & 0,4175 \\
\hline Boa Vista & $-0,0270$ & 0,0567 & 324,6 & 121 & 0,0006 & 242,1 & 115 & 0,0316 \\
\hline Porto Alegre & $-0,0245$ & 0,0000 & 258,8 & 96 & 0,5855 & 199,4 & 95 & 0,4699 \\
\hline Florianópolis & $-0,0422$ & 0,0000 & 248,2 & 93 & 0,2348 & 164,0 & 78 & 0,0016 \\
\hline Aracaju & $-0,0210$ & 0,1349 & 297,8 & 111 & 0,0754 & 237,3 & 113 & 0,0687 \\
\hline São Paulo & $-0,0210$ & 0,0000 & 274,9 & 102 & 0,7056 & 222,7 & 106 & 0,4176 \\
\hline
\end{tabular}

* 100.000 hab. 
Tabela 4. Coeficiente de regressão loglinear e taxa de mortalidade* por todas as causas evitáveis padronizada por idade e razão de mortalidade padronizada para as capitais brasileiras

1979/1982

$1989 / 1992$

Capital

b

p Taxa RMP

p Taxa RMP

p

\begin{tabular}{lrrrrrrrr}
\hline & & & & & & & \\
Rio Branco & $-0,0123$ & 0,0467 & 223,9 & 78 & 0,0002 & 184,2 & 93 & 0,3578 \\
Maceió & $-0,0486$ & 0,0000 & 468,4 & 163 & 0,0000 & 284,4 & 144 & 0,0000 \\
Macapá & $-0,0422$ & 0,0008 & 256,6 & 89 & 0,0668 & 162,4 & 82 & 0,0136 \\
Manaus & $-0,0109$ & 0,1132 & 345,4 & 120 & 0,0008 & 322,6 & 163 & 0,0000 \\
Salvador & $-0,0463$ & 0,0000 & 282,1 & 98 & 0,7403 & 178,7 & 90 & 0,1907 \\
Fortaleza & $-0,1449$ & 0,0000 & 841,4 & 292 & 0,0000 & 199,9 & 101 & 0,8988 \\
Brasilia & $-0,0067$ & 0,1480 & 173,8 & 60 & 0,0000 & 163,7 & 83 & 0,0174 \\
Vitória & $-0,0041$ & 0,5311 & 243,8 & 85 & 0,0097 & 240,3 & 122 & 0,0027 \\
Goiânia & $-0,0385$ & 0,0001 & 277,8 & 96 & 0,5609 & 184,0 & 93 & 0,3519 \\
São Luís & $-0,1235$ & 0,0000 & 789,6 & 274 & 0,0000 & 229,5 & 116 & 0,0256 \\
Belo Horizonte & $-0,0573$ & 0,0000 & 351,5 & 122 & 0,0002 & 196,3 & 99 & 0,9534 \\
Campo Grande & $-0,0225$ & 0,0024 & 229,7 & 80 & 0,0006 & 188,8 & 96 & 0,5555 \\
Cuiabá & $-0,0612$ & 0,0000 & 337,5 & 117 & 0,0041 & 182,0 & 92 & 0,2819 \\
Belém & $-0,0655$ & 0,0000 & 365,1 & 127 & 0,0000 & 192,8 & 98 & 0,7618 \\
João Pessoa & $-0,0623$ & 0,0000 & 478,7 & 166 & 0,0000 & 257,2 & 130 & 0,0000 \\
Curitiba & $-0,0428$ & 0,0000 & 272,4 & 95 & 0,3691 & 178,6 & 90 & 0,1893 \\
Recife & $-0,0228$ & 0,0001 & 308,0 & 109 & 0,1547 & 251,5 & 129 & 0,0000 \\
Terezina & $-0,0571$ & 0,0002 & 258,2 & 90 & 0,0823 & 158,1 & 80 & 0,0055 \\
Rio de Janeiro & $-0,0142$ & 0,0289 & 220,1 & 76 & 0,0001 & 193,7 & 98 & 0,8063 \\
Natal & $-0,0783$ & 0,0000 & 326,4 & 113 & 0,0265 & 150,8 & 76 & 0,0010 \\
Porto Velho & $-0,0272$ & 0,0264 & 339,4 & 118 & 0,0028 & 278,3 & 141 & 0,0000 \\
Boa Vista & $-0,0349$ & 0,0056 & 332,3 & 115 & 0,0102 & 236,5 & 120 & 0,0064 \\
Porto Alegre & $-0,0117$ & 0,1006 & 178,9 & 62 & 0,0000 & 162,4 & 82 & 0,0134 \\
Florianónpolis & $-0,0358$ & 0,0001 & 176,4 & 61 & 0,0000 & 123,7 & 63 & 0,0000 \\
Aracaju & $-0,0307$ & 0,0019 & 370,0 & 128 & 0,0000 & 274,0 & 139 & 0,0000 \\
São Paulo & $-0,0360$ & 0,0000 & 268,1 & 93 & 0,2495 & 187,7 & 95 & 0,5023 \\
& & & & & & & & \\
\hline
\end{tabular}

- 100.000 hab. 


\subsection{Declínio da mortalidade por CIPSS}

Como já apresentado (Tabela 2), a taxa de mortalidade por CIPSS no conjunto das capitais mantémse estacionária durante o período estudado $(b=-0,004 p=0,3251)$. Contudo, Fortaleza $(b=-0,077$ $p=0,0000)$, São Luiz $(b=-0,081 p=0,0000)$, Belo Horizonte $(b=-0,047 p=0,0000)$, Belém $(b=-0,030$ $\mathrm{p}=0,0002)$ e Curitiba $(\mathrm{b}=-0,020 \quad \mathrm{p}=0,0006)$ apresentam tendência exponencial de declínio, e Brasilia $(b=0,0038 p=0,0001)$ e Recife $(b=0,035 p=0,0000)$ têm tendência exponencial de crescimento da taxa de mortalidade por CIPSS.

Quando é analisada a evolução da RMP para CIPSS (Tabela 5), a tendência de estagnação ocorre em vinte capitais que mantêm o status inicial durante o período estudado: quatorze capitais com taxa de mortalidade igual à esperada, quatro capitais com taxa superior à esperada (Maceió, Recife, Porto Velho e Boa Vista) e duas capitais com taxa de mortalidade inferior à esperada (Salvador e Terezina). Entretanto, seis capitais contrariam essa tendência, seja porque evoluem de um nível de mortalidade inferior ao esperado para o nível esperado (Rio Branco) ou para nível superior ao esperado (Vitória), seja porque evoluem de um nível superior ao esperado para o nível esperado (Fortaleza, São Luiz e Belo Horizonte), ou do nível esperado para um nível inferior ao esperado (Cuiabá). A mortalidade por CIPSS é significativamente superior a esperada em sete capitais no período de 1979-1982 e em cinco capitais no período de 1989-1992, quando passa a incluir Vitória $(\mathrm{RMP}=136 \mathrm{p}=0,002)$. 
Tabela 5. Coeficiente de regressão loglinear e taxa de mortalidade* por Causas Indicadoras de Políticas Sociais e de Saúde padronizada por idade e razão de mortalidade padronizada para as capitais brasileiras

$1979 / 1982$

Taxa RMP
$1989 / 1992$

Capital

b

p

0,0203

0,1124

0,1821

0,1542

0,4057

0,0000

0,0001

0,4133

0,0820

0,0000

0,0000

0,0048

0,1258

0,0002

0,1525

0,0006

0,0000

0,2214

0,1146

0,0335

0,1075

0,2403

0,1579

0,9423

0,0500

0,1433

$\begin{array}{rrr}46,7 & 61 & 0,0010 \\ 116,7 & 154 & 0,0000 \\ 62,3 & 82 & 0,1298 \\ 88,1 & 116 & 0,1806 \\ 43,4 & 57 & 0,0000\end{array}$

$\begin{array}{lll}123,8 & 163 & 0,0002\end{array}$

$\begin{array}{lll}55,4 & 73 & 0,0212\end{array}$

$87,2 \quad 115 \quad 0,2171$

$63,9 \quad 84 \quad 0,1852$

$\begin{array}{lll}169,1 & 223 & 0,0000\end{array}$

$104,3 \quad 137 \quad 0,0014$

$\begin{array}{lll}61,8 & 81 & 0,1168\end{array}$

$56,2 \quad 74 \quad 0,0273$

$\begin{array}{lll}82,8 & 109 & 0,4673\end{array}$

$\begin{array}{lll}72,8 & 96 & 0,7568\end{array}$

$\begin{array}{lll}94,5 & 124 & 0,0384\end{array}$

$73,4 \quad 132 \quad 0,0200$

$49,7 \quad 65 \quad 0,0031$

$\begin{array}{lll}69,9 & 92 & 0,5221\end{array}$

79,1104

0,7573

$\begin{array}{lll}94,8 & 125 & 0,0349\end{array}$

$89,4 \quad 118 \quad 0,1387$

$\begin{array}{lll}60,5 & 80 & 0,0871\end{array}$

$56,5 \quad 74 \quad 0,0296$

$79,8 \quad 105$

0,7025

0,9725

$\begin{array}{rrr}60,5 & 82 & 0,1262 \\ 103,7 & 140 & 0,0007 \\ 71,4 & 96 & 0,7915 \\ 81,0 & 109 & 0,4574 \\ 38,3 & 52 & 0,0000 \\ 58,5 & 79 & 0,0797 \\ 78,2 & 105 & 0,6786 \\ 100,7 & 136 & 0,0025 \\ 74,9 & 101 & 0,9748 \\ 70,7 & 95 & 0,7321 \\ 64,3 & 87 & 0,2786 \\ 76,4 & 103 & 0,8376 \\ 37,5 & 51 & 0,0000 \\ 63,1 & 85 & 0,2199 \\ 64,6 & 87 & 0,2928 \\ 77,3 & 104 & 0,7538 \\ 96,0 & 158 & 0,0000 \\ 45,0 & 61 & 0,0009 \\ 70,0 & 94 & 0,6724 \\ 57,2 & 77 & 0,0559 \\ 134,8 & 182 & 0,0000 \\ 117,4 & 158 & 0,0000 \\ 69,6 & 94 & 0,6429 \\ 58,2 & 78 & 0,0723 \\ 76,1 & 103 & 0,8660 \\ 86,1 & 116 & 0,1813\end{array}$

* 100.000 hab. 
5. Impacto da Intervenção Médica sobre a Mortalidade por CICS no Conjunto das Capitais

O impacto da assistência médica sobre o declínio da mortalidade é estimado pela Razão de Mortalidade Evitável (RME). A RME indica a diferença percentual do nível de mortalidade por CICS observada em 1992 em relação ao que provavelmente ocorreria na ausência da assistência médica. Esse cenário de previsão é simulado pela aplicação do coeficiente de regressão obtido pela análise de regressão loglinear das taxas padronizadas de mortalidade por CIPSS (1979-1992) na taxa de mortalidade por CICS estimada para 1979 por regressão loglinear.

A taxa de mortalidade por CICS no conjunto das capitais declina 5,4\% aa., evoluindo de $230,86 / 100.000$ para $114,03 / 100.000$, quando ajustadas por regressão loglinear (Tabela 2). A intervenção médica contribui com $47,9 \%$ deste declínio. Como este efeito ( $-2,5 \%$ aa.) produz uma diferença significativa entre a taxa estimada e a esperada na sua ausência ( $R M E=52,01 p \leq 0,002$ ), é possível inferir que a intervenção médica contribui de forma expressiva para o declínio da mortalidade por CICS no conjunto das capitais em 1992 (Tabela 6).

O impacto da intervenção médica no declínio da mortalidade varia de acordo com as causas de óbito evitável. Por exemplo, ele corresponde a $8,6 \%$ do declínio da taxa de mortalidade por causas mal definidas $(8,6 \%$ de $-0,011$ corresponde a $-0,1 \%$ aa.). Como este efeito não produz uma diferença significativa $(R M E=91,40 p=0,6740)$ entre a taxa estimada para $1992\left(Y^{*}=21,87\right)$ e a esperada na ausência da intervenção médica $\left(Y^{n}=23,93\right)$, pode-se afirmar que a intervenção médica contribui de forma pouco expressiva para o declínio da mortalidade por causas mal definidas no conjunto das capitais em 1992.

Entretanto, a intervenção médica mostra-se muito mais efetiva em relação a outras causas de óbito evitável, contribuindo de forma expressiva para o declínio da mortalidade por doenças infecciosas intestinais $(R M E=16,18 p=0,0000)$, por septicemia $(R M E=44,69 p=0,0002)$, meningite $(R M E=37,69 p=0,0003)$, infecções respiratórias agudas $(\mathrm{RME}=19,26 \mathrm{p}=0,0003)$ e pneumonia e gripe $(\mathrm{RME}=44,24 \mathrm{p}=0,0003)$.

Portanto, dentre as 17 causas (ou grupos de causas) de óbito por CICS com tendência exponencial de declínio no conjunto das capitais, é detectada a contribuição significativa $(p \leq 0,002)$ da intervenção médica para esse declínio em cinco causas de óbito. Isto porque não é possível rejeitar a hipótese nula de 
inexistência de diferença percentual entre a taxa estimada na presença da assistência médica e a taxa esperada na sua ausência para o ano de 1992, a partir dos dados disponíveis, considerando o nível de significância de $\mathrm{p} \leq 0,002$.

Tabela 6. Análise de regressão, percentual da taxa de declínio da mortalidade devido à intervenção médica (PTD) e Razão de Mortalidade Evitável (RME) no conjunto das capitais, 1979-1992

CICS Causas indicadoras de cuidados de saúde

\section{1-009}

010-018

038

172

179

180

201

250

320-322

393-398

$401-405$

$430-436$

$460-466$

480-487

491-492

493

$531-534$

540-543

$550-553$

574-575

$580-589$

630-639

780-799
Doenças infecciosas intestinais

Tuberculose

Septicemia

Melanoma maligno da pele

Tumor maligno do útero não especificado

Tumor maligno do colo do útero

Doença de Hodgkin

Diabetes melito

Meningite

Doença reumática crônica do coração

Hipertensão arterial

Doença cerebrovascular

Infeç̧ões respiratórias agudas

Pneumonia e gripe

Doença pulmonar obstrutiva crônica

Asma

Úlcera gástrica, duodenal, jejunal

Apendicite

Hérnia da cavidade abdominal

Colelitíase e colecistite

Nefrite e nefrose

Complicação da gravidez, parto e puerpério

Sintomas, sinais e afeç̧ões mal definidas

$\begin{array}{rrcc}114,03 & 219,23 & 47,9 & 52,01^{* * *} \\ 82,49 & 509,80 & 83,8 & 16,18^{* * *} \\ 4,90 & 9,19 & 46,7 & 53,30 \\ 20,74 & 46,40 & 55,3 & 44,69^{* * *} \\ 0,44 & 0,42 & - & - \\ 1,61 & 2,17 & 25,6 & 74,39 \\ 3,61 & 4,55 & 20,7 & 79,34 \\ 0,47 & 0,66 & 29,1 & 70,91 \\ 12,02 & 11,93 & -- & 100,74 \\ 12,98 & 34,44 & 62,3 & 37,69^{* * *} \\ 0,84 & 1,58 & 46,6 & 53,38 \\ 23,13 & 32,68 & 29,2 & 70,77 \\ 89,66 & 113,73 & 21,2 & 78,84^{*} \\ 3,80 & 19,73 & 80,7 & 19,26^{* * *} \\ 18,47 & 41,76 & 55,8 & 44,24^{* * *} \\ 3,31 & 8,12 & 59,3 & 40,71 \\ 0,45 & 0,67 & 32,3 & 67,71 \\ 1,56 & 2,55 & 38,6 & 61,39 \\ 1,35 & 0,37 & -- & -- \\ 0,25 & 0,34 & 27,1 & 72,85 \\ 0,49 & 0,58 & 16,1 & 83,94 \\ 3,68 & 5,50 & 33,5 & 66,50 \\ 1,44 & 3,85 & 62,6 & 37,36 \\ 21,87 & 23,93 & 8,6 & 91,40 \\ . & & & \end{array}$

Y' - taxa estimada por regressão loglinear; Y" - taxa esperada na ausência de intervenção médica;

"ps $0,05 \%$ p $\leq 0,01-p \leq 0,002$ em branco: $p>0,05$

Para as demais causas de óbito evitável (CICS), a participação expressiva (PTD) da intervenção médica na taxa de declínio não gera um efeito capaz de produzir diferença significativa (ao nível de significância de $\mathrm{p} \leq 0,002$ ) entre a taxa de mortalidade estimada para 1992 e a esperada na ausência da 
intervenção médica. A menor influência da intervenção médica ocorre sobre a taxa de declínio da mortalidade por causas mal definidas ( $\mathrm{PTD}=8,6$ ). Essa influência, em relação ao melanoma maligno de pele e à apendicite, não é mensurável pelo modelo de análise proposto porque não há declínio da taxa de mortalidade por estas causas no período estudado. 


\section{Impacto da Intervenção Médica sobre a Mortalidade por CICS nas Capitais}

A taxa de mortalidade por CICS no conjunto das capitais declina 5,4\% aa., evoluindo de 230,86/100.000 para 114,03/100.000, quando ajustadas por regressão loglinear (Tabela 2). A intervenção médica contribui com 47,9 deste declínio. Como este efeito $(-2,6 \%$ aa.) produz uma diferença significativa entre a taxa estimada e a esperada na sua ausência ( $R M E=52,01 p \leq 0,002)$, é possivel inferir que a intervenção médica contribui de forma expressiva para o declínio da mortalidade por CICS no conjunto das capitais em 1992 (Tabela 6).

Qual a contribuição da intervenção médica para o declínio da mortalidade por CICS nas capitais?

Doze capitais têm nivel de mortalidade igual ao esperado $(p>0,002)$ durante todo o periodo estudado (Tabela 6). As demais, encontram-se em situações distintas: três capitais mantêm nivel de mortalidade superior ao esperado (RMP> $100 \quad \mathrm{p} \leq 0,002$ ) e duas capitais mantêm nível de mortalidade inferior ao esperado (RMP<100 p $\leq 0,002$ ), durante todo o periodo estudado; quatro capitais evoluem favoravelmente: do nível superior ao inferior (Fortaleza) ou ao nível esperado (São Luiz, Cuiabá, e Belém); Vitória, Rio de Janeiro e Porto Alegre evoluem do nível inferior para o nível esperado e Manaus evolui do nível esperado para o nível superior ao esperado de mortalidade por CICS. Portanto há um aumento expressivo da mortalidade por CICS em Manaus e um discreto aumento em Vitória, Rio de Janeiro e Porto Alegre quando são comparados os níveis de mortalidade padronizada no início e final do período estudado.

Inicialmente, a $R M P$ é superior a esperada em oito capitais. Em Maceió $\left(\operatorname{RMP}_{79 / 82}=166 \mathrm{p}=0,0000\right.$; $\left.\operatorname{RMP}_{89 / 92}=146 \mathrm{p}=0,0000\right)$, São Luiz $\left(\operatorname{RMP}_{79 / 82}=292 \mathrm{p}=0,0000 ; \operatorname{RMP}_{89 / 92}=129 \mathrm{p}=0,002\right)$ e João Pessoa $\left(\mathrm{RMP}_{79 / / 22}=191 \mathrm{p}=0,0000 ; \mathrm{RMP}_{\mathrm{BO/92}}=156 \mathrm{p}=0,0000\right)$ ocorre discreta diminuição do nível da mortalidade, apesar de permanecer superior ao esperado até ao final do período estudado. Em Manaus (RMP ( $_{7822}=121$ $\left.\mathrm{p}=0,002 ; \mathrm{RMP}_{89 / 92}=196 \mathrm{p}=0,0000\right)$ e Aracaju $\left(\mathrm{RMP}_{79 / 82}=134 \mathrm{p}=0,0000 ; \mathrm{RMP}_{8 / 92}=156 \mathrm{p}=0,0000\right)$ há aumento do nivel de mortalidade. Em Fortaleza $\left(\operatorname{RMP}_{79 / 82}=338 p=0,0000 ; \operatorname{RMP}_{82 / 92}=114 p=0,118\right)$, Cuiabá (RMP $\left.\operatorname{Rg}_{7 / 82}=133 \quad \mathrm{p}=0,0000 ; \mathrm{RMP}_{89 / 92}=117 \quad \mathrm{p}=0,065\right)$ e Belém $\left(\mathrm{RMP}_{79 / 82}=133 \quad \mathrm{p}=0,0000\right.$; $\mathrm{RMP}_{89 / 22}=105 \mathrm{p}=0,602$ ) há expressiva redução no nível da mortalidade por CICS. 
Tabela 6. Razão de mortalidade padronizada (RMP), coeficiente de regressão loglinear (b), percentual da taxa de declínio da mortalidade devido à intervenção médica (PTD) e razão de mortalidade evitável $\left(\mathrm{RME}_{1922}\right)$ por Causas Indicadoras de Cuidados de Saúde (CICS) nas capitais brasileiras

\begin{tabular}{|c|c|c|c|c|c|}
\hline \multirow[b]{2}{*}{ Capital } & \multicolumn{2}{|c|}{$\mathrm{RMP}$} & \multirow{2}{*}{$\begin{array}{l}\text { Coeficiente } \\
\text { de } \\
\text { Regressão } \\
\text { (b) }\end{array}$} & \multirow{2}{*}{$\begin{array}{r}\text { PTD } \\
(\%)\end{array}$} & \multirow[b]{2}{*}{$\mathrm{RME}$} \\
\hline & $1979-1982$ & 1989-1992 & & & \\
\hline Rio Branco & $83^{\circ}$ & 100 & $-0,033^{* * *}$ & 53,3 & $46,7^{\cdots \cdots}$ \\
\hline Maceió & $166^{* * *}$ & $146^{* * *}$ & $-0,064^{* * *}$ & 49,0 & $51,0 *$ \\
\hline Macapá & 92 & $74^{* *}$ & $-0,070^{* * * *}$ & 68,7 & $31,3^{* * *}$ \\
\hline Manaus & $121^{* *}$ & $196^{* * *}$ & $-0,012$ & 4,8 & 95,2 \\
\hline Salvador & 112 & 114 & $-0,053^{* * *}$ & 39,2 & $60,8 * *$ \\
\hline Fortaleza & $338^{* * *}$ & 114 & $-0,164^{* * *}$ & 67,7 & $32,3^{* * *}$ \\
\hline Brasília & $56^{* * *}$ & $69^{* * *}$ & $-0,035^{* * *}$ & 61,8 & $38,2 \cdots$ \\
\hline Vitória & $74^{* * *}$ & 113 & $-0,012$ & 23,3 & $76,7^{* *}$ \\
\hline Goiânia & 101 & 88 & $-0,064^{* * *}$ & 64,7 & $35,3^{* * *}$ \\
\hline São Luiz & $292^{* * *}$ & $129^{* *}$ & $-0,138^{* * *}$ & 56,0 & $44,0^{* * *}$ \\
\hline Belo Horizonte & $116^{*}$ & 107 & $-0,062^{* * *}$ & 16,9 & 83,1 \\
\hline Campo Grande & $79^{* *}$ & 91 & $-0,042^{* * *}$ & 55,0 & $45,0^{* *}$ \\
\hline Cuiabá & $133^{* * *}$ & 117 & $-0,065^{* * *}$ & 34,5 & $65,5^{* * *}$ \\
\hline Belém & $133^{* * *}$ & 105 & $-0,079^{* * *}$ & 46,8 & $53,2 \cdots$ \\
\hline João Pessoa & $191^{* * *}$ & $156^{* * *}$ & $-0,075^{* * *}$ & 55,7 & $44,3^{* * *}$ \\
\hline Curitiba & $84^{*}$ & 82 & $-0,051^{* * *}$ & 39,0 & $61,4^{* * *}$ \\
\hline Recife & 103 & 117 & $-0,044^{* * *}$ & 63,9 & $36,1^{* * *}$ \\
\hline Terezina & 98 & 92 & $-0,052^{* * *}$ & 39,0 & $61,0 * *$ \\
\hline Rio de Janeiro & $71^{* * *}$ & 100 & $-0,014^{* * *}$ & - & 105,7 \\
\hline Natal & $116^{*}$ & $76^{* *}$ & $-0,098^{* * *}$ & 58,5 & $41,5^{* \cdots}$ \\
\hline Porto Velho & $119^{* *}$ & 115 & $-0,062^{* * *}$ & 68,8 & $31,2^{* * *}$ \\
\hline Boa Vista & 113 & 98 & $-0,068^{* * *}$ & 71,6 & $28,4^{* * *}$ \\
\hline Porto Alegre & $54^{* * *}$ & $73^{* *}$ & $-0,026^{* *}$ & 40,3 & $59,7^{* * *}$ \\
\hline Florianópolis & $54^{* * *}$ & $51^{* * *}$ & $-0,058^{* * *}$ & 53,2 & $46,8^{* * *}$ \\
\hline Aracaju & $134^{* * *}$ & $153^{* * *}$ & $-0,033^{* * *}$ & - & 115,7 \\
\hline São Paulo & 88 & $80^{\circ}$ & $-0,063^{* * *}$ & 60,8 & $39,2^{* * *}$ \\
\hline
\end{tabular}

$\mathrm{p} \leq 0,05 \quad * * \mathrm{p} \leq 0,01 \quad * * 0,002 \quad$ em branco: $\mathrm{p}>0,05$

A análise de regressão toma evidente que vinte e quatro capitais acompanham a tendência exponencial de declínio da mortalidade por CICS observada no conjunto das capitais. Fortaleza $(b=-0,164$ $p=0,0000)$ e São Luiz $(b=-0,138 p=0,0000)$ apresentam os maiores coeficientes de regressão. Manaus 
$(b=-0,012 p>0,05)$ e Vitória $(b=-0,012 p>0,05)$, apesar do coeficiente de regressão negativo, não apresentam tendência exponencial de declínio.

A maioria das capitais apresentam RME estatisticamente significativa $(p \leq 0,002)$. Isto significa que a contribuição da intervenção médica para o declínio da taxa de mortalidade por CICS produz uma diferença significativa entre a taxa estimada e a esperada para 1992 na ausência da intervenção médica. Portanto é possível afirmar que a intervenção médica contribui de forma expressiva para o declínio da taxa de mortalidade por CICS em 1992 nessas capitais. Essa contribuição varia de 71,6\% (Boa Vista) a 23,3\% (Vitória) da taxa de declínio.

Em Manaus, Belo Horizonte, Rio de Janeiro e Aracaju, a contribuição da intervenção médica não produz uma diferença significativa entre a taxa estimada e a esperada para 1992 na ausência da intervenção médica (RME $>0,05$ ). Portanto, baseado nos dados disponíveis e no modelo de análise proposto, é possível afirmar que a contribuição da intervenção médica não é significativa para o declínio da taxa de mortalidade por CICS em 1992 nessas capitais.

6.1. Impacto da intervenção médica na mortalidade por doenças infecciosas intestinais

A taxa de mortalidade por doenças infecciosas intestinais (CID9 001-009) declina 14,4\% aa., evoluindo de 537,84/100.000 (a maior taxa de óbito de 1979) para 82,49/100.000 (a segunda maior taxa de óbito entre as CICS em 1992) no conjunto das capitais, quando ajustadas por regressão loglinear (Tabela 2). A intervenção médica contribui com $84 \%$ deste declínio. Este efeito ( $-12 \%$ aa.) produz uma diferença significativa entre a taxa estimada e a esperada para 1992 na ausência da intervenção médica. Portanto, é possível afirmar que a intervenção médica contribui de forma expressiva para o declínio da taxa de mortalidade por doenças infecciosas intestinais $(\mathrm{RME}=16,18 \mathrm{p} \leq 0,02)$ no conjunto das capitais em 1992 (Tabela 6).

Entre as capitais, poucas possuem nível de mortalidade igual ao esperado (Tabela 7). A maioria das capitais encontra-se em extremos opostos: das treze capitais que têm nível de mortalidade superior ao 
esperado (RMP>100 ps0,002) em 1979-1982, doze capitais mantêm-se nesta situação em 1989-1992 todas localizadas nas regiões norte e nordeste -; das onze capitais com nível de mortalidade inferior ao esperado (RMP<100 ps0,002) em 1979-1982, nove capitais assim permanecem em 1989-1992.

Tabela 7. Razão de mortalidade padronizada (RMP), coeficiente de regressão loglinear, percentual da taxa de declínio da mortalidade devido à intervenção médica (PTD) e razão de mortalidade evitável (RME ${ }_{1992)}$ das doenças infecciosas intestinais (CID9 001-009) nas capitais brasileiras.

\begin{tabular}{|c|c|c|c|c|c|}
\hline \multirow[b]{2}{*}{ Capital } & \multicolumn{2}{|c|}{ RMP } & \multirow{2}{*}{$\begin{array}{l}\text { Coeficiente } \\
\text { de } \\
\text { Regressão } \\
\text { (b) }\end{array}$} & \multirow{2}{*}{$\begin{array}{r}\text { PTD } \\
(\%)\end{array}$} & \multirow[b]{2}{*}{ RME } \\
\hline & 1979-1982 & 1989-1992 & & & \\
\hline Rio Branco & $88^{*}$ & 96 & $-0,121^{* * *}$ & 85,0 & $15,0^{* * *}$ \\
\hline Maceió & $356^{* * *}$ & $356^{* * *}$ & $-0,137^{* * *}$ & 80,1 & $19,9^{\circ \cdots}$ \\
\hline Macapá & $65^{* * *}$ & 85 & $-0,108^{* *}$ & 80,9 & $19,1^{* * *}$ \\
\hline Manaus & $212^{* * *}$ & $261^{* * *}$ & $-0,132^{* * *}$ & 80,0 & $20,0^{* * *}$ \\
\hline Salvador & $131^{* * *}$ & $171^{* * *}$ & $-0,117^{* * *}$ & 73,5 & $26,5^{* * *}$ \\
\hline Fortaleza & $410^{* * *}$ & $134^{* * *}$ & $-0,253^{* * *}$ & 89,9 & $10,1^{* * *}$ \\
\hline Brasilia & $33^{* * *}$ & $46^{* * *}$ & $-0,116^{* * *}$ & 86,6 & $13,4^{* * *}$ \\
\hline Vitória & $62^{* * *}$ & $58^{* * *}$ & $-0,143^{* * *}$ & 86,0 & $14,0^{* * *}$ \\
\hline Goiânia & $31^{* * *}$ & $30^{* * *}$ & $-0,127^{* * *}$ & 84,6 & $15,4^{* * *}$ \\
\hline São Luiz & $501^{* * *}$ & $197^{* * *}$ & $-0,234^{* * *}$ & 87,4 & $12,6^{* * *}$ \\
\hline Belo Horizonte & $87^{*}$ & 94 & $-0,131^{* * *}$ & 66,3 & $33,7^{* * *}$ \\
\hline Campo Grande & $75^{* * *}$ & $44^{* * *}$ & $-0,193^{* * *}$ & 93,6 & $6,4^{* * *}$ \\
\hline Cuiabá & $43^{* * *}$ & $35^{* * *}$ & $-0,179^{* * *}$ & 85,1 & $14,9^{* * *}$ \\
\hline Belém & $188^{* * *}$ & $208^{* * *}$ & $-0,136^{\circ * *}$ & 74,7 & $25,3^{* * *}$ \\
\hline João Pessoa & $266^{* * *}$ & $160^{* * *}$ & $-0,207^{* * *}$ & 92,1 & $7,9^{* \ldots *}$ \\
\hline Curitiba & $70^{* * * *}$ & 86 & $-0,124^{\circ * *}$ & 74,3 & $25,7^{* * *}$ \\
\hline Recife & $116^{* * *}$ & $205^{* * *}$ & $-0,093^{* * *}$ & 80,9 & $19,1^{* * *}$ \\
\hline Terezina & $134^{* * *}$ & $142^{* * *}$ & $-0,133^{* * *}$ & 78,7 & $21,3^{* * *}$ \\
\hline Rio de Janeiro & $32^{* * *}$ & $33^{* * *}$ & $-0,143^{* * *}$ & 80,2 & $19,8^{* * *}$ \\
\hline Natal & $198^{* * *}$ & 92 & $-0,230^{* * *}$ & 92,6 & $7,4^{\cdots \cdots}$ \\
\hline Porto Velho & $154^{* * *}$ & $238^{* * *}$ & $-0,119^{* * *}$ & 14,9 & $85,1^{* * *}$ \\
\hline Boa Vista & $130^{* * *}$ & $134^{* * *}$ & $-0,148^{* * *}$ & 10,1 & $89,9^{* * *}$ \\
\hline Porto Alegre & $16^{* * *}$ & $23^{* * *}$ & $-0,103^{* * *}$ & 78,2 & $21,8^{* * *}$ \\
\hline Florianópolis & $17^{* * *}$ & $24^{* * *}$ & $-0,130^{*}$ & 81,7 & $18,3^{* * *}$ \\
\hline Aracaju & $192^{* * *}$ & $335^{* * *}$ & $-0,069^{*}$ & 27,8 & $72,2^{* \ldots *}$ \\
\hline São Paulo & $70^{* * *}$ & $46^{* * *}$ & $-0,186^{* * *}$ & 92,1 & $7,9^{* * *}$ \\
\hline
\end{tabular}

$\mathrm{p} \leq 0,05 * \mathrm{p} \leq 0,01 \quad * * * \mathrm{p} \leq 0,002 \quad$ em branco: $\mathrm{p}>0,05$ 
O expressivo declínio da mortalidade não modifica o quadro geral desenhado pela análise da RMP, exceto para Natal que evolui do nivel superior para o esperado de mortalidade, e para Macapá e Curitiba que evoluem desfavoravelmente de um nível inferior para o nível esperado de mortalidade.

A análise de regressão evidencia o expressivo declínio da mortalidade em vinte e três capitais. Apenas em Macapá, Florianópolis e Aracaju o declínio da mortalidade não foi exponencial ( $>>0,002)$.

Todas as capitais apresentam RME estatisticamente significativa ( $p \leq 0,002)$, pois o efeito da intervenção médica na taxa de declínio da mortalidade produz uma diferença significativa $(p>0,002)$ entre a taxa estimada e a esperada na ausência da intervenção médica. Portanto é possível inferir que a intervenção médica contribui de forma expressiva para o declínio da mortalidade por doenças infecciosas intestinais em 1992 em todas as capitais estudadas. Essa contribuição é bastante uniforme entre as capitais e superior a $60 \%$ da taxa de declínio, exceto em Aracaju com apenas $27,8 \%$.

6.2. Impacto da intervenção médica na mortalidade por tuberculose

A taxa padronizada de mortalidade por tuberculose (CID9 010-018) no conjunto das capitais declina a 5,2\% aa., evoluindo de $9,68 / 100.000$ para 4,9/100.000 no periodo de 1979 a 1992, quando ajustadas por regressão loglinear. A intervenção médica contribui com 46,7\% deste declínio em 1992 (Tabela 2). Como este efeito $(-2,4 \%$ aa.) não produz uma diferença significativa entre a taxa estimada e a esperada na ausência da intervenção médica ( $R M E=53,3 p>0,05)$, é possível inferir que a intervenção médica contribui de forma pouco expressiva para o declínio da taxa de mortalidade por tuberculose no conjunto das capitais em 1992 (Tabela 6).

No período de 1979-1982, Salvador, São Luiz, Belém e Porto Velho têm nível de mortalidade superior ao esperado. Em 1989-1992, apesar dos valores elevados encontrados em Recife (RMP=193), Salvador $(\mathrm{RMP}=161)$, Rio de Janeiro (RMP=144) e São Luiz (RMP=142), nenhuma capital apresenta nível de mortalidade significativamente superior ao esperado (Tabela 8). 
Tabela 8. Razão de mortalidade padronizada (RMP), coeficiente de regressão loglinear, percentual da taxa de declínio da mortalidade devido à intervenção médica e razão de mortalidade evitável $\left(\mathrm{RME}_{1992}\right)$ por tuberculose (CID9 010-018) nas capitais brasileiras.

\begin{tabular}{|c|c|c|c|c|c|}
\hline \multirow[b]{2}{*}{ Capital } & \multicolumn{2}{|l|}{ RMP } & \multirow{2}{*}{$\begin{array}{l}\text { Coeficiente } \\
\text { de } \\
\text { Regressão } \\
\text { (b) }\end{array}$} & \multirow{2}{*}{$\begin{array}{r}\text { PTD } \\
\text { (\%) }\end{array}$} & \multirow[b]{2}{*}{ RME } \\
\hline & $1979-1982$ & 1989-1992 & & & \\
\hline Rio Branco & 65 & 68 & $-0,058$ & 65,9 & $34,1^{*}$ \\
\hline Maceió & 101 & 88 & $-0,072^{* * *}$ & 53,7 & 46,3 \\
\hline Macapá & 109 & 76 & $-0,104^{*}$ & 79,9 & $20,1^{*}$ \\
\hline Manaus & $180^{\circ}$ & 105 & $-0,111^{* * *}$ & 73,6 & $26,4^{* * *}$ \\
\hline Salvador & $219^{* * *}$ & 161 & $-0,089^{\cdots * *}$ & 61,9 & $38,1^{\circ}$ \\
\hline Fortaleza & $201 *$ & 92 & $-0,129^{* * *}$ & 49,0 & 51,0 \\
\hline Brasília & 41 & 31 & $-0,076^{\circ}$ & 77,6 & 22,4 \\
\hline Vitória & 81 & 71 & $-0,062^{*}$ & 59,6 & 40,4 \\
\hline Goiânia & 40 & 22 & $-0,111^{\circ}$ & 81,0 & 19,0 \\
\hline São Luiz & $565^{* * *}$ & 142 & $-0,191^{* * *}$ & 88,0 & $22,0^{\circ \cdots *}$ \\
\hline Belo Horizonte & 88 & 47 & $-0,112^{* * *}$ & 47,0 & 43,0 \\
\hline Campo Grande & 49 & 51 & $-0,049^{\circ}$ & 58,6 & 41,4 \\
\hline Cuiabá & 152 & 70 & $-0.124^{* * *}$ & 69,3 & $30,5^{\circ}$ \\
\hline Belém & $212^{* * *}$ & 123 & $-0,104^{* * *}$ & 61,7 & $38,3^{*}$ \\
\hline João Pessoa & 90 & 75 & $-0,073^{\circ}$ & 54,9 & 45,1 \\
\hline Curitiba & 60 & 37 & $-0,102^{* * *}$ & 65,5 & 34,5 \\
\hline Recife & $197^{* *}$ & $193^{\circ}$ & $-0,057^{* * *}$ & 69,5 & $30,5^{\circ \cdots}$ \\
\hline Terezina & 116 & 87 & $-0,091^{* * *}$ & 63,1 & $36,9^{*}$ \\
\hline Rio de Janeiro & 95 & 144 & $-0,009$ & - & 113,3 \\
\hline Natal & 94 & 59 & $-0,107^{* * *}$ & 63,1 & 36,9 \\
\hline Porto Velho & $235^{* \cdots *}$ & 127 & $-0,126^{* * *}$ & 86,3 & $13,7^{* \cdots}$ \\
\hline Boa Vista & 83 & 103 & $-0,085$ & 77,2 & $22,8^{*}$ \\
\hline Porto Alegre & 95 & 94 & $-0,047^{\circ}$ & 54,4 & 45,6 \\
\hline Florianópolis & $18^{\circ}$ & 28 & $-0,005$ & 6,6 & 93,4 \\
\hline Aracaju & 105 & 55 & $-0,114^{\cdots \cdots}$ & 59,9 & 40,1 \\
\hline São Paulo & 60 & 95 & $-0,006$ & 17,9 & 82,1 \\
\hline
\end{tabular}

"p $\leq 0,05 \quad * * 0,01 \quad * * p \leq 0,002 \quad$ em branco: $p>0,05$

A análise de regressão loglinear demonstra que todas as capitais apresentam coeficiente de regressão negativo, mas em cinco capitais ele não alcança significância estatística: em Rio Branco $(b=-0,58)$, Rio de Janeiro $(b=-0,009)$, Boa Vista $(b=-0,085)$, Florianópolis $(b=-0,005)$ e São Paulo $(b=-0,006)$ a taxa de 
mortalidade por tuberculose mantém-se estacionária de 1979 a 1992. Nestas capitais, houve discreto aumento da $R M P$, especialmente no Rio de Janeiro $\left(\mathrm{RMP}_{89 / 22}=144 \mathrm{p}>0,05\right)$.

Em sete capitais, o coeficiente de regressão negativo alcança algum nível de significância $(p<0,05)$, tornando plausível a suposição de discreto declínio exponencial da mortalidade por tuberculose. Contudo, apenas quatorze capitais apresentam tendência exponencial de declínio ao nível de significância de p $\leq 0,002$. A velocidade do declínio varia de $-19,1 \%$ aa. em São Luiz a $-5,7 \%$ aa. em Recife.

A intervenção médica contribui com $88 \%$ da taxa de declínio da mortalidade por tuberculose em São Luiz, 86,3\% em Porto Velho, 73,6\% em Manaus e 69,5\% em Recife. Como esse efeito produz uma diferença significativa entre a taxa estimada e a esperada na ausência da intervenção médica $(p \leq 0,002)$, possivel inferir que a intervenção médica contribui de forma expressiva para o declínio da mortalidade por tuberculose nestas capitais em 1992.

Em Rio Branco, Macapá, Salvador, Cuiabá, Belém, Terezina e Boa Vista, apesar da importante contribuição na taxa de declínio da mortalidade, a diferença entre a taxa de mortalidade estimada e a esperada na ausência da intervenção médica é significativa apenas ao nível de $p<0,05$ o que não permite concluir que esta contribuição tenha sido expressiva para o declínio da mortalidade por tuberculose nestas capitais.

Nas demais capitais, a participação expressiva da intervenção médica na taxa de declínio não gera um efeito capaz de produzir diferença significativas (ao nível de significância de $p \leq 0,002$ ) entre a taxa de mortalidade da tuberculose estimada para 1992 e a esperada na ausência da intervenção médica. Florianópolis apresenta a menor influência da intervenção médica $(\mathrm{PTD}=6,6)$ sobre a taxa de declínio da mortalidade por tuberculose e para o Rio de Janeiro essa influência não é mensurável pelo modelo de análise proposto. 
6.3. Impacto da intervenção médica na mortalidade por septicemia

A taxa padronizada de mortalidade por septicemia (CID9 038) no conjunto das capitais declina 6,6\% aa., evoluindo de 48,86/100.000 para 20,74/100.000 no período de 1979 a 1992 , quando ajustadas por regressão loglinear (Tabela 2). A intervenção médica contribui com cerca de $55 \%$ deste declínio em 1992. Este efeito $(-3,6 \%$ aa.) produz uma diferença significativa $(R M E=44,69 p \leq 0,02)$ entre a taxa estimada na ausência da intervenção médica. Portanto é possível inferir que a intervenção médica contribui de forma expressiva para o declínio da taxa de mortalidade por septicemia no conjunto das capitais em 1992 (Tabela 6).

No periodo de 1979-1982, das sete capitais que apresentam nível de mortalidade significativamente inferior ao esperado (Rio Branco, Maceió, Manaus, Brasília, Vitória, João Pessoa e Aracaju), duas (Rio Branco e Maceió) evoluem para o extremo oposto, quatro (Macapá, Manaus, João Pessoa e Aracaju) evoluem para o nível de mortalidade esperado, e apenas duas capitais (Brasília e Vitória) permanecem com o nivel de mortalidade inferior ao esperado para o período 1989-1992 (Tabela 9).

Dentre as cinco capitais que apresentam nível de mortalidade superior ao esperado para o periodo de 1979-1982 (Salvador, Fortaleza, Belo Horizonte, Natal e Boa Vista), duas (Salvador e Fortaleza) mantêm o mesmo status no período seguinte e as demais evoluem para o nível de mortalidade esperado para o período de 1989-1992.

Contudo, a análise de regressão demonstra que a taxa de mortalidade não segue uma tendência uniforme nas diversas capitais: sete capitais apresentam coeficiente de regressão positivo que varia de 0,180 $(p<0,002)$ em Rio Branco a 0,004 ( $p=0,9167)$ em Manaus. As demais capitais apresentam coeficiente de regressão negativo, entre elas, nove capitais com tendência exponencial de declínio (Tabela 9).

Dentre as dezenove capitais com coeficiente de regressão negativo, treze apresentam RME estatisticamente significativa $(p \leq 0,002)$. Para essas capitais, é possível inferir que a intervenção médica contribui de forma expressiva para o declínio da taxa de mortalidade por septicemia. Entretanto, esse efeito sobre a taxa de mortalidade varia amplamente entre as capitais: a intervenção médica contribui com $96,6 \%$ da taxa de declínio da mortalidade por septicemia em Belo Horizonte e com 49,8\% em Goiânia. 
Tabela 9. Razão de mortalidade padronizada (RMP), coeficiente de regressão loglinear, percentual da taxa de declínio da mortalidade devido à intervenção médica (PTD) e razão de mortalidade evitável (RME $\left.{ }_{1992}\right)$ por septicemia (CID9 038) nas capitais brasileiras.

\begin{tabular}{|c|c|c|c|c|c|}
\hline \multirow[b]{2}{*}{ Capital } & \multicolumn{2}{|l|}{ RMP } & \multirow{2}{*}{$\begin{array}{l}\text { Coeficiente } \\
\text { de } \\
\text { Regressão } \\
\text { (b) }\end{array}$} & \multirow{2}{*}{$\begin{array}{r}\text { PTD } \\
(\%)\end{array}$} & \multirow[b]{2}{*}{ RME } \\
\hline & $1979-1982$ & 1989-1992 & & & \\
\hline Rio Branco & $40^{*+*}$ & $342^{* * * *}$ & $0,180^{* * *}$ & - & $745,7^{* * *}$ \\
\hline Maceió & $41^{* * *}$ & $250^{* * *}$ & $0,124^{* *}$ & -- & $587,1^{* * *}$ \\
\hline Macapá & $60^{\circ}$ & 113 & 0,007 & - & 85,7 \\
\hline Manaus & $51^{* * *}$ & 113 & 0,004 & - & 116,6 \\
\hline Salvador & $161^{* * *}$ & $209^{* * *}$ & $-0,019$ & 5,7 & 94,3 \\
\hline Fortaleza & $318^{* * *}$ & $179^{* * *}$ & $-0,134^{* * *}$ & 52,3 & $47,7^{* * *}$ \\
\hline Brasilia & $13^{* * *}$ & $29^{* * *}$ & 0,008 & - & 67,2 \\
\hline Vitória & $44^{* * *}$ & $15^{* * *}$ & $-0,111^{*}$ & 78,8 & $21,2^{* * *}$ \\
\hline Goiânia & 110 & $153^{\circ}$ & $-0,037$ & 49,8 & $50,2^{* * *}$ \\
\hline São Luiz & $133^{*}$ & 104 & $-0,089^{*}$ & 17,4 & 82,6 \\
\hline Belo Horizonte & $238^{* * *}$ & 72 & $-0,307^{* * *}$ & 96,6 & $3,4^{* * *}$ \\
\hline Campo Grande & 111 & 72 & $-0,123^{* * *}$ & 84,2 & $15,8^{* \cdots *}$ \\
\hline Cuiabá & 128 & 81 & $-0,128^{* * *}$ & 71,0 & $29,0^{* * *}$ \\
\hline Belém & $62^{*}$ & 96 & $-0,042$ & 14,6 & 85,4 \\
\hline João Pessoa & $32^{* * *}$ & $149^{*}$ & 0,135 & - & 678,8 \\
\hline Curitiba & 71 & $31^{\circ}$ & $-0,141^{* * *}$ & 79,2 & $20,8^{* * *}$ \\
\hline Recife & 101 & 76 & $-0,106^{* * * *}$ & 83,9 & $16,1^{* * *}$ \\
\hline Terezina & 70 & 102 & $-0,014$ & 0,0 & 100,0 \\
\hline Rio de Janeiro & $59^{\circ}$ & 96 & $-0,017$ & - & 101,6 \\
\hline Natal & $150^{* * *}$. & 62 & $-0,196^{* * *}$ & 88,5 & $11,5^{* * *}$ \\
\hline Porto Velho & $51^{* *}$ & 99 & $-0,023$ & 47,9 & $52,1^{* *}$ \\
\hline Boa Vista & $200^{\circ * *}$ & 99 & $-0,165^{* *}$ & 91,9 & $8,1^{* * *}$ \\
\hline Porto Alegre & $63^{*}$ & 61 & $-0,074^{* *}$ & 68,0 & $32,0^{* * *}$ \\
\hline Florianópolis & 74 & $30^{*}$ & $-0,161^{* * *}$ & 87,7 & $12,3^{* * *}$ \\
\hline Aracaju & $29^{* 0 *}$ & 112 & 0,065 & - & $411,4^{* * *}$ \\
\hline São Paulo & 108 & 77 & $-0,099^{* * *}$ & 75,7 & $24,3^{* * *}$ \\
\hline
\end{tabular}

${ }^{*} \mathrm{p} \leq 0,05 \quad * * \mathrm{p} \leq 0,01 \quad * * * 0,002 \quad$ em branco; $p>0,05$

Para as demais capitais, a influência da intervenção médica sobre a taxa de declínio parece afetar pouco a taxa de mortalidade, pois não produz uma diferença significativa $(p>0,002)$ entre a taxa de mortalidade por septicemia estimada para 1992 e a esperada na ausência da intervenção médica. 
6.4. Impacto da intervenção médica na mortalidade por tumor maligno de pele

A taxa padronizada de mortalidade por tumor maligno de pele no conjunto das capitais mantém-se estacionária no periodo de 1979 a 1992 (Tabela 2). Consequentemente, não é possivel aferir a contribuição da intervenção médica na definição do nível de mortalidade por tumor maligno de pele em 1992 no conjunto das capitais (Tabela 6).

Tabela 10. Razão de mortalidade padronizada (RMP), coeficiente de regressão loglinear, percentual da taxa de declínio da mortalidade devido à intervenção médica (PTD) e razão de mortalidade evitável $\left(\mathrm{RME}_{1922}\right)$ por melanoma maligno de pele (CD9 172) nas capitais brasileiras.

\begin{tabular}{|c|c|c|c|c|c|}
\hline \multirow[b]{2}{*}{ Capital } & \multicolumn{2}{|c|}{ RMP } & \multirow{2}{*}{$\begin{array}{l}\text { Coeficiente } \\
\text { de } \\
\text { Regressão } \\
\text { (b) }\end{array}$} & \multirow{2}{*}{$\begin{array}{r}\text { PTD } \\
(\%)\end{array}$} & \multirow[b]{2}{*}{$\mathrm{RME}$} \\
\hline & $1979-1982$ & $1989-1992$ & & & \\
\hline Rio Branco & 22 & 184 & 0,027 & 49,5 & 50,5 \\
\hline Maceió & 54 & 241 & 0,023 & 12,6 & 87,4 \\
\hline Macapá & 37 & 542 & 0,063 & - & 177,6 \\
\hline Manaus & 38 & 125 & 0,023 & 18,0 & 82,0 \\
\hline Salvador & 82 & 194 & $-0,037$ & 25,0 & 75,0 \\
\hline Fortaleza & 123 & 277 & $-0,022$ & $-\cdots$ & 202,3 \\
\hline Brasilia & 180 & 456 & 0,036 & 62,2 & 37,8 \\
\hline Vitória & 71 & 291 & $-0,001$ & 11,3 & 88,7 \\
\hline Goiânia & 82 & 204 & $-0,047$ & 56,3 & 43,7 \\
\hline São Luiz & 170 & 105 & $-0,133^{*}$ & 53,3 & 46,7 \\
\hline Belo Horizonte & 113 & 421 & $-0,010$ & -- & 211,1 \\
\hline Campo Grande & 164 & 263 & $-0,050$ & 59,0 & 41,0 \\
\hline Cuiabá & 239 & $637^{*}$ & $-0,054$ & 23,6 & 76,4 \\
\hline Belém & 75 & 340 & $-0,046$ & - & 268,9 \\
\hline João Pessoa & 132 & $698^{* *}$ & 0,067 & - & 277,6 \\
\hline Curitiba & 225 & 302 & $-0,101^{* *}$ & 65,4 & 34,6 \\
\hline Recife & 45 & 237 & $-0,037$ & - & 102,8 \\
\hline Terezina & 26 & 182 & $-0,046$ & - & 219,5 \\
\hline Rio de Janeiro & 175 & 283 & $-0,071^{* * *}$ & 49,5 & 50,5 \\
\hline Natal & 152 & 461 & $-0,028$ & - & 103,1 \\
\hline Porto Velho & 108 & 47 & $-0,122$ & 85,7 & 14,3 \\
\hline Boa Vista & 27 & 43 & $-0,087$ & 77,7 & 22,3 \\
\hline Porto Alegre & 228 & 279 & $-0,091^{\circ}$ & 74,4 & 25,6 \\
\hline Florianópolis & 167 & 304 & $-0,100$ & 73,1 & 26,9 \\
\hline Aracaju & 57 & 409 & 0,053 & - & 351,1 \\
\hline São Paulo & 119 & 237 & $-0,050^{* * *}$ & 53,9 & 46,1 \\
\hline
\end{tabular}

${ }^{*} \mathrm{p} \leq 0,05 \quad *{ }^{*} \mathrm{p} \leq 0,01 \quad{ }^{* * *} \mathrm{p} \leq 0,002 \quad$ em branco: $\mathrm{p}>0,05$ 
Nenhuma capital apresenta nível de mortalidade inferior ou superior ao esperado ao nível de significância exigido. Apenas Rio de Janeiro $(b=-0,071)$ e São Paulo $(b=-0,050)$ apresentam tendência exponencial de declínio da taxa de mortalidade por tumor maligno de pele (Tabela 10).

Nenhuma capital apresenta RME com significância estatística (Tabela 10). Consequentemente, não é possível afirmar que a intervenção médica contribui de forma expressiva na definição do nível da mortalidade, seja porque não há declínio no período, seja porque a taxa estimada para 1992 não difere significativamente daquela esperada na ausência da intervenção médica.

6.5. Impacto da intervenção médica na mortalidade por tumor maligno de útero não especificado

A taxa padronizada de mortalidade por tumor maligno de útero não especificado (CID9 179) declina $2,7 \%$ aa. no periodo de 1979 a 1992, evoluindo de 2,22/100.000 para 1,61/100.000 quando ajustada por regressão loglinear (Tabela 2). A RME de 74,39 indica que a intervenção médica contribui com cerca de $26 \%$ deste declínio. Como este efeito $(-0,7 \%$ aa.) não prođuz uma diferença significativa entre as taxas estimadas $(p>0,05)$, é possivel inferir que a intervenção médica contribui de forma pouco expressiva para o declínio da taxa de mortalidade por tumor maligno de útero não especificado no conjunto das capitais em 1992 (Tabela 6).

No período de 1979-1982, três capitais apresentam nivel de mortalidade significativamente superior ao esperado (Tabela 11 ): Manaus, São Luiz e Porto Velho. No período de 1989-1992, todas as capitais apresentam nível de mortalidade que não difere do esperado $(p>0,002)$.

A análise de regressão loglinear das taxas de mortalidade revela sete capitais com coeficiente de regressão positivo sem significância estatística e as demais capitais com coeficiente de regressão negativo sem significância estatística, exceto para São Paulo $(b=0,033 p=0,0000)$, a única capital com tendência exponencial de declínio da taxa de mortalidade por tumor maligno do útero não especificado (Tabela 11). 
Tabela 11. Razão de mortalidade padronizada (RMP), coeficiente de regressão loglinear, percentual da taxa de declínio da mortalidade devido à intervenção médica (PTD) e razão de mortalidade evitável $\left(\mathrm{RME}_{1992}\right)$ por tumor maligno de útero não especificado (CID9 179) nas capitais brasileiras.

\begin{tabular}{|c|c|c|c|c|c|}
\hline \multirow[b]{2}{*}{ Capital } & \multicolumn{2}{|c|}{ RMP } & \multirow{2}{*}{$\begin{array}{l}\text { Coeficiente } \\
\text { de } \\
\text { Regressão } \\
\quad \text { (b) }\end{array}$} & \multirow{2}{*}{$\begin{array}{l}\text { PTD } \\
(\%)\end{array}$} & \multirow[b]{2}{*}{$\mathrm{RME}$} \\
\hline & $1979-1982$ & 1989-1992 & & & \\
\hline Rio Branco & 27 & 112 & $-0,030$ & 51,3 & 48,7 \\
\hline Maceió & $300^{* *}$ & 167 & $-0,084^{*}$ & 60,6 & 39,4 \\
\hline Macapá & $309^{* *}$ & 89 & $-0,084$ & 73,8 & 26,2 \\
\hline Manaus & $395^{* * *}$ & 220 & $-0,081^{\circ}$ & 61,0 & 39,0 \\
\hline Salvador & 61 & 69 & 0,001 & - & 122,9 \\
\hline Fortaleza & 154 & 203 & $-0,006$ & - & 250,5 \\
\hline Brasilia & 35 & 92 & $0,080^{* *}$ & -- & 172,5 \\
\hline Vitória & 41 & 134 & 0,039 & - & 150,3 \\
\hline Goiânia & 68 & 63 & $-0,045$ & 54,9 & 45,1 \\
\hline Săo Luiz & $338^{* * *}$ & 249 & $-0,064^{* *}$ & - & 115,1 \\
\hline Belo Horizonte & 115 & 92 & $-0,042^{*}$ & -- & 106,7 \\
\hline Campo Grande & 57 & 38 & $-0,057$ & 62,9 & 37,1 \\
\hline Cuiabá & 13 & 94 & 0,002 & $\cdots$ & 156,8 \\
\hline Belém & 145 & 207 & 0,008 & $-\ldots$ & 162,9 \\
\hline João Pessoa & 187 & 165 & $-0,040^{\circ}$ & 30,2 & 69,8 \\
\hline Curitiba & 93 & 73 & $-0,049$ & 30,9 & 68,1 \\
\hline Recife & 180 & 121 & $-0,058^{*}$ & 70,1 & 29,9 \\
\hline Terezina & 65 & 142 & 0,042 & - & 208,2 \\
\hline Rio de Janeiro & 84 & 97 & $-0,015^{*}$ & - & 104,9 \\
\hline Natal & 76 & 67 & $-0,073$ & 43,2 & 56,8 \\
\hline Porto Velho & $333^{* * *}$ & 167 & $-0,098^{*}$ & 80,4 & $19,6^{*}$ \\
\hline Boa Vista & 105 & 56 & $-0,176^{*}$ & 93,0 & $7,0^{*+}$ \\
\hline Porto Alegre & 85 & 64 & $-0,064^{* *}$ & 63,1 & 36,6 \\
\hline Florianópolis & 101 & 27 & $-0,086$ & 67,4 & 32,6 \\
\hline Aracaju & 56 & 60 & 0,029 & - & 258,3 \\
\hline São Paulo & 81 & 77 & $-0,033^{* * *}$ & 48,7 & 57,3 \\
\hline
\end{tabular}

"p $50,05 \quad * * * 0,01 \quad * * p \leq 0,002 \quad$ em branco: $p>0,05$

Apenas Boa Vista apresenta $\mathrm{RME}$ estatisticamente significativa $(\mathrm{RME}=7,0 \mathrm{p} \leq 0,002)$ indicando a que contribuição da intervenção médica de $93 \%$ na taxa de declínio da mortalidade produz uma diferença 
significativa entre a taxa de mortalidade estimada e a esperada na ausência da intervenção médica. Portanto podemos afirmar que a intervenção médica contribui de forma expressiva para o declínio da mortalidade por tumor maligno de útero não especificado nesta capital. Nas demais capitais, não é possivel afirmar que a contribuição da intervenção médica seja expressiva para o declínio da mortalidade, seja porque não há declínio no período, seja porque a taxa de mortalidade por tumor maligno de útero não especificado estimada para 1992 não difere significativamente daquela estimada na ausência de intervenção médica.

6.6. Impacto da intervenção médica na mortalidade por tumor maligno de colo de útero

A taxa padronizada de mortalidade por tumor maligno de colo de útero (CID9 180) no conjunto das capitais declina 2,2\% aa. no período de 1979 a 1992, evoluindo de 4,79/100.000 para 3,61/100.000 quando ajustada por regressão loglinear (Tabela 2). A RME de 79,34 indica que a intervenção médica contribui com cerca de $21 \%$ deste declínio. Como este efeito $(-0,4 \%$ aa. $)$ não produz uma diferença significativa entre a taxa de mortalidade estimada para 1992 e a esperada na ausência da intervenção médica $(p>0,05)$, é possível inferir que a intervenção médica contribui de forma pouco expressiva para o declínio da mortalidade por tumor maligno de colo de útero no conjunto das capitais em 1992 (Tabela 6).

Apenas quatro capitais apresentam taxa padronizada de mortalidade significativamente superior a esperada para o período de 1979-1982: Salvador $(R M P=1150)$, São Luiz $(R M P=592)$, Belém $(R M P=289)$ e Fortaleza $(R M P=247)$; Aracaju $(R M P=228)$ e Maceió $(R M P=215)$ apresentam elevado nível de mortalidade, mas que não diferem do esperado para o período ao nível de significância exigido. No periodo de 1989-1992, Salvador $(\mathrm{RMP}=875)$ e São Luiz $(\mathrm{RMP}=340)$ mantêm o nível de mortalidade superior ao esperado, e Macapá, cujo nível de mortalidade não diferia do esperado para o periodo anterior $(R M P=195$ $\mathrm{p} \leq 0,05)$, evolui para um nível superior ao esperado $(\mathrm{RMP}=291 \mathrm{p} \leq 0,002)$. A evolução em Belém é favorável, pois o nível de mortalidade apresentado passa a não diferir do esperado para o periodo $(\mathrm{RMP}=223 \mathrm{p} \leq 0,05)($ Tabela 12). 
Tabela 12. Razão de mortalidade padronizada (RMP), coeficiente de regressão loglinear, percentual da taxa de declínio da mortalidade devido à intervenção (PTD) e razão de mortalidade evitável $\left(\mathrm{RME}_{1992}\right)$ por tumor maligno do colo do útero (CID9 180) nas capitais brasileiras.

\begin{tabular}{|c|c|c|c|c|c|}
\hline \multirow[b]{2}{*}{ Capital } & \multicolumn{2}{|c|}{ RMP } & \multirow{2}{*}{$\begin{array}{l}\text { Coeficiente } \\
\text { de } \\
\text { Regressão } \\
\text { (b) }\end{array}$} & \multirow{2}{*}{$\begin{array}{l}\text { PTD } \\
(\%)\end{array}$} & \multirow[b]{2}{*}{ RME } \\
\hline & $1979-1982$ & 1989-1992 & & & \\
\hline Rio Branco & 52 & 82 & 0,044 & $\ldots$ & 127,9 \\
\hline Maceió & $215^{*}$ & 198 & $-0,046^{*}$ & 35,5 & 64,5 \\
\hline Macapá & $195^{*}$ & $291^{* * *}$ & 0,009 & 11,4 & 88,6 \\
\hline Manaus & 136 & 196 & 0,015 & - & 134,6 \\
\hline Salvador & $1150^{* * *}$ & $875^{* * *}$ & $-0,047^{* *}$ & 34,3 & $65,7^{\circ}$ \\
\hline Fortaleza & $247^{* * *}$ & 110 & $-0,100^{* * *}$ & 26,3 & 73,7 \\
\hline Brasília & 123 & 119 & $-0,028$ & 57,6 & 42,4 \\
\hline Vitória & 94 & 134 & 0,019 & - & 114,8 \\
\hline Goiânia & $206^{\circ}$ & 126 & $-0,075^{* * *}$ & 69,5 & $30,5^{*}$ \\
\hline São Luiz & $592^{* * *}$ & $340^{* * *}$ & $-0,070^{* * *}$ & 28,2 & 71,8 \\
\hline Belo Horizonte & 86 & 69 & $-0,038^{* *}$ & -- & 112,4 \\
\hline Campo Grande & 155 & 133 & $-0,044^{*}$ & 55,9 & 44,1 \\
\hline Cuiabá & 160 & 106 & $-0,093^{\circ}$ & 54,2 & 45,8 \\
\hline Belém & $289^{* * *}$ & $223^{*}$ & $-0,045^{* * *}$ & 18,1 & 81,9 \\
\hline João Pessoa & 161 & 95 & $-0,069^{*}$ & 52,6 & 47,4 \\
\hline Curitiba & 116 & 128 & $-0,016$ & -- & 105,6 \\
\hline Recife & 147 & 154 & $-0,024$ & 53,1 & 46,9 \\
\hline Terezina & 193 & 164 & $-0,042$ & 30,5 & 69,5 \\
\hline Rio de Janeiro & 52 & 66 & 0,000 & - & 127,6 \\
\hline Natal & 193 & 175 & $-0,033^{* *}$ & 4,1 & 95,9 \\
\hline Porto Velho & 118 & 101 & $-0,066$ & 70,3 & $29,7^{\circ}$ \\
\hline Boa Vista & 95 & 94 & $-0,120^{*}$ & 85,4 & $14,6^{* * 4}$ \\
\hline Porto Alegre & 69 & 97 & $-0,005$ & 21,5 & 78,5 \\
\hline Florianópolis & 57 & 121 & $0,049^{* *}$ & - & 188,4 \\
\hline Aracaju & $228^{*}$ & 190 & $-0,032$ & - & 117,3 \\
\hline São Paulo & 66 & 64 & $-0,025^{* * *}$ & 35,9 & 64,1 \\
\hline
\end{tabular}

$\mathrm{p} \leq 0,05^{* *} \mathrm{p} \leq 0,01 \quad{ }^{* * *} \mathrm{p} \leq 0,002 \quad$ em branco: $p>0,05$

A análise de regressão loglinear revela cinco capitais com tendência exponencial de declínio da taxa de mortalidade por tumor maligno de colo de útero: Fortaleza $(b=-0,1)$, Goiânia $(b=-0,075)$, São Luiz $(b=-0,070)$, Belém $(b=-0,045)$ e São Paulo $(b=-0,025)$. Contudo esta tendência não é uniforme entre as 
demais capitais: 15 capitais apresentam coeficiente de regressão negativo e seis capitais apresentam coeficiente de regressão positivo, todos sem significância estatística ao nível exigido de $p \leq 0,002$ (Tabela 12).

Em Boa Vista, a iniervenção médica contribui com cerca de $85 \%$ da taxa de declínio da mortalidade por tumor maligno de colo de útero. Como este efeito produz uma diferença significativa entre a taxa de mortalidade estimada para 1992 e a esperada na ausência da intervenção médica $(R M E=14,6$ ps0,002) é possível inferir que a intervenção médica contribui de forma expressiva para o declínio da taxa de mortalidade por este tumor nesta capital (Tabela 12).

Nas demais capitais, não é possível afirmar que a contribuição da intervenção médica é significativa na definição do nível de mortalidade, seja porque não há declínio no periodo, seja porque a taxa de mortalidade por tumor maligno de colo de útero estimada para 1992 não difere significativamente daquela estimada na ausência de intervenção médica.

6.7. Impacto da intervenção médica na mortalidade por doença de Hodgkin

A taxa padronizada de mortalidade da Doença de Hodgkin (CID9 201) no conjunto das capitais declina 3\% aa. no período de 1979 a 1992, evoluindo de 0,70/100.000 para 0,47/100.000 quando ajustada por regressão loglinear (Tabela 2). A intervenção médica contribui com cerca de $29 \%$ deste declínio em 1992. Como este efeito ( $-1,9 \%$ aa.) não produz uma diferença significativa entre a taxa de mortalidade estimada para 1992 e a esperada na ausência da intervenção médica ( $R M E=70,91$ p >0,05), é possível inferir que a intervenção médica contribui de forma pouco expressiva para o declínio da taxa de mortalidade por doença de Hodgkin no conjunto das capitais em 1992 (Tabela 6).

Não há registro de óbito por Doença de Hodgkin em Macapá no período de 1979-1989 e em Boa Vista durante todo o período de estudo. Nenhuma capital apresenta nível de mortalidade inferior ou superior ao esperado ao nível de significância exigido. Apenas Rio de Janeiro $(b=-0,070)$ apresenta tendência exponencial de declínio da taxa de mortalidade (Tabela 13). 
Tabela 13. Razão de mortalidade padronizada (RMP), coeficiente de regressão loglinear, percentual da taxa de declínio da mortalidade devido à intervenção médica (PTD) e razão de mortalidade evitável $\left(\mathrm{RME}_{1992)}\right.$ por Doença de Hodgkin (CID9 201) nas capitais brasileiras.

\begin{tabular}{|c|c|c|c|c|c|}
\hline \multirow[b]{2}{*}{ Capital } & \multicolumn{2}{|c|}{ RMP } & \multirow{2}{*}{$\begin{array}{l}\text { Coeficiente } \\
\text { de } \\
\text { Regressão } \\
\text { (b) }\end{array}$} & \multirow{2}{*}{$\begin{array}{c}\text { PTD } \\
(\%)\end{array}$} & \multirow[b]{2}{*}{$\mathrm{RME}$} \\
\hline & 1979-1982 & $1989-1992$ & & & \\
\hline Rio Branco & 37 & 55 & $-0,047$ & 70,9 & 39,1 \\
\hline Maceió & 65 & 67 & $-0,050$ & 38,5 & 61,5 \\
\hline Macapá & - & 162 & 0,028 & $\ldots$ & 113,2 \\
\hline Manaus & 44 & 143 & 0,006 & - & 119,4 \\
\hline Salvador & 73 & 96 & 0,006 & - & 131,5 \\
\hline Fortaleza & 70 & 100 & $-0,022$ & - & 205,0 \\
\hline Brasilia & 105 & 94 & $-0,040$ & 63,9 & 36,1 \\
\hline Vitória & 75 & 75 & $-0,010$ & 21,0 & 79,0 \\
\hline Goiânia & 127 & 109 & $-0,050$ & 57,7 & 42,3 \\
\hline São Luiz & 96 & 37 & $-0,074$ & - & 101,6 \\
\hline Belo Horizonte & 128 & 114 & $-0,029$ & - & 127,7 \\
\hline Campo Grande & 121 & 138 & 0,004 & 17,5 & 82,5 \\
\hline Cuiabá & 123 & 88 & $-0,104$ & 60,1 & 39,9 \\
\hline Belém & 96 & 173 & 0,037 & - & 238,8 \\
\hline João Pessoa & 38 & 26 & $-0,057$ & 44,7 & 55,3 \\
\hline Curitiba & 155 & 119 & $-0,055^{*}$ & 37,0 & 63,0 \\
\hline Recife & 88 & 77 & $-0,024$ & 53,2 & 46,8 \\
\hline Terezina & 28 & 54 & $-0,037$ & 25,5 & 74,5 \\
\hline Rio de Janeiro & 109 & 78 & $-0,070^{* * *}$ & 48,6 & 51,4 \\
\hline Natal & 106 & 211 & 0,011 & -- & 171,0 \\
\hline Porto Velho & 136 & 72 & $-0,108^{*}$ & 82,7 & 17,3 \\
\hline Boa Vista & -- & -- & -- & -- & - \\
\hline Porto Alegre & 96 & 185 & 0,014 & 89,8 & 10,2 \\
\hline Florianópolis & 185 & 76 & $-0,098^{*}$ & 72,2 & 27,8 \\
\hline Aracaju & 60 & 86 & $-0,039$ & - & 107,1 \\
\hline São Paulo & 98 & 100 & $-0,028^{*}$ & 38,1 & 61,9 \\
\hline
\end{tabular}

${ }^{*} \mathrm{p} \leq 0,05 \quad * \mathrm{p} \leq 0,01 \quad * \mathrm{p} \leq 0,002 \quad$ em branco: $\mathrm{p}>0,05$

Em nenhuma capital é detectado RME com significância estatística. Portanto é possível afirmar que a intervenção médica contribui de forma pouco expressiva para o declínio da mortalidade, seja porque não há declínio no periodo, seja porque a taxa de mortalidade por Doença de Hodgkin estimada para 1992 não difere significativamente daquela estimada na ausência de intervenção médica (Tabela 13). 
6.8. Impacto da intervenção médica na mortalidade por diabetes melito

A taxa padronizada de mortalidade por diabetes melito no conjunto mantém-se estacionária $(b=-0,003 p>0,05)$ durante o período de estudo, evoluindo de 12,56/100.000 para 12,02/100.000 quando ajustada por regressão loglinear (Tabela 2). Consequentemente, não é possível detectar o efeito da contribuição da intervenção médica na definição do nível de mortalidade por diabetes melito em 1992 no conjunto das capitais com os dados disponíveis de acordo com o modelo de análise proposto (Tabela 6).

Apenas São Luiz (RMP=190), no período de 1979-1989, apresenta nível de mortalidade superior ao esperado (Tabela 14).

Duas capitais apresentam tendência exponencial de declínio da taxa de mortalidade por diabetes melito: Fortaleza $(b=-0,054)$ e São Paulo $(b=-0,024)$; e apenas Natal apresenta tendência exponencial de crescimento da taxa de mortalidade por diabetes melito. Para dezoito capitais, o coeficiente de regressão é positivo e em quatro capitais o coeficiente de regressão é negativo, mas, em ambos os casos, sem significância estatística ao nível de p $\leq 0,002$ (Tabela 14).

Não é possível demonstrar a importância da intervenção médica porque não há declínio da taxa de mortalidade por diabetes melito na maioria das capitais. Dentre as seis capitais com coeficiente de regressão negativo, apenas em Macapá o efeito da contribuição de $82 \%$ da taxa de declínio da mortalidade se traduz em uma diferença significativa entre a taxa de mortalidade estimada para 1992 e a esperada na ausência da intervenção médica $(\mathrm{RME}=18 \mathrm{p} \leq 0,002)$. Para Macapá, podemos concluir que a intervenção médica contribui de forma expressiva para o declínio da mortalidade por diabetes melito em 1992. Para as outras quatro capitais, a contribuição da intervenção médica para a taxa de declínio parece afetar pouco a taxa de mortalidade, pois não produz uma diferença significativa $(p>0,002)$ entre a taxa de mortalidade por estimada para 1992 e a esperada na ausência da intervenção médica (Tabela 14). 
Tabela 14 . Razão de mortalidade padronizada (RMP), coeficiente de regressão loglinear, percentual da taxa de declínio da mortalidade devido à intervenção médica (PTD) e razão de mortalidade evitável $\left(\mathrm{RME}_{1922}\right)$ por diabetes melito (CID9 250) nas capitais brasileiras.

\begin{tabular}{|c|c|c|c|c|c|}
\hline \multirow[b]{2}{*}{ Capital } & \multicolumn{2}{|c|}{ RMP } & \multirow{2}{*}{$\begin{array}{l}\text { Coeficiente } \\
\text { de } \\
\text { Regressão } \\
\text { (b) }\end{array}$} & \multirow{2}{*}{$\begin{array}{c}\text { PTD } \\
(\%)\end{array}$} & \multirow[b]{2}{*}{ RME } \\
\hline & $1979-1982$ & 1989-1992 & & & \\
\hline Rio Branco & 51 & 55 & 0,095 & - & $249,4^{*}$ \\
\hline Maceió & $165^{*}$ & $172^{\circ}$ & 0,003 & -- & 121,5 \\
\hline Macapá & 68 & 36 & $-0,113$ & 82,0 & $18,0^{* * *}$ \\
\hline Manaus & 45 & 79 & $0,048^{*}$ & - & $207,7^{\circ}$ \\
\hline Salvador & 116 & $174^{*}$ & $0,044^{* *}$ & - & $214,3^{\cdots \cdots}$ \\
\hline Fortaleza & 99 & 61 & $-0,054^{\cdots \cdots *}$ & - & 133,5 \\
\hline Brasília & 68 & 79 & 0,004 & 36,0 & 64,0 \\
\hline Vitória & 53 & 92 & $0,076^{*}$ & - & $241,1 \cdots$ \\
\hline Goiânia & 68 & 65 & 0,006 & 12,9 & 87,1 \\
\hline São Luiz & $190^{* * * *}$ & 119 & $-0,049^{* *}$ & - & 139,4 \\
\hline Belo Horizonte & 119 & 124 & 0,004 & - & $194,5^{* *}$ \\
\hline Campo Grande & 50 & 77 & $0,041^{\circ}$ & - & 133,4 \\
\hline Cuiabá & 47 & 94 & 0,035 & - & $240,6^{* *}$ \\
\hline Belém & 66 & 86 & 0,024 & - & $200,8^{*}$ \\
\hline João Pessoa & 87 & 116 & 0,022 & -- & 156,2 \\
\hline Curitiba & 88 & 96 & 0,015 & - & 156,4 \\
\hline Recife & 115 & 130 & 0,002 & 34,5 & 65,5 \\
\hline Terezina & 49 & 70 & $0,046^{*}$ & $\ldots$ & $218,4^{*}$ \\
\hline Rio de Janeiro & 122 & 119 & $-0,006$ & - & 117,8 \\
\hline Natal & 41 & 102 & 0,098 & -.- & $530,5^{\cdots \cdots *}$ \\
\hline Porto Velho & 54 & 89 & 0,059 & -- & 150,6 \\
\hline Boa Vista & $19^{* *}$ & 75 & 0,061 & -- & 153,1 \\
\hline Porto Alegre & 44 & 72 & $0,043^{* *}$ & -- & 146,4 \\
\hline Florianópolis & 65 & 55 & $-0,024$ & 27,4 & 72,6 \\
\hline Aracaju & 143 & 145 & 0,006 & - & $191,3^{* *}$ \\
\hline São Paulo & 101 & 83 & $-0,024^{* * *}$ & 35,2 & 64,8 \\
\hline
\end{tabular}

" $\mathrm{p} \leq 0,05 \quad * * \mathrm{p} \leq 0,01 \quad * * * 0,002 \quad$ em branco: $p>0,05$ 
6.9. Impacto da intervenção médica na mortalidade por meningite

A taxa padronizada de mortalidade por meningite (CID9 320-322) declina 7,9\% aa. no período de 1979 a 1992 no conjunto das capitais, evoluindo de 36,27/100.000 para 12,98/100.000 quando ajustada por regressão loglinear (Tabela 15). A RME de 37,69 indica que a intervenção médica contribui com cerca de $62 \%$ deste declínio. Como este efeito $(-4,9 \%$ aa.) produz uma diferença significativa entre a taxa estimada para 1992 e a esperada na ausência de intervenção $(p \leq 0,002)$, é possível inferir que a intervenção médica contribui de forma expressiva para o declínio da mortalidade por meningite no conjunto das capitais em 1992 (Tabela 6).

No período de 1979-1982, seis capitais apresentam nível de mortalidade significativamente inferior ao esperado: Rio Branco ( $\mathrm{RMP}=15)$, Manaus $(\mathrm{RME}=20)$, Terezina $(\mathrm{RME}=20)$, Belém $(\mathrm{RME}=30)$, Porto Velho $(\mathrm{RME}=31)$ e Macapá ( $\mathrm{RME}=36)$. No periodo de 1989-1992, apenas Boa Vista (RME=10) apresenta nível de mortalidade inferior ao esperado, com significância estatística (Tabela 15).

No período de 1979-1982, três capitais apresentam nível de mortalidade significativamente superior ao esperado: Fortaleza $(\mathrm{RMP}=255)$, Belo Horizonte $(\mathrm{RMP}=178)$ e Salvador $(\mathrm{RME}=160)$. No periodo de 1989-1992, Salvador (RMP=206) mantém o nível de mortalidade superior ao esperado, e Vitória evolui do nível esperado para um nível significativamente superior ( $\mathrm{RMP}=226)$ ao esperado para o periodo (Tabela 15).

A análise de regressão revela seis capitais com coeficiente de regressão positivo (nenhum com significância estatística) e vinte capitais com coeficiente de regressão negativo e dentre elas seis capitais com tendência exponencial de declínio da taxa de mortalidade: Belo Horizonte $(b=-0,108)$, Rio de Janeiro $(b=-0,086)$, Brasília $(b=-0,084)$, Curitiba $(b=-0,75)$, São Paulo $(b=-0,74)$ e Porto Alegre $(b=-0,61)$ (Tabela 15).

Dentre as vinte capitais com coeficiente de regressão negativo, quinze apresentam RME estatisticamente significativa $(\mathrm{p} \leq 0,002)$. Para estas capitais, é possível inferir que a intervenção médica contribui de forma expressiva para o declínio da mortalidade por meningite. Entretanto, a contribuição da 
intervenção médica (PTD) e, especialmente, o efeito (RME) provocado sobre a taxa de mortalidade variam amplamente entre elas: em Rio Branco, a intervenção médica é responsável por $85,3 \%$ da taxa de declínio tomando a taxa estimada cerca de $1 / 7(\mathrm{RME}=14,7)$ da esperada e, em Campo Grande, a taxa estimada é cerca da metade $(\mathrm{RME}=48)$ da esperada na ausência da intervenção médica (Tabela 15).

Tabela 15. Razão de mortalidade padronizada (RMP), coeficiente de regressão loglinear, percentual da taxa de declínio da mortalidade devido à intervenção médica (PTD) e razão de mortalidade evitável $\left(\mathrm{RME}_{1992}\right)$ por meningite (CID9 320-322) nas capitais brasileiras.

\begin{tabular}{|c|c|c|c|c|c|}
\hline \multirow[b]{2}{*}{ Capital } & \multicolumn{2}{|c|}{ RMP } & \multirow{2}{*}{$\begin{array}{l}\text { Coeficiente } \\
\text { de } \\
\text { Regressão } \\
\text { (b) }\end{array}$} & \multirow{2}{*}{$\begin{array}{r}\text { PTD } \\
(\%)\end{array}$} & \multirow[b]{2}{*}{$\mathrm{RME}$} \\
\hline & $1979-1982$ & 1989-1992 & & & \\
\hline Rio Branco & $15^{* * *}$ & $25^{* *}$ & $-0,123^{*}$ & 85,3 & $14,7^{* * *}$ \\
\hline Maceió & $54^{\circ}$ & 92 & 0,025 & - & 115,2 \\
\hline Macapá & $36 * \cdots$ & 47 & $-0,017$ & 37,8 & 62,2 \\
\hline Manaus & $20^{* * *}$ & 57 & 0,056 & $\ldots$ & $199,4^{*}$ \\
\hline Salvador & $160^{* * *}$ & $206^{* * *}$ & $-0,060^{*}$ & 44,4 & $55,6^{\circ *}$ \\
\hline Fortaleza & $255^{\circ \cdots}$ & 76 & $-0,181^{*}$ & 74,3 & $25,7^{\cdots \cdots}$ \\
\hline Brasília & 98 & 89 & $-0,084^{* * *}$ & 79,7 & $20,3^{* * *}$ \\
\hline Vitória & 129 & $226^{* * *}$ & 0,000 & 10,1 & 89,9 \\
\hline Goiânia & 97 & 87 & $-0,076$ & 69,8 & $30,2^{* \cdots *}$ \\
\hline São Luiz & 90 & 68 & $-0,093$ & 20,9 & 79,1 \\
\hline Belo Horizonte & $178^{* * *}$ & 133 & $-0,108^{* * *}$ & 54,4 & $45,6 * *$ \\
\hline Campo Grande & 79 & 112 & $-0,037$ & 52,0 & $48,0^{* * *}$ \\
\hline Cuiabá & $56^{*}$ & 69 & $-0,039$ & 7,5 & 92,5 \\
\hline Belém & $30^{* * *}$ & 68 & 0,025 & -- & $205,5^{*}$ \\
\hline João Pessoa & 67 & $157^{\circ}$ & 0,014 & --- & 139,6 \\
\hline Curitiba & 119 & 131 & $-0,075^{* * *}$ & 51,5 & $48,5^{* *}$ \\
\hline Recife & 128 & 132 & $-0,075^{* *}$ & 76,1 & $23,9^{* * *}$ \\
\hline Terezina & $20^{* * *}$ & $40^{*}$ & $-0,034$ & 22,4 & 77,6 \\
\hline Rio de Janeiro & 102 & 96 & $-0,086^{* * *}$ & 58,3 & $41,7^{* *}$ \\
\hline Natal & $140^{*}$ & 138 & $-0,107^{*}$ & 63,2 & $36,8^{* \cdots}$ \\
\hline Porto Velho & $31^{* * *}$ & 113 & 0,062 & $\ldots$ & $156,6^{*}$ \\
\hline Boa Vista & $53^{* *}$ & $10^{* * *}$ & $-0,086$ & 77,4 & $22,6 \cdots$ \\
\hline Porto Alegre & $59^{*}$ & 69 & $-0,061^{* * *}$ & 62,0 & $38,0^{* *}$ \\
\hline Florianópolis & 70 & 51 & $-0,051$ & 48,5 & $51,5^{\circ}$ \\
\hline Aracaju & $56^{*}$ & 108 & $-0,011$ & - & 152,8 \\
\hline São Paulo & 89 & 90 & $-0,074 * * *$ & 66,2 & $33,8^{* * *}$ \\
\hline
\end{tabular}

${ }^{*} \mathrm{p} \leq 0,05 \quad \cdots p \leq 0,01 \quad \cdots{ }^{*} \mathrm{p} \leq 0,002 \quad$ em branco: $p>0,05$ 
Nas demais capitais, a participação da intervenção médica na taxa de declínio, mesmo quando expressiva como em Porto Alegre (PTD=62\%), Rio de Janeiro (PTD=58,3) e Salvador (PTD=44,4\%), não gera um efeito capaz de produzir diferença significativa (ao nível de significância de p $\leq 0,002$ ) entre a taxa de mortalidade da estimada para 1992 e a esperada na ausência da intervenção médica (Tabela 15).

Nas capitais com coeficiente de regressão positivo, a influência da assistência médica sobre a mortalidade não é mensurável pelo modelo de análise proposto.

\subsection{Impacto da intervenção médica na mortalidade por doença reumática crônica do coração}

A taxa padronizada de mortalidade por doença reumática crônica do coração (CID9 393398) declina 5,2\% aa. no período de 1979 a 1992 no conjunto das capitais, evoluindo de 1,67/100.000 para 0,84/100.000 quando ajustada por regressão loglinear (Tabela 2). A RME de 53,38 indica que a intervenção médica contribui com cerca de $47 \%$ deste declínio. Como este efeito $(-2,4 \%$ aa. $)$ não produz uma diferença significativa entre as taxa estimada para 1992 e a esperada na ausência de intervenção ( $>0,05)$, é possível inferir que a intervenção médica contribui de forma pouco expressiva para o declínio da taxa de mortalidade por doença crônica do coração no conjunto das capitais em 1992 (Tabela 6).

Durante o período estudado, todas as capitais apresentam nível de mortalidade sem diferença estatisticamente significativa em relação ao esperado no período. Inexiste registro de óbito por esta causa em Boa Vista para a maior parte do periodo estudado (Tabela 16).

A análise de regressão revela quatro capitais com coeficiente de regressão positivo (nenhum com significância estatística) e vinte e uma capitais com coeficiente de regressão negativo e dentre elas quatro capitais com tendencia exponencial de declínio da taxa de mortalidade: Porto Alegre $(b=-0,097)$, Curitiba $(b=-0,090)$, Belo Horizonte $(b=-0,074)$ e Rio de Janeiro $(b=-0,071)$ (Tabela 16).

Nenhuma das capitais apresenta RME estatisticamente significativa. Portanto, é possivel inferir que a intervenção médica contribui de forma pouco expressiva para o declínio da mortalidade, seja porque não há declínio no período, seja porque a taxa de mortalidade por doença reumática crônica do coração 
estimada para 1992 não difere significativamente daquela esperada na ausência da intervenção médica (Tabela 16).

Tabela 16. Razão de mortalidade padronizada (RMP), coeficiente de regressão loglinear, percentual da taxa de declínio da mortalidade devido à intervenção médica (PTD) e razão de mortalidade evitável $\left(\mathrm{RME}_{1992}\right)$ por doença reumática crônica do coração (CID9 393-398) nas capitais brasileiras.

\begin{tabular}{|c|c|c|c|c|c|}
\hline \multirow[b]{2}{*}{ Capital } & \multicolumn{2}{|c|}{ RMP } & \multirow{2}{*}{$\begin{array}{l}\text { Coeficiente } \\
\text { de } \\
\text { Regressão } \\
\quad \text { (b) }\end{array}$} & \multirow{2}{*}{$\begin{array}{l}\text { PTD } \\
\text { (\%) }\end{array}$} & \multirow[b]{2}{*}{$\mathrm{RME}$} \\
\hline & $1979-1982$ & 1989-1992 & & & \\
\hline Rio Branco & 11 & 110 & $-0,010$ & 36,8 & 63,2 \\
\hline Maceió & 10 & 83 & 0,020 & - & 152,9 \\
\hline Macapá & 5 & 61 & $-0,052$ & 60,0 & 40,0 \\
\hline Manaus & 10 & 47 & 0,020 & -- & 144,5 \\
\hline Salvador & 46 & 110 & $-0,040$ & 28,3 & 71,7 \\
\hline Fortaleza & 47 & 71 & $-0,099^{* *}$ & 25,1 & 74,9 \\
\hline Brasilia & 45 & 148 & $-0,026$ & 56,6 & 43,4 \\
\hline Vitória & 24 & 101 & 0,020 & $\ldots$ & 116,6 \\
\hline Goiânia & 43 & 91 & $-0,088^{*}$ & 74.4 & 25,6 \\
\hline São Luiz & 25 & 32 & $-0,109$ & 35,6 & 64,4 \\
\hline Belo Horizonte & 74 & 145 & $-0,074^{* * *}$ & 29,5 & 70,5 \\
\hline Campo Grande & 14 & 107 & 0,003 & 19,3 & 80,7 \\
\hline Cuiabá & 45 & 81 & $-0,094^{*}$ & 55,1 & 44,9 \\
\hline Belém & 40 & 74 & $-0,084^{*}$ & 50,3 & 49,7 \\
\hline João Pessoa & 42 & 39 & $-0,121^{*}$ & 75,9 & 24,1 \\
\hline Curitiba & 99 & 151 & $-0,090^{* * *}$ & 60,0 & 40,0 \\
\hline Recife & 63 & 131 & $-0,076^{*}$ & 76,2 & 23,8 \\
\hline Terezina & 7 & 57 & $-0,024$ & 12,6 & 87,4 \\
\hline Rio de Janeiro & 42 & 90 & $-0,071^{* * *}$ & 49,5 & 50,5 \\
\hline Natal & 23 & 59 & $-0,039$ & 10,6 & 89,4 \\
\hline Porto Velho & 31 & 40 & $-0,074$ & 73,1 & 26,9 \\
\hline Boa Vista & - & 26 & - & - & - \\
\hline Porto Alegre & 38 & 69 & $-0,097^{* * *}$ & 76,3 & 23,7 \\
\hline Florianópolis & 46 & 44 & $-0,086^{\circ}$ & 67,4 & 32,6 \\
\hline Aracaju & 32 & 42 & $-0,099^{*}$ & 51,3 & 48,7 \\
\hline São Paulo & 40 & 112 & $-0,032^{*}$ & 41,6 & 58,4 \\
\hline
\end{tabular}

${ }^{*} \mathrm{p} \leq 0,05 \quad{ }^{*} \mathrm{p} \leq 0,01 \quad \cdots *{ }^{* *} \leq 0,002 \quad$ em branco: $p>0,05$ 
6.11. Impacto da intervenção médica na mortalidade por hipertensão arterial

A taxa padronizada de mortalidade por hipertensão arterial (CID9 401-405) declina 3,1\% aa. no período de 1979 a 1992 no conjunto das capitais, evoluindo de 34,42/100.000 para 23,13/100.000 quando ajustada por regressão loglinear (Tabela 2). A RME de 70,77 indica que a intervenção médica contribui com cerca de $29 \%$ deste declínio. Como este efeito $(-0,9 \%$ aa.) não produz uma diferença significativa entre as taxas estimadas ( $p>0,05$ ), é possivel inferir que a intervenção médica contribui de forma pouco expressiva para o declínio da mortalidade por hipertensão arterial no conjunto das capitais em 1992 (Tabela 6).

No período de 1979-1982, seis capitais apresentam nível de mortalidade significativamente superior ao esperado: Natal $(R M P=229)$, Cuiabá $(R M E=213)$, Maceió $(R M E=208)$, Belo Horizonte $(R M E=196)$, Salvador $(\mathrm{RME}=185)$ e São Luiz $(\mathrm{RME}=159)$. No período de 1989-1992, todas as capitais apresentam nível de mortalidade que não diferem do esperado, exceto Fortaleza $(R M P=31 \quad p \leq 0,002)$ e Rio Branco $(R M P=25 p 50,002)$ que evoluem do nivel esperado para um nivel inferior de mortalidade. Neste período, Boa Vista $(R M P=157 p \leq 0,01)$, Recife $(R M P=156 p \leq 0,002)$ e Belo Horizonte $(R M P=152 p \leq 0,05)$ têm evolução insatisfatória do nível de mortalidade (Tabela 17).

No período estudado, todas as capitais apresentam coeficiente de regressão negativo, exceto Terezina $(b=0,05 p>0,05)$, João Pessoa $(b=0,028 p>0,05)$, Florianópolis $(b=0,019 p>0,05)$ e Boa Vista $(b=0,014 p>0,05)$. Dentre as demais, cinco capitais apresentam tendência exponencial de declínio da taxa de mortalidade por hipertensão arterial $(p \leq 0,002)$ : Natal $(b=-0,145)$, Goiânia $(b=-0,113)$, Belém $(b=-0,108)$, Curitiba $(b=-0,082)$ e Belo Horizonte $(b=-0,061)$ (Tabela 17).

Dentre as vinte e uma capitais com coeficiente de regressão negativo, a RME foi estatisticamente significativa em oito delas. Para essas capitais, é possivel afirmar que a intervenção médica contribui de forma expressiva para o declínio da mortalidade por hipertensão arterial. Entretanto, a contribuição da intervenção médica (PTD) e, especialmente, o efeito (RME) provocado sobre a taxa de mortalidade variam amplamente entre elas: em Rio Branco, a intervenção médica é responsável por $91 \%$ da taxa de declínio tomando a taxa estimada cerca de 1/10 (RME=9) da esperada, e em Maceió, a taxa estimada é cerca da metade $(\mathrm{RME}=53,7)$ da esperada na ausência da intervenção médica (Tabela 17). 
Tabela 17. Razão de mortalidade padronizada (RMP), coeficiente de regressão loglinear, percentual da taxa de declínio da mortalidade devido à intervenção médica (PTD) e razão de mortalidade evitável $\left(\mathrm{RME}_{1992}\right)$ por hipertensão arterial (CID9 401-405) nas capitais brasileiras.

\begin{tabular}{|c|c|c|c|c|c|}
\hline \multirow[b]{2}{*}{ Capital } & \multicolumn{2}{|c|}{ RMP } & \multirow{2}{*}{$\begin{array}{l}\text { Coeficiente } \\
\text { de } \\
\text { Regressão } \\
\text { (b) }\end{array}$} & \multirow{2}{*}{$\begin{array}{l}\text { PTD } \\
\text { (\%) }\end{array}$} & \multirow[b]{2}{*}{$\mathrm{RME}$} \\
\hline & 1979-1982 & 1989-1992 & & & \\
\hline Rio Branco & 99 & $25^{* * *}$ & $-0,160^{\circ}$ & 91,0 & $9,0^{* * *}$ \\
\hline Maceió & $208^{* * *}$ & 100 & $-0,060$ & 46,3 & $53,7^{* \cdots}$ \\
\hline Macapá & 110 & 124 & $-0,005$ & 26,9 & 73,1 \\
\hline Manaus & 96 & $49^{\circ}$ & $-0,087$ & 64,0 & $36,0^{* *}$ \\
\hline Salvador & $185^{* * *}$ & 139 & $-0,026^{\circ}$ & 13,6 & 86,4 \\
\hline Fortaleza & 85 & $31^{* * *}$ & $-0,153^{* *}$ & 63,0 & $37,0^{\circ}$ \\
\hline Brasília & $150^{*}$ & 124 & $-0,034^{\circ}$ & 61,0 & $39,0^{* \cdots *}$ \\
\hline Vitória & 90 & 99 & $-0,009$ & 19,3 & 80,7 \\
\hline Goiânia & 114 & $57^{*}$ & $-0,113^{* * *}$ & 81,4 & $18,6^{* * *}$ \\
\hline São Luiz & $159^{* * *}$ & 79 & $-0,075^{*}$ & 0,5 & 99,5 \\
\hline Belo Horizonte & $196^{* * *}$ & $152^{*}$ & $-0,061^{* * *}$ & 16,2 & 83,8 \\
\hline Campo Grande & 75 & 84 & $-0,007$ & 29,1 & 70,9 \\
\hline Cuiabá & $213^{* * *}$ & 130 & $-0,078$ & 44,4 & $55,6^{* *}$ \\
\hline Belém & 129 & $56^{*}$ & $-0,108^{* * *}$ & 63,9 & $36,1^{* * *}$ \\
\hline João Pessoa & $46^{* *}$ & $47^{*}$ & 0,028 & $\ldots$ & $167,2^{\circ}$ \\
\hline Curitiba & 90 & 62 & $-0,082^{* * *}$ & 55,4 & $44,6^{\circ}$ \\
\hline Recife & 130 & $156^{* *}$ & $-0,027$ & 54,8 & $45,2^{* * *}$ \\
\hline Terezina & 68 & 103 & 0,050 & $\ldots$ & $229,6^{* * *}$ \\
\hline Rio de Janeiro & $152^{*}$ & 129 & $-0,048^{* *}$ & 31,5 & $68,5^{*}$ \\
\hline Natal & $229^{* * *}$ & 79 & $-0,145^{* * *}$ & 77,5 & $22,5^{* * *}$ \\
\hline Porto Velho & 71 & 58 & $-0,015$ & 42,2 & $57,8^{*}$ \\
\hline Boa Vista & $158^{* *}$ & $157^{* *}$ & 0,014 & 17,3 & 82,7 \\
\hline Porto Alegre & 85 & $48^{*}$ & $-0,073^{*}$ & 67,7 & $32,3^{* * *}$ \\
\hline Florianópolis & $49^{* *}$ & $51^{*}$ & 0,019 & $\ldots$ & 127,1 \\
\hline Aracaju & 68 & $55^{*}$ & $-0,084$ & 40,4 & 59,6 \\
\hline São Paulo & 96 & 94 & $-0,040^{* *}$ & 47,1 & $52,9^{* *}$ \\
\hline
\end{tabular}

${ }^{*} \mathrm{p} \leq 0,05 \quad *{ }^{* *} \mathrm{p} \leq 0,01 \quad *{ }^{* * *} \mathrm{p} \leq 0,002 \quad$ em branco: $p>0,05$

Para as demais capitais com coeficiente de regressão negativo, mesmo a influência expressiva da intervenção médica sobre a taxa de declínio, como ocorre em Manaus (PTD=64\%), São Paulo $(\mathrm{PTD}=47,1 \%)$ e Cuiabá $(\mathrm{PTD}=44,4 \%)$ não é suficiente para produzir uma diferença significativa 
$(p>0,002)$ entre a taxa de mortalidade por estimada para 1992 e a esperada na ausência da intervenção médica (Tabela 17).

Nas capitais em que o coeficiente de regressão é positivo, a influência da intervenção médica não é mensurável pelo modelo de análise proposto.

6.12. Impacto da intervenção médica na mortalidade por doença cerebrovascular

A taxa padronizada de mortalidade por (CID9 430-436) declina a 2,2\% aa., evoluindo de 119,77/100.000 para 89,66/100.000 no período de 1979 a 1992 no conjunto das capitais, quando ajustada por regressão loglinear (Tabela 2). A intervenção médica contribui com cerca de $21,2 \%$ deste declínio em 1992. Como este efeito $(-0,05 \%$ aa.) não produz uma diferença significativa entre as taxa estimada e a esperada na ausência da intervenção $(R M E=78,84 p>0,01)$, é possivel inferir que a intervenção médica contribui de forma pouco expressiva para o declínio da mortalidade por doença cerebrovascular no conjunto das capitais em 1992 (Tabela 6).

No período de 1879-1982, três capitais têm nível de mortalidade inferior ao esperado ( $p \leq 0,002)$ : Rio Branco ( $R M P=24)$, Brasilia $(R M P=62)$ e Natal $(R M P=65)$; e quatro capitais têm nivel de mortalidade superior ao esperado $(p \leq 0,002)$ : São Luiz $(R M P=326)$, Maceió $(R M P=173)$, Fortaleza $(R M P=165)$ e Curitiba (RMP=154). No período 1898-1992, cinco capitais têm nível de mortalidade inferior ao esperado ( $\mathrm{p} \leq 0,002)$ : Rio Branco $(\mathrm{RMP}=33)$, Macapá $(\mathrm{RMP}=40)$, Boa Vista $(\mathrm{RMP}=42)$, Florianópolis $(\mathrm{RMP}=58)$ e Natal (RMP=59); e duas capitais têm nivel de mortalidade superior ao esperado $(p \leq 0,002)$ : São Luiz $(\mathrm{RMP}=147)$ e Maceió (RMP=143) (Tabela 18).

$\mathrm{Na}$ análise de regressão, das cinco capitais com coeficiente de regressão positivo, Brasilia $(b=0,03$ $\mathbf{p}<0,05$ ) apresenta tendência exponencial de crescimento da taxa de mortalidade por doença cerebrovascular, se for considerado o nível de significância de $p<0,05$. Entre as demais, vinte e uma capitais têm coeficiente de regressão negativo e, destas, oito apresentam tendência exponencial de declínio da taxa 
de mortalidade $(p \leq 0,002)$. A maior taxa de declínio foi alcançada em São Luiz $(b=0,089 p \leq 0,002)$ e a menor em Porto Alegre $(b=-0,021 \mathrm{p} \leq 0,002)$ (Tabela 18).

Tabela 18. Razão de mortalidade padronizada (RMP), coeficiente de regressão loglinear, percentual da taxa de declínio da mortalidade devido à intervenção (PTD) e razão de mortalidade evitável $\left(\mathrm{RME}_{1992}\right)$ por doença cerebrovascular (CID9 430-436) nas capitais brasileiras.

\begin{tabular}{|c|c|c|c|c|c|}
\hline \multirow[b]{2}{*}{ Capital } & \multicolumn{2}{|c|}{$\mathrm{RMP}$} & \multirow{2}{*}{$\begin{array}{l}\text { Coeficiente } \\
\text { de } \\
\text { Regressão } \\
\text { (b) }\end{array}$} & \multirow{2}{*}{$\begin{array}{r}\text { PTD } \\
\text { (\%) }\end{array}$} & \multirow[b]{2}{*}{$\mathrm{RME}$} \\
\hline & 1979-1982 & $1989-1992$ & & & \\
\hline Rio Branco & $24^{* * *}$ & $33^{* * *}$ & 0,038 & $\ldots$ & 118,0 \\
\hline Maceió & $173^{* * *}$ & $143^{* * *}$ & $-0,026^{* * *}$ & 15,8 & 84,2 \\
\hline Macapá & $70^{* *}$ & $40^{* * *}$ & $-0,058^{*}$ & 63,3 & $36,7^{* \cdots *}$ \\
\hline Manaus & 90 & 84 & $-0,013$ & 6,0 & 94,0 \\
\hline Salvador & 116 & 106 & $-0,016$ & 1,9 & 98,1 \\
\hline Fortaleza & $165^{* * *}$ & 86 & $-0,068^{* * *}$ & $\ldots$ & 111,7 \\
\hline Brasilia & $62^{* * *}$ & 88 & $0,030^{*}$ & 10,7 & 89,3 \\
\hline Vitória & $134^{* * *}$ & $123^{*}$ & $-0,016$ & 27,1 & $72,9^{* * *}$ \\
\hline Goiânia & 119 & 101 & $-0,025^{* *}$ & 41,8 & $58,2^{* * *}$ \\
\hline São Luiz & $326^{* * *}$ & $147^{* * *}$ & $-0,089^{* * *}$ & 16,6 & $83,4^{*}$ \\
\hline Belo Horizonte & $126^{* *}$ & 114 & $-0,020^{* *}$ & $\ldots$ & $143,2^{* * *}$ \\
\hline Campo Grande & 102 & 112 & 0,005 & 16,7 & 83,3 \\
\hline Cuiabá & 97 & $72^{* *}$ & $-0,008$ & $\ldots$ & $138,2^{* *}$ \\
\hline Belém & 116 & 100 & $-0,023^{* * *}$ & ..- & 109,1 \\
\hline João Pessoa & 90 & 113 & 0,005 & - & $124,1^{*}$ \\
\hline Curitiba & $154^{* * *}$ & 108 & $-0,042^{* * *}$ & 25,0 & $75,0^{* *}$ \\
\hline Recife & 105 & 114 & $-0,002$ & 37,6 & $62,4^{* \cdots}$ \\
\hline Terezina & 93 & 97 & 0,010 & --- & $136,4 * *$ \\
\hline Rio de Janeiro & $121^{*}$ & 118 & $-0,009$ & $\ldots$ & 113,1 \\
\hline Natal & $65^{* * *}$ & $59^{* * *}$ & $-0,010$ & $\ldots$ & $129,8^{*}$ \\
\hline Porto Velho & 119 & 82 & $-0,042^{*}$ & 59,5 & $40,5^{* * *}$ \\
\hline Boa Vista & $76^{\circ}$ & $42^{* * *}$ & $-0,055^{*}$ & 66,4 & $33,6^{* * *}$ \\
\hline Porto Alegre & 95 & 83 & $-0,021^{* * *}$ & 36,6 & $63,4^{* * *}$ \\
\hline Florianópolis & 110 & $58^{* * *}$ & $-0,065^{* * *}$ & 57,2 & $42,8^{* * *}$ \\
\hline Aracaju & $130^{* *}$ & 116 & $-0,017$ & $\ldots$ & $141,1^{\cdots \cdots}$ \\
\hline São Paulo & 114 & 88 & $-0,033^{* * *}$ & 42,2 & $57,8^{* * *}$ \\
\hline
\end{tabular}

" $\mathrm{p} \leq 0,05 \quad *{ }^{*} \mathrm{p} \leq 0,01 \quad * * * 0,002 \quad$ em branco: $p>0,05$ 
Dentre as capitais com coeficiente de regressão negativo, em nove capitais a contribuição da intervenção médica na taxa de declínio da mortalidade gerou diferença significativa $(p \leq 0,002)$ entre a taxa estimada para 1992 e a esperada na sua ausência. Consequentemente, é possível afirmar que a intervenção médica contribui de forma expressiva para o declínio da mortalidade por doenças cerebrovasculares em 1992 nessas capitais. Entretanto, a contribuição da intervenção médica (PTD) e, especialmente, o efeito (RME) provocado sobre a taxa de mortalidade variam amplamente entre elas: em Boa Vista, a intervenção médica é responsável por $66,4 \%$ da taxa de declínio da mortalidade e torna a taxa estimada cerca de $1 / 3$ $(\mathrm{RME}=33,6)$ da esperada, e em Vitória, a taxa estimada é cerca de $3 / 4 \quad(\mathrm{RME}=72,9)$ da esperada na ausência da intervenção médica. Nas demais capitais, a participação da intervenção médica na taxa de declínio, mesmo quando expressiva como em Curitiba $(\mathrm{PTD}=25 \%)$, não gera um efeito capaz de produzir diferença significativa (ao nível de significância de $\mathrm{p} \leq 0,002$ ) entre a taxa de mortalidade da estimada para 1992 e a esperada na ausência da intervenção médica (Tabela 18). Nas capitais com coeficiente de regressão positivo, a influência da assistência médica sobre a mortalidade não é mensurável pelo modelo de análise proposto.

6.13. Impacto da intervenção médica na mortalidade por infecções respiratórias agudas

A taxa de mortalidade por (CID9 460-466) declina 13,1\% aa., evoluindo de 20,78/100.000 para 3,8/100.000 no conjunto das capitais, quando ajustada por regressão loglinear (Tabela 2). A intervenção médica contribui com $80,3 \%$ deste declínio. Como este efeito $(-10,5 \%$ aa.) produz uma diferença significativa entre a taxas estimada para 1992 e a esperada na ausência da intervenção (RME=19,26 p $\leq 0,02)$, é possível inferir que a intervenção médica contribui de forma expressiva para o declínio da mortalidade por infeç̧̃̃es respiratórias agudas no conjunto das capitais em 1992 (Tabela 6).

No período de 1879-1982, dez capitais têm nível de mortalidade inferior ao esperado $(p \leq 0,002)$ e duas capitais têm nível de mortalidade superior ao esperado $(p \leq 0,002)$. No período 1898-1992, nenhuma capital apresenta nível de mortalidade superior ao esperado $(p \leq 0,002)$ (Tabela 19).

$\mathrm{Na}$ análise de regressão, observa-se cinco capitais com coeficiente de regressão positivo mas sem significância estatística (b>0 $\quad p>0,05)$. Entre as demais, vinte e uma capitais têm coeficiente de regressão 
negativo e, destas, sete apresentam tendência exponencial de declínio da taxa de mortalidade $(p \leq 0,002)$. A maior taxa de declínio foi alcançada em São Luiz $(b=-0,274 p \leq 0,002)$ e a menor em Belo Horizonte $(b=-0,082 \mathrm{p} \leq 0,002)$ (Tabela 19).

Tabela 19. Razão de mortalidade padronizada (RMP), coeficiente de regressão loglinear, percentual da taxa de declínio da mortalidade devido à intervenção médica (PTD) e razão de mortalidade evitável (RME ${ }_{1992)}$ por doenças respiratórias agudas (CID9 460-466) nas capitais brasileiras.

\begin{tabular}{|c|c|c|c|c|c|}
\hline \multirow[b]{2}{*}{ Capital } & \multicolumn{2}{|c|}{ RMP } & \multirow{2}{*}{$\begin{array}{l}\text { Coeficiente } \\
\text { de } \\
\text { Regressão } \\
\text { (b) }\end{array}$} & \multirow{2}{*}{$\begin{array}{c}\text { PTD } \\
(\%)\end{array}$} & \multirow[b]{2}{*}{ RME } \\
\hline & $1979-1982$ & 1989-1992 & & & \\
\hline Rio Branco & $45^{*}$ & $234^{* *}$ & 0,029 & - & 105,8 \\
\hline Maceió & $160^{*}$ & 59 & $-0,234^{* * *}$ & 94,4 & $5,6^{* * *}$ \\
\hline Macapá & $24^{* * *}$ & 58 & $-0,085^{*}$ & 74,0 & $26,0^{* *}$ \\
\hline Manaus & $17^{* * * *}$ & 100 & 0,022 & - & 147,2 \\
\hline Salvador & 116 & 83 & $-0,162^{* * *}$ & 85,2 & $14,8^{* * *}$ \\
\hline Fortaleza & $50^{\circ}$ & 19 & $-0,200^{* * *}$ & 80,0 & 20,0 \\
\hline Brasília & $7^{* *}$ & 23 & 0,010 & 31,1 & 68,9 \\
\hline Vitória & 32 & 85 & $-0,007$ & 17,4 & 82,6 \\
\hline Goiânia & 63 & 49 & $-0,125^{* *}$ & 84,0 & $16,0^{* * *}$ \\
\hline São Luiz & $240^{* * *}$ & 68 & $-0,274^{* * *}$ & 92,5 & $7,5^{* \cdots *}$ \\
\hline Belo Horizonte & 54 & 92 & $-0,082^{* * *}$ & 36,2 & 63,8 \\
\hline Campo Grande & $24^{* * *}$ & 35 & $-0,098^{\circ}$ & 78,3 & $21,7^{*}$ \\
\hline Cuiabá & $15^{* * *}$ & 34 & $-0,079$ & 45,2 & 54,8 \\
\hline Belém & 115 & 73 & $-0,171^{* * *}$ & 84,1 & $15,9^{* \cdots *}$ \\
\hline João Pessoa & $7^{* * *}$ & 19 & $-0,108^{*}$ & 71,5 & 28,5 \\
\hline Curitiba & 75 & 162 & $-0,067^{*}$ & 45,9 & 54,1 \\
\hline Recife & 89 & 123 & $-0,095^{* *}$ & 81,4 & $18,6^{* * *}$ \\
\hline Terezina & $11^{* * *}$ & 14 & $-0,027$ & 15,9 & 84,1 \\
\hline Rio de Janeiro & $47^{*}$ & 121 & $-0,039$ & 22,8 & 77,2 \\
\hline Natal & $14^{* * *}$ & 15 & $-0,073^{*}$ & 42,5 & 57,5 \\
\hline Porto Velho & $25^{* * *}$ & 118 & 0,033 & $\ldots$ & 108,4 \\
\hline Boa Vista & 129 & 28 & $-0,134$ & 87,8 & $12,2^{* * *}$ \\
\hline Porto Alegre & $22^{* * *}$ & 128 & 0,030 & - & 123,6 \\
\hline Florianópolis & $15^{* * * *}$ & 107 & 0,125 & $\ldots$ & $500,8^{* * *}$ \\
\hline Aracaju & 76 & 23 & $-0,117$ & 61,2 & 38,8 \\
\hline São Paulo & $218^{* * *}$ & 153 & $-0,164^{* * *}$ & 89,5 & $10,5^{* * *}$ \\
\hline
\end{tabular}

"p $\leq 0,05 \quad *{ }^{* *} \leq 0,01 \quad{ }^{* * *} \mathrm{p} \leq 0,002 \quad$ em branco: $p>0,05$ 
Dentre as capitais com coeficiente de regressão negativo, em oito capitais a contribuição da intervenção médica na taxa de declínio da mortalidade gerou diferença significativa $(p \leq 0,002)$ entre a taxa estimada para 1992 e a esperada na sua ausência. Consequentemente, é possível afirmar que a intervenção médica contribui de forma expressiva para o declínio da mortalidade por infeç̧ões respiratórias agudas em 1992 nessas capitais. Entretanto, a contribuição da intervenção médica (PTD) e, especialmente, o efeito (RME) provocado sobre a taxa de mortalidade variam amplamente entre elas: em Maceió, a intervenção médica é responsável por $94,4 \%$ da taxa de declínio da mortalidade e torna a taxa estimada cerca de $1 / 18$ $(\mathrm{RME}=5,6)$ da esperada, e em Recife, a taxa estimada é cerca de $1 / 5(\mathrm{RME}=18,6)$ da esperada na ausência da intervenção médica. Nas demais capitais, a participação da intervenção médica na taxa de declínio, mesmo quando expressiva como em Campo Grande (PTD=78,3\%), não gera um efeito capaz de produzir diferença significativa (ao nível de significância de $\mathrm{p} \leq 0,002$ ) entre a taxa de mortalidade da estimada para 1992 e a esperada na ausência da intervenção médica (Tabela 19). Nas capitais com coeficiente de regressão positivo, a influência da assistência médica sobre a mortalidade não é mensurável pelo modelo de análise proposto.

\subsection{Impacto da intervenção médica na mortalidade por pneumonia e gripe}

A taxa de mortalidade por pneumonia e gripe (CID9 480-487) no conjunto das capitais declina $6,7 \%$ aa., evoluindo de 43,97/100.000 para 18,47/100.000 no período de 1979 e 1992, quando ajustadas por regressão loglinear (Tabela 2). A intervenção médica contribui com $55,8 \%$ deste declínio. Como este cfoito $(-3,7 \%$ aa.) produz uma diforonça significativa ontre as taxas estimadas ( $R M E=44,24 p \leq 0,02)$, possivel inferir que a intervenção médica contribui de forma expressiva para o declínio da taxa de mortalidade por pneumonia e gripe no conjunto das capitais em 1992 (Tabela 6).

Durante o período de 1979-1982, todas as capitais têm nível de mortalidade inferior ao esperado ( $\mathbf{p} \leq 0,002)$. No periodo de 1989-1992, todas as capitais têm nivel de mortalidade que não diferem significativamente do esperado (Tabela 20). 
Tabela 20. Razão de mortalidade padronizada (RMP), coeficiente de regressão loglinear, percentual da taxa de declínio da mortalidade devido à intervenção médica (PTD) e razão de mortalidade evitável $\left(\mathrm{RME}_{1992}\right)$ por pneumonia e gripe (CID9 480-487) nas capitais brasileiras.

\begin{tabular}{|c|c|c|c|c|c|}
\hline \multirow[b]{2}{*}{ Capital } & \multicolumn{2}{|c|}{ RMP } & \multirow{2}{*}{$\begin{array}{l}\text { Coeficiente } \\
\text { de } \\
\text { Regressão } \\
\text { (b) }\end{array}$} & \multirow{2}{*}{$\begin{array}{c}\text { PTD } \\
(\%)\end{array}$} & \multirow[b]{2}{*}{ ME } \\
\hline & $1979-1982$ & 1989-1992 & & & \\
\hline Rio Branco & $13^{* * *}$ & $39^{*}$ & $-0,077^{* *}$ & 73,6 & $26,4^{* \cdots *}$ \\
\hline Maceió & $25^{* * *}$ & 117 & $-0,033^{* *}$ & 23,9 & 76,1 \\
\hline Macapá & $16^{* * *}$ & 83 & $-0,012$ & 33,4 & 66,6 \\
\hline Manaus & $18^{* * *}$ & 79 & $-0,041^{\cdots * *}$ & 34,7 & 65,3 \\
\hline Salvador & $35^{* \cdots}$ & 79 & $-0,099^{* * *}$ & 66,7 & $33,3^{\cdots \cdots}$ \\
\hline Fortaleza & $47^{* * *}$ & 61 & $-0,161^{* * *}$ & 66,7 & $33,3^{* * *}$ \\
\hline Brasilia & $20^{* * *}$ & 61 & $-0,081^{* * *}$ & 78,8 & $21,2^{* * *}$ \\
\hline Vitória & $22^{* * *}$ & $52^{*}$ & $-0,103^{* * *}$ & 76,3 & $23,7^{* *}$ \\
\hline Goiânia & $18^{* * *}$ & $46^{*}$ & $-0,073^{* * *}$ & 68,8 & $31,2^{* * *}$ \\
\hline São Luiz & $55^{* * *}$ & 62 & $-0,169^{* * *}$ & 70,8 & $29,2^{* * *}$ \\
\hline Belo Horizonte & $42^{* * *}$ & 129 & $-0,069^{* * *}$ & 24,8 & 75,2 \\
\hline Campo Grande & $20 * *$ & 97 & $-0,024$ & 42,9 & $57,1^{\circ}$ \\
\hline Cuiabá & 18 & $40^{*}$ & $-0,115^{* * *}$ & 65,6 & $34,4^{* *}$ \\
\hline Belém & $38 * *$ & 87 & $-0,104^{* * *}$ & 61,8 & $38,2 \cdots$ \\
\hline João Pessoa & $8 * * *$ & 97 & $0,068^{* *}$ & - & $284,1^{\cdots \cdots}$ \\
\hline Curitiba & $26^{* * *}$ & 95 & $-0,055^{* * *}$ & 36,9 & 63,1 \\
\hline Recife & $36^{* * *}$ & 123 & $-0,063^{* * *}$ & 71,8 & $28,2 \cdots$ \\
\hline Terezina & $23^{* * *}$ & 77 & $-0,053^{* * *}$ & 39,5 & $60,5^{*}$ \\
\hline Rio de Janeiro & $20^{* * * *}$ & 77 & $-0,051^{* * *}$ & 34,4 & 65,6 \\
\hline Natal & $43^{* * *}$ & 77 & $-0,129^{* * *}$ & 72,4 & $27,6 * \cdots$ \\
\hline Porto Velho & $18^{* * *}$ & 73 & $-0,057^{*}$ & 66,4 & $33,6 * *$ \\
\hline Boa Vista & $29^{* * * *}$ & 74 & $-0,090^{\circ \cdots *}$ & 78,4 & $21,6 * *$ \\
\hline Porto Alegre & $21^{* * *}$ & 118 & $-0,018$ & 33,5 & 66,5 \\
\hline Florianópolis & $18 * *$ & 72 & $-0,039$ & 39,9 & 60,1 \\
\hline Aracaju & $29^{* * *}$ & 91 & $-0,043$ & $\ldots$ & 101,2 \\
\hline São Paulo & $46^{* * *}$ & 137 & $-0,073^{* * *}$ & 65,6 & $34,4^{* * *}$ \\
\hline
\end{tabular}

"p $\leq 0,05 \quad *{ }^{*} \leq 0,01 \quad * * * 0,002 \quad$ em branco: $p>0,05$

$\mathrm{Na}$ análise de regressão, João Pessoa apresenta coeficiente de regressão positivo $(b=0,068 p<0,01)$. Dentre as demais capitais com coeficiente de regressão negativo, dezessete apresentam tendência 
exponencial de declínio da taxa de mortalidade $(p \leq 0,002)$. A maior taxa de declínio é alcançada em São Luiz $(b=-0,169 p \leq 0,002)$ e a menor em Manaus $(b=-0,041 p \leq 0,002)$ (Tabela 20).

Dentre as capitais com coeficiente de regressão negativo, em treze capitais a contribuição da intervenção médica na taxa de declínio da mortalidade gerou diferença significativa $(p \leq 0,002)$ entre a taxa estimada para 1992 e a esperada na sua ausência. Consequentemente, é possível afirmar que a intervenção médica contribui de forma expressiva para o declínio da mortalidade por pneumonia e gripe em 1992 nessas capitais. Entretanto, a contribuição da intervenção médica (PTD) e, especialmente, o efeito (RME) provocado sobre a taxa de mortalidade variam amplamente entre elas: em Rio Branco, a intervenção médica é responsável por $73,6 \%$ da taxa de declínio da mortalidade e torna a taxa estimada cerca de $1 / 4$ $(R M E=26,4)$ da esperada, e em Belém, a taxa estimada é cerca de $1 / 3(R M E=38,2)$ da esperada na ausência da intervenção médica. Nas demais capitais, a participação da intervenção médica na taxa de declínio, mesmo quando expressiva como em Cuiabá $(\mathrm{PTD}=65,6 \%)$, não gera um efeito capaz de produzir diferença significativa (ao nível de significância de ps0,002) entre a taxa de mortalidade da estimada para 1992 e a esperada na ausência da intervenção médica (Tabela 20).

\subsection{Impacto da intervenção na mortalidade por doença pulmonar obstrutiva crônica}

A taxa padronizada de mortalidade por doença pulmonar obstrutiva crônica (CID9 491-492) declina a 7,3\% aa., evoluindo de 8,55/100.000 para 3,31/100.000 no período de 1979 a 1992 no conjunto das capitais, quando ajustada por regressão loglinear (Tabela2). A intervenção médica contribui com cerca de $59,3 \%$ deste declínio em 1992 . Como este efeito ( $-4,3 \%$ aa.) não produz uma diferença significativa entre as taxas estimadas $(\mathrm{RME}=40,71 \mathrm{p}>0,05)$, é possível inferir que a intervenção médica contribui de forma pouco expressiva para o declínio da mortalidade por doença pulmonar obstrutiva crônica no conjunto das capitais em 1992 (Tabela 6).

No período de 1879-1982, duas capitais têm nível de mortalidade superior ao esperado $(\mathrm{p} \leq 0,002)$ : João Pessoa $(\mathrm{RMP}=305)$ e Curitiba $(\mathrm{RMP}=258)$ e Goiânia apresenta nível de mortalidade elevado $(\mathrm{RMP}=217 \mathrm{p}<0,01)$, mas cuja diferença com o esperado não tem significância estatística ao nível exigido ( $\mathbf{p} \leq 0,002)$. No período 1989-1992, nenhuma capital apresenta nível de mortalidade superior ao esperado $(\mathrm{p} \leq 0,002)$, apesar de Curitiba manter um nivel elevado de mortalidade $(\mathrm{RMP}=234 \mathrm{p}<0,05)($ Tabela 21$)$. 
Tabela 21. Razão de mortalidade padronizada (RMP), coeficiente de regressão loglinear, percentual da taxa de declínio da mortalidade devido à intervenção médica (PTD) e razão de mortalidade evitável $\left(\mathrm{RME}_{1992}\right)$ por doença pulmonar obstrutiva crônica (CID9 491-492) nas capitais brasileiras.

\begin{tabular}{|c|c|c|c|c|c|}
\hline \multirow[b]{2}{*}{ Capital } & \multicolumn{2}{|c|}{ RMP } & \multirow{2}{*}{$\begin{array}{l}\text { Coeficiente } \\
\text { de } \\
\text { Regressão } \\
\text { (b) }\end{array}$} & \multirow{2}{*}{$\begin{array}{r}\text { PTD } \\
\text { (\%) }\end{array}$} & \multirow[b]{2}{*}{$\mathrm{RME}$} \\
\hline & $1979-1982$ & 1989-1992 & & & \\
\hline Rio Branco & 77 & 103 & $-0,041$ & 57,4 & 42,6 \\
\hline Maceió & 97 & 57 & $-0,102^{* *}$ & 69,0 & 31,0 \\
\hline Macapá & 61 & 52 & $-0,053$ & 60,9 & 39,1 \\
\hline Manaus & 87 & 81 & $-0,099^{*}$ & 69,3 & $30,7^{\circ}$ \\
\hline Salvador & 51 & 66 & $-0,052$ & 37,9 & 62,1 \\
\hline Fortaleza & 77 & 66 & $-0,112^{* * *}$ & 36,5 & 63,5 \\
\hline Brasília & 37 & 57 & $-0,028$ & 58,0 & 42,0 \\
\hline Vitória & 39 & 85 & $-0,086^{*}$ & 70,5 & 29,5 \\
\hline Goiânia & $217^{* *}$ & 151 & $-0,087^{* * *}$ & 74,1 & $25,9 \cdots$ \\
\hline São Luiz & 162 & 70 & $-0,161^{* * *}$ & 67,5 & 32,5 \\
\hline Belo Horizonte & 140 & 92 & $-0,111^{* * *}$ & 56,3 & 43,7 \\
\hline Campo Grande & 124 & 119 & $-0,046$ & 57,1 & 42,9 \\
\hline Cuiabá & 77 & 57 & $-0,081$ & 46,3 & 53,7 \\
\hline Belém & 142 & 119 & $-0,097^{* * *}$ & 58,2 & 41,8 \\
\hline João Pessoa & $305^{* * *}$ & 143 & $-0,154^{* *}$ & 84,3 & $15,7^{* * *}$ \\
\hline Curitiba & $258^{* * *}$ & $234^{*}$ & $-0,084^{* * *}$ & 56,7 & $43,3^{*}$ \\
\hline Recife & 83 & 79 & $-0,084^{* *}$ & 78,5 & $21,5^{*}$ \\
\hline Terezina & 74 & 55 & $-0,080$ & 57,3 & 42,7 \\
\hline Rio de Janeiro & 94 & 87 & $-0,084^{* * *}$ & 57,5 & 42,5 \\
\hline Natal & 39 & 27 & $-0,129^{* * *}$ & 72,3 & 27,7 \\
\hline Porto Velho & 172 & 54 & $-0,160^{* * *}$ & 91,3 & $8,7^{* * *}$ \\
\hline Boa Vista & 122 & 76 & $-0,031$ & 54,0 & $46,0^{\circ}$ \\
\hline Porto Alegre & 79 & 162 & $-0,007$ & 23,6 & 76,4 \\
\hline Florianópolis & 174 & 110 & $-0,071$ & 60,8 & 39,2 \\
\hline Aracaju & 89 & 28 & $-0,130^{\circ}$ & 67,5 & 32,5 \\
\hline São Paulo & 92 & 111 & $-0,051^{* * *}$ & 54,2 & 45,8 \\
\hline
\end{tabular}

" $p \leq 0,05 \quad * p \leq 0,01 \quad * * p \leq 0,002 \quad$ em branco: $p>0,05$

$\mathrm{Na}$ análise de regressão, todas as capitais apresentam coeficiente de regressão negativo e, destas, dez apresentam tendência exponencial de declínio da taxa de mortalidade $(p \leq 0,002)$. As maiores taxas de 
declínio são de São Luiz $(b=-0,161 p \leq 0,002)$ e Porto Velho $(b=-0,160 p \leq 0,002)$ e a menor em São Paulo $(b=-0,051 p \leq 0,002)$ (Tabela 21).

Em três capitais a contribuição da intervenção médica na taxa de declínio da mortalidade gera diferença significativa ( $\leq \leq 0,002)$ entre a taxa estimada para 1992 e a esperada na sua ausência: Porto Velho $(\mathrm{RME}=8,7)$, João Pessoa ( $\mathrm{RME}=15,7)$ e Goiânia $(\mathrm{RME}=25,9)$. Consequentemente, é possível afirmar que a intervenção médica contribui de forma expressiva para o declínio da mortalidade por doença pulmonar obstrutiva crônica em 1992 nestas capitais. Entretanto, a contribuição da intervenção médica (PTD) e, especialmente, o efeito (RME) provocado sobre a taxa de mortalidade variam amplamente entre elas: em Goiânia, a intervenção médica é responsável por $74,1 \%$ da taxa de declínio da mortalidade e torna a taxa estimada cerca de $1 / 4(\mathrm{RME}=25,9)$ da esperada, e em Porto Velho, a taxa estimada é cerca de 1/10 $(\mathrm{RME}=8,7)$ da esperada na ausência da intervenção médica (Tabela 21).

Nas demais capitais, a participação da intervenção médica na taxa de declínio, mesmo quando expressiva como em Recife $(\mathrm{PTD}=78,5 \%)$, não gera um efeito capaz de produzir diferença significativa (ao nível de significância de $\mathrm{p} \leq 0,002)$ entre a taxa de mortalidade da estimada para 1992 e a esperada na ausência da intervenção médica (Tabela 21).

6.16. Impacto da intervenção médica na mortalidade por asma

A taxa padronizada de mortalidade por asma (CID9 493) declina a 3,4\% aa., evoluindo de 0,70/100.000 para 0,45/100.000 no período de 1979 a 1992 no conjunto das capitais, quando ajustada por regressão loglinear (Tabela 2). A intervenção médica contribui com cerca de $32,3 \%$ deste declínio em 1992. Como este efeito $(-1,1 \%$ aa.) não produz uma diferença significativa entre a taxa estimada e a esperada na ausência da intervenção $(\mathrm{RME}=67,71 \mathrm{p}>0,05)$, é possível inferir que a intervenção médica contribui de forma pouco expressiva para o declínio da mortalidade por asma no conjunto das capitais em 1992 (Tabela 6). 
Tabela 22. Razão de mortalidade padronizada (RMP), coeficiente de regressão loglinear, percentual da taxa de declínio da mortalidade devido à intervenção médica (PTD) e razão de mortalidade evitável (RME ${ }_{1992)}$ por asma (CID9 493) nas capitais brasileiras.

\begin{tabular}{|c|c|c|c|c|c|}
\hline \multirow[b]{2}{*}{ Capital } & \multicolumn{2}{|c|}{ RMP } & \multirow{2}{*}{$\begin{array}{l}\text { Coeficiente } \\
\text { de } \\
\text { Regressão } \\
\quad \text { (b) }\end{array}$} & \multirow{2}{*}{$\begin{array}{r}\text { PTD } \\
(\%)\end{array}$} & \multirow[b]{2}{*}{ RME } \\
\hline & $1979-1982$ & 1989-1992 & & & \\
\hline Rio Branco & - & --- & - & -- & - \\
\hline Maceió & 103 & 34 & $-0,055$ & 62,7 & 37,3 \\
\hline Macapá & -- & -- & -- & - & - \\
\hline Manaus & 70 & 29 & $-0,050$ & 42,2 & 57,8 \\
\hline Salvador & 149 & 124 & $-0,051$ & 37,2 & 62,8 \\
\hline Fortaleza & 126 & 137 & $-0,011$ & - & 233,7 \\
\hline Brasília & 41 & 95 & 0,065 & - & 141,6 \\
\hline Vitória & 190 & 109 & $-0,077^{*}$ & 66,7 & 33,3 \\
\hline Goiânia & 38 & 30 & $-0,058$ & 61,8 & 38,2 \\
\hline São Luiz & 333 & 174 & $-0,090$ & 17,7 & 82,3 \\
\hline Belo Horizonte & 107 & 71 & $-0,091^{*}$ & 42,9 & 57,1 \\
\hline Campo Grande & 20 & 100 & $-0,037$ & 51,7 & 48,3 \\
\hline Cuiabá & 177 & 20 & $-0,135^{\circ}$ & 73,3 & 26,7 \\
\hline Belém & 208 & 94 & $-0,159^{* * *}$ & 81,4 & 18,6 \\
\hline João Pessoa & 98 & 48 & $-0,072$ & 54,1 & 45,9 \\
\hline Curitiba & 46 & 109 & 0,018 & $\ldots$ & 163,0 \\
\hline Recife & 61 & 87 & $-0,005$ & 40,0 & 60,0 \\
\hline Terezina & 150 & 71 & $-0,097^{*}$ & 65,9 & 34,1 \\
\hline Rio de Janeiro & 109 & 95 & $-0,044^{* *}$ & 28,2 & 71,8 \\
\hline Natal & 77 & 52 & 0,002 & - & 150,9 \\
\hline Porto Velho & 129 & 69 & $-0,070^{*}$ & 71,8 & 28,2 \\
\hline Boa Vista & $\ldots$ & 45 & $\ldots$ & - & - \\
\hline Porto Alegre & --- & 140 & 0,016 & - & 103,2 \\
\hline Florianópolis & 149 & 195 & $-0,048$ & 47,0 & 53,0 \\
\hline Aracaju & --- & 41 & $-0,086$ & 41,8 & 58,2 \\
\hline São Paulo & 94 & 124 & $-0,010$ & 22,2 & 77,8 \\
\hline
\end{tabular}

${ }^{*} \mathrm{p} \leq 0,05 \quad{ }^{* *} \mathrm{p} \leq 0,01 \quad{ }^{* * *} \mathrm{p} \leq 0,002 \quad$ em branco: $\mathrm{p}>0,05$

Em várias capitais, não há registro de óbito por asma em diversos anos do período de estudo. Apesar dos níveis elevados de mortalidade encontrados em São Luiz ( $R M P=333$ ), Belém $(R M P=208)$, Vitória $(R M P=190)$ e Cuiabá $(R M P=177)$ no período 1979-1982, em Florianópolis $(R M P=195)$ e São Luiz 
(RMP=174) no período de $1989-1992$, nenhuma capital apresenta nível de mortalidade com diferença significativa do esperado $(p \leq 0,002)$ (Tabela 22).

Dentre as vinte e três capitais analisadas, dezenove possuem coeficiente de regressão negativo mas apenas para Belém $(\mathrm{RME}=18,6 \mathrm{p} \leq 0,002)$ pode ser afirmado que a intervenção médica contribui de forma expressiva para o declínio da taxa de mortalidade por asma. Nesta capital, a intervenção médica é responsável por $81,4 \%$ da taxa de declínio da mortalidade tornando a taxa estimada em cerca de $1 / 5 \mathrm{da}$ esperada na ausência da intervenção médica (Tabela 22).

Nas demais capitais, a participação da intervenção médica na taxa de declinio, mesmo quando expressiva como em Cuiabá ( $\mathrm{PTD}=73,3 \%$ ), Porto Velho $(\mathrm{PTD}=71,8)$ e Vitória ( $\mathrm{PTD}=66,7 \%)$, não gera um efeito capaz de produzir diferença significativa (ao nível de significância de $\mathrm{p} \leq 0,002$ ) entre a taxa de mortalidade da estimada para 1992 e a esperada na ausência da intervenção médica (Tabela 22). Nas capitais com coeficiente de regressão positivo, a influência da assistência médica sobre a mortalidade não é mensurável pelo modelo de análise proposto.

\subsection{Impacto da intervenção médica na mortalidade por úlcera gástrica, duodenal e jejunal}

A taxa padronizada de mortalidade por úlcera gástrica, duodenal e jejunal (CID9 531-534) declina a 4,2\% aa., evoluindo de 2,68/100.000 para 1,56/100.000 no período de 1979 a 1992 no conjunto das capitais, quando ajustada por regressão loglinear (Tabela 2). A intervenção médica contribui com cerca de $38,6 \%$ deste declínio em 1992. Como este efeito $(-1,33 \%$ aa.) não produz uma diferença significativa entre a taxa estimada e a esperada na ausência da intervenção ( $R M E=61,39 p>0,05)$, é possível inferir que a intervenção médica contribui de forma pouco expressiva para o declínio da mortalidade por úlcera gástrica, duodenal e jejunal no conjunto das capitais em 1992 (Tabela 6).

No período de 1879-1982, duas capitais têm nível de mortalidade diferente do esperado ( $p \leq 0,002)$ : Florianópolis ( $\mathrm{RMP}=68)$ com nível de mortalidade inferior ao esperado e São Luiz (RMP=337) com nível de mortalidade superior ao esperado; Porto Velho também apresenta nível de mortalidade elevado 
$(\mathrm{RMP}=251 \mathrm{p}<0,05)$, mas cuja diferença com o esperado não em significância estatística ao nível exigido $(p \leq 0,002)$. No periodo 1898-1992, nenhuma capital apresenta nível de mortalidade diferente do esperado $(p \leq 0,002)$, apesar de São Luiz manter um nível elevado de mortalidade $(R M P=204 p>0,05)($ Tabela 23).

Tabela 23. Razão de mortalidade padronizada (RMP), coeficiente de regressão loglinear, percentual da taxa de declínio da mortalidade devido à intervenção médica (PTD) e razão de mortalidade evitável $\left(\mathrm{RME}_{1992}\right)$ por úlcera gástrica, duodenal e jejunal (CID9 531-534) nas capitais brasileiras.

\begin{tabular}{|c|c|c|c|c|c|}
\hline \multirow[b]{2}{*}{ Capital } & \multicolumn{2}{|c|}{ RMP } & \multirow{2}{*}{$\begin{array}{l}\text { Coeficiente } \\
\text { de } \\
\text { Regressão } \\
\text { (b) }\end{array}$} & \multirow{2}{*}{$\begin{array}{r}\text { PTD } \\
(\%)\end{array}$} & \multirow[b]{2}{*}{ RME } \\
\hline & 1979-1982 & 1989-1992 & & & \\
\hline Rio Branco & 168 & 101 & $-0,036$ & 54,9 & 45,1 \\
\hline Maceió & 46 & 79 & $-0,025$ & 15,6 & 84,4 \\
\hline Macapá & 164 & 74 & $-0,149^{* *}$ & 88,7 & $11,3^{* *}$ \\
\hline Manaus & 185 & 66 & $-0,152^{* * *}$ & 84,5 & 15,5 \\
\hline Salvador & 75 & 132 & 0,016 & -- & 149,3 \\
\hline Fortaleza & 139 & 120 & $-0,069^{* *}$ & - & 110,5 \\
\hline Brasilia & 110 & 88 & $-0,073^{* * *}$ & 76,5 & 23,5 \\
\hline Vitória & 76 & 117 & 0,007 & 0,2 & 99,8 \\
\hline Goiânia & 131 & 84 & $-0,100^{* * *}$ & 78,1 & 21,9 \\
\hline São Luiz & $337^{* * *}$ & 204 & $-0,091^{* * *}$ & 18,6 & 81,4 \\
\hline Belo Horizonte & 97 & 92 & $-0,048^{*}$ & 0,8 & 99,2 \\
\hline Campo Grande & 106 & 129 & $-0,037$ & 51,6 & 48,4 \\
\hline Cuiabá & 86 & 66 & $-0,063$ & 31,9 & 68,1 \\
\hline Belém & 189 & 100 & $-0,090^{* * *}$ & 57,3 & 45,7 \\
\hline João Pessoa & 73 & 44 & $-0,105^{*}$ & 70,0 & 30,0 \\
\hline Curitiba & 87 & 115 & $-0,013$ & -- & 109,2 \\
\hline Recife & 57 & 87 & $-0,004$ & 39,3 & 60,7 \\
\hline Terezina & 108 & 67 & $-0,091^{*}$ & 63,1 & 36,9 \\
\hline Rio de Janeiro & 107 & 91 & $-0,063^{* * *}$ & 43,6 & 56,4 \\
\hline Natal & 82 & 39 & $-0,098^{* *}$ & 58,7 & 41,3 \\
\hline Porto Velho & $251^{*}$ & 83 & $-0,140^{* *}$ & 88,7 & $11,3^{*+}$ \\
\hline Boa Vista & 49 & 41 & $-0,115^{*}$ & 84,4 & $15,6^{*}$ \\
\hline Porto Alegre & 63 & 93 & 0,011 & 4,0 & 96,0 \\
\hline Florianópolis & $68^{* * *}$ & 98 & $-0,029$ & 32,2 & 67,8 \\
\hline Aracaju & 77 & 61 & $-0,081$ & 38,3 & 61,7 \\
\hline São Paulo & 94 & 07 & $-0,029^{* * *}$ & 39,5 & 60,5 \\
\hline
\end{tabular}

${ }^{*} \mathrm{p} \leq 0,05 \quad *{ }^{*} \mathrm{p} \leq 0,01 \quad * * \mathrm{p} \leq 0,002 \quad$ em branco: $p>0,05$ 
A análise de regressão revela que vinte e três capitais têm coeficiente negativo, mas que apenas sete apresentam tendência exponencial de declínio $(p \leq 0,002)$. A maior taxa de declínio é encontrada em Manaus $(b=-0,152 p \leq 0,002)$ e a menor em São Paulo $(b=-0,029 p \leq 0,002)$ (Tabela 23).

Nenhuma capital apresenta RME com significância estatística ao nivel exigido de $\mathrm{p} \leq 0,002$. Consequentemente, é possivel inferir que a intervenção médica contribui de forma pouco expressiva para o declínio da mortalidade por úlcera gástrica, duodenal e jejunal nas capitais em 1992, seja porque não há declínio no período, seja porque a taxa estimada para 1992 não difere significativamente daquela esperada na ausência da intervenção médica (Tabela 23).

6.18. Impacto da intervenção médica na mortalidade por apendicite

A taxa padronizada de mortalidade por apendicite cresce $9,5 \%$ aa., apesar de não apresentar uma tendência exponencial de crescimento ao nível de significância exigido $(b=0,095 p<0,01)$, evoluindo de 0,39/100.000 para 1,35/100.000 no conjunto das capitais, quando ajustada por regressão loglinear (Tabela 2). Consequentemente, não é possivel aferir a contribuição da intervenção médica na definição do nível de mortalidade em 1992 no conjunto das capitais pelo modelo de análise proposto (Tabela 6).

No período de 1979-1982, apenas Cuiabá (RMP=80 p $\leq 0,002$ ) apresenta nível de mortalidade inferior ao esperado e Porto Velho nível de mortalidade superior ao esperado ( $R M P=217 \mathrm{p} \leq 0,002)$, apesar de Belém ( $R M P=387)$, São Luiz $(R M P=325)$, Macapá $(R M P=212)$, Fortaleza $(R M P=192)$ e Manaus $(\mathrm{RMP}=168)$ apresentarem níveis elevados de mortalidade. No período de 1989-1992, apenas Boa Vista $(R M P=41 p \leq 0,002)$ apresenta nível de mortalidade inferior ao esperado. São Luiz ( $R M P=204 p>0,05)$ mantém nível elevado de mortalidade neste período, mas sem significância estatística (Tabela 24).

A análise de regressão revela que nenhuma capital apresenta tendência exponencial de declínio da taxa de mortalidade por apendicite (Curitiba apresenta tendência exponencial de crescimento, $b=0,148$ 
$p \leq 0,002)$. Sete capitais apresentam coeficiente de regressão negativo sem significância estatística (Tabela 24).

Tabela 24 . Razão de mortalidade padronizada (RMP), coeficiente de regressão loglinear, percentual da taxa de declínio da mortalidade devido à intervenção médica (PTD) e razão de mortalidade evitável $\left(\mathrm{RME}_{1922}\right)$ por apendicite (CID9 540-543) nas capitais brasileiras.

\begin{tabular}{|c|c|c|c|c|c|}
\hline \multirow[b]{2}{*}{ Capital } & \multicolumn{2}{|c|}{ RMP } & \multirow{2}{*}{$\begin{array}{l}\text { Coeficiente } \\
\text { de } \\
\text { Regressão } \\
\text { (b) }\end{array}$} & \multirow{2}{*}{$\begin{array}{c}\text { PTD } \\
(\%)\end{array}$} & \multirow[b]{2}{*}{ RME } \\
\hline & $1979-1982$ & 1989-1992 & & & \\
\hline Rio Branco & 54 & 101 & 0,111 & -- & 304,3 \\
\hline Maceió & 52 & 79 & 0,080 & - & 330,3 \\
\hline Macapá & 212 & 74 & $-0,050$ & 59,2 & 40,8 \\
\hline Manaus & 168 & 66 & 0,001 & - & 112,2 \\
\hline Salvador & 79 & 132 & $0,147^{* *}$ & - & $824,3^{* * *}$ \\
\hline Fortaleza & 192 & 119 & 0,055 & - & $556,2^{*}$ \\
\hline Brasilia & 51 & 88 & $0,118^{* *}$ & - & 280,4 \\
\hline Vitória & 60 & 126 & 0,050 & - & 173,8 \\
\hline Goiânia & 138 & 84 & 0,066 & - & 190,2 \\
\hline São Luiz & 325 & 204 & 0,036 & - & $421,7^{*}$ \\
\hline Belo Horizonte & 88 & 91 & $0,112^{* *}$ & - & $798,1^{* *}$ \\
\hline Campo Grande & 76 & 128 & $0,123^{* *}$ & $\ldots$ & 386,1 \\
\hline Cuiabá & $80^{* * *}$ & 66 & 0,028 & - & 221,5 \\
\hline Belém & 387 & 99 & $-0,033$ & 3,7 & 96,3 \\
\hline João Pessoa & 24 & 44 & $-0,004$ & - & 111,0 \\
\hline Curitiba & 72 & 117 & $0,148 * *$ & $\cdots$ & $881,6^{* * *}$ \\
\hline Recife & 84 & 88 & 0,110 & -- & 266,6 \\
\hline Terezina & - & 67 & 0,057 & -- & 252,5 \\
\hline Rio de Janeiro & 86 & 91 & $0,099^{*}$ & --- & 463,1 \\
\hline Natal & 128 & 39 & $-0,017$ & - & 118,9 \\
\hline Porto Velho & $217^{* * *}$ & 82 & $-0,011$ & 38,8 & 61,2 \\
\hline Boa Vista & 82 & $41^{* * *}$ & $-0,081$ & 75,8 & 24,2 \\
\hline Porto Alegre & 79 & 93 & $0,135^{*}$ & - & 483,7 \\
\hline Florianópolis & - & 98 & 0,022 & - & 132,4 \\
\hline Aracaju & 117 & 61 & $-0,011$ & - & 153,3 \\
\hline São Paulo & 90 & 107 & $0,115^{* *}$ & - & 394,7 \\
\hline
\end{tabular}

${ }^{*} \mathrm{p} \leq 0,05 \quad \cdots p \leq 0,01 \quad \cdots p \leq 0,002 \quad$ em branco: $p>0,05$ 
Nenhuma capital apresenta RME com significância estatística. Consequentemente, é possível afirmar que a intervenção médica contribui de forma pouco expressiva na definição do nível da mortalidade por apendicite nas capitais, seja porque não há declínio no período, seja porque a taxa estimada para 1992 não difere significativamente daquela esperada na ausência da intervenção médica (Tabela 24).

6.19. Impacto da intervenção médica na mortalidade por hérnia da cavidade abdominal

A taxa padronizada de mortalidade por hérnia abdominal (CID9 550-553) declina a 2,8\% aa., evoluindo de 0,36/100.000 para 025,/100.000 no período de 1979 a 1992 no conjunto das capitais, quando ajustada por regressão loglinear (Tabela2). A intervenção médica contribui com cerca de $27,1 \%$ deste declínio em 1992. Como este efeito $(-0,8, \%$ aa.) não produz uma diferença significativa entre a taxa estimada e a esperada na ausência da intervenção $(R M E=72,85, p>0,05)$, é possivel inferir que a intervenção médica contribui de forma pouco expressiva para o declínio da mortalidade por hémia abdominal no conjunto das capitais em 1992 (Tabela 6).

Durante todo o período estudado, nenhuma capital apresentou nivel de mortalidade diferente do esperado, com significância estatística (Tabela 25).

Contudo, deve ser destacado que Boa Vista $(R M P=453)$, Macapá ( $R M P=329)$, Belém $(R M P=282)$, Porto Velho $(\mathrm{RMP}=203)$, Maceió $(\mathrm{RMP}=186)$ e Campo Grande $(\mathrm{RMP}=156)$ apresentam nível de mortalidade elevado no periodo de 1979-1982, e São Luiz ( $R M P=209$ ), Aracaju ( $R M P=201)$, Belém (RMP=199), Campo Grande ( $R M P=196)$, Terezina ( $R M P=173$ ), Rio Branco ( $R M P=168)$ e Recife $(\mathrm{RMP}=155)$ apresentam nível de mortalidade elevado no período de 1989-1992 (Tabela 25).

A análise de regressão revela que vinte e uma capitais têm coeficiente de regressão negativo e cinco capitais têm coeficiente de regressão positivo. Contudo, nenhuma capital apresenta tendência exponencial de declínio ou crescimento da mortalidade por hérnia abdominal ao nível de significância estatística exigido 
$(p \leq 0,002)$. As maiores taxas de declínio são de Macapá $(b=-0,129 p>0,05)$ e Manaus $(b=-0,128 p \leq 0,01)$. As maiores taxas de crescimento são de João Pessoa $(b=0,072 p>0,05)$ e Aracaju $(b=0,060 p>0,05)$.

Tabela 25. Razão de mortalidade padronizada (RMP), coeficiente de regressão loglinear, percentual da taxa de declínio da mortalidade devido à intervenção médica (PTD) e razão de mortalidade evitável $\left(\mathrm{RME}_{1992}\right)$ por hérnia abdominal (CID9 550-553) nas capitais brasileiras.

\begin{tabular}{|c|c|c|c|c|c|}
\hline \multirow[b]{2}{*}{ Capital } & \multicolumn{2}{|c|}{ RMP } & \multirow{2}{*}{$\begin{array}{l}\text { Coeficiente } \\
\text { de } \\
\text { Regressão } \\
\text { (b) }\end{array}$} & \multirow{2}{*}{$\begin{array}{r}\text { PTD } \\
(\%)\end{array}$} & \multirow[b]{2}{*}{$\mathrm{RME}$} \\
\hline & $1979-1982$ & $1989-1992$ & & & \\
\hline Rio Branco & 59 & 168 & 0,038 & --- & 117,8 \\
\hline Maceió & 186 & 79 & $-0,104$ & 69,7 & 30,3 \\
\hline Macapá & 329 & -- & $-0,129$ & 85,3 & 14,7 \\
\hline Manaus & 204 & 48 & $-0,128^{* *}$ & 79,0 & 21,0 \\
\hline Salvador & 91 & 52 & $-0,067^{*}$ & 49,3 & 50,7 \\
\hline Fortaleza & 132 & 72 & $-0,110^{* *}$ & 35,2 & 64,8 \\
\hline Brasilia & 82 & 106 & 0,014 & 27,5 & 72,5 \\
\hline Vitória & 80 & 128 & $-0,002$ & 12,5 & 87,5 \\
\hline Goiânia & 149 & 40 & $-0,102^{*}$ & 78,5 & 21,5 \\
\hline São Luiz & 111 & 209 & $-0,051$ & - & 135,5 \\
\hline Belo Horizonte & 126 & 70 & $-0,079$ & 33,7 & 66,3 \\
\hline Campo Grande & 156 & 196 & $-0,060^{*}$ & 64,1 & 35,9 \\
\hline Cuiabá & 32 & 45 & $-0,035$ & 2,1 & 97,9 \\
\hline Belém & 282 & 199 & $-0,075^{*}$ & 44,1 & 55,9 \\
\hline João Pessoa & -- & 54 & 0,072 & - & 299,4 \\
\hline Curitiba & 67 & 98 & 0,002 & -- & 132,4 \\
\hline Recife & 100 & 155 & $-0,010$ & 43,8 & 56,2 \\
\hline Terezina & 115 & 173 & $-0,081$ & 57,9 & 42,1 \\
\hline Rio de Janeiro & 58 & 87 & $-0,010$ & -- & 111,6 \\
\hline Natal & 109 & 39 & $-0,043$ & 15,9 & 84,1 \\
\hline Porto Velho & 203 & 30 & $-0,099$ & 80,7 & 19,3 \\
\hline Boa Vista & 453 & 96 & $-0,112$ & 83,8 & $16,2^{\circ}$ \\
\hline Porto Alegre & 87 & 79 & $-0,058$ & 60,7 & 39,3 \\
\hline Florianópolis & 60 & 46 & $-0,067^{*}$ & 58,5 & 41,5 \\
\hline Aracaju & 57 & 201 & 0,060 & -- & 384,2 \\
\hline São Paulo & 108 & 120 & $-0,014$ & 25,9 & 74,1 \\
\hline
\end{tabular}

${ }^{*} \mathrm{p} \leq 0,05 \quad{ }^{* *} \mathrm{p} \leq 0,01 \quad{ }^{* * *} \mathrm{p} \leq 0,002 \quad$ em branco: $p>0,05$ 
Nenhuma capital apresenta RME com significância estatística ( $p \leq 0,002)$. Consequentemente, é possível afirmar que a intervenção médica contribui de forma pouco expressiva na definição do nível da mortalidade por hémia abdominal nas capitais, seja porque não há declínio no período, seja porque a taxa estimada para 1992 não difere significativamente daquela esperada na ausência da intervenção médica.

6.20. Impacto da intervenção médica na mortalidade por colelitíase e colecistite

A taxa padronizada de mortalidade por colelitiase e colecistite (CID9 574-575) declina a 1,7\% aa., evoluindo de $0,61 / 100.000$ para $0,49 / 100.000$ no período de 1979 a 1992 no conjunto das capitais, quando ajustada por regressão loglinear (Tabela 2). A intervenção médica contribui com cerca de $16,1 \%$ deste declínio em 1992 . Como este efeito $(-0,27 \%$ aa.) não produz uma diferença significativa entre as taxas estimadas $(\mathrm{RME}=83,94 \mathrm{p}>0,05)$, é possível afirmar que a intervenção médica contribui de forma pouco expressiva para o declínio da mortalidade por colelitiase e colecistite no conjunto das capitais em 1992 (Tabela 6).

No periodo de 1979-1982, nenhuma capital apresentou nível de mortalidade com diferença significativa $(p \leq 0,002)$ do esperado. No período de 1989-1992, Boa Vista apresenta nível de mortalidade superior ao esperado $(\mathrm{RMP}=170 \mathrm{p} \leq 0,002)$. Contudo, deve ser destacado que Terezina $(\mathrm{RMP}=194)$, Belém $(\mathrm{RMP}=164)$, Curitiba $(\mathrm{RMP}=158)$ e São Luiz $(\mathrm{RMP}=157)$ apresentam nível de mortalidade elevado neste período (Tabela 26).

A análise de regressão revela que dezoito capitais têm coeficiente de regressão negativo e oito capitais têm coeficiente de regressão positivo. Contudo, apenas Fortaleza $(b=-0,138 p \leq 0,002)$ apresenta tendência exponencial de declínio da taxa de mortalidade por colelitiase e colecistite. As demais capitais não apresentam tendência exponencial de declínio ou crescimento da mortalidade ao nível de significância estatística exigido $(p \leq 0,002)$. As maiores taxas de declínio, além de Fortaleza, são de Cuiabá $(b=-0,165$ $\mathrm{p} \leq 0,05)$, Belo Horizonte $(b=-0,128 \mathrm{p} \leq 0,01)$ e Porto Velho $(b=-0,103 \mathrm{p}>0,05)$. As maiores taxas de crescimento são de Salvador $(b=0,044 p>0,05)$ e Vitória $(b=0,032 p \leq 0,05)$ (Tabela 26). 
Tabela 26. Razão de mortalidade padronizada (RMP), coeficiente de regressão loglinear, percentual da taxa de declínio da mortalidade devido à intervenção médica (PTD) e razão de mortalidade evitável $\left(\mathrm{RME}_{1992}\right)$ por colelitíase e colecistite (CID9 574-575) nas capitais brasileiras.

\begin{tabular}{|c|c|c|c|c|c|}
\hline \multirow[b]{2}{*}{ Capital } & \multicolumn{2}{|c|}{$\mathrm{RMP}$} & \multirow{2}{*}{$\begin{array}{l}\text { Coeficiente } \\
\text { de } \\
\text { Regressão } \\
\text { (b) }\end{array}$} & \multirow{2}{*}{$\begin{array}{c}\text { PTD } \\
\text { (\%) }\end{array}$} & \multirow[b]{2}{*}{$\mathrm{RME}$} \\
\hline & $1979-1982$ & $1989-1992$ & & & \\
\hline Rio Branco & 15 & 22 & $-0,072^{* *}$ & 71,6 & 28,4 \\
\hline Maceió & 13 & 146 & $-0,014$ & 1,6 & 98,4 \\
\hline Macapá & 23 & --- & 0,011 & 9,3 & 90,7 \\
\hline Manaus & 50 & 146 & $-0,026$ & 20,8 & 79,2 \\
\hline Salvador & 16 & 99 & 0,044 & - & 215,6 \\
\hline Fortaleza & 54 & 55 & $-0,138^{* * *}$ & 54,6 & 45,4 \\
\hline Brasília & 21 & 95 & 0,008 & 32,7 & 67,3 \\
\hline Vitória & 19 & 72 & $-0,032^{\circ}$ & 40,3 & 59,7 \\
\hline Goiânia & 26 & 115 & 0,009 & 8,2 & 91,2 \\
\hline São Luiz & 69 & 157 & $-0,079$ & 4,8 & 95,2 \\
\hline Belo Horizonte & -- & 67 & $-0,105^{* *}$ & 52,8 & 47,2 \\
\hline Campo Grande & 8 & 110 & 0,030 & -. & 115,3 \\
\hline Cuiabá & 80 & 42 & $-0,164^{*}$ & 82,0 & 18,1 \\
\hline Belém & 46 & 164 & $-0,030$ & 0,6 & 99,4 \\
\hline João Pessoa & 24 & 90 & 0,011 & $\ldots$ & 134,9 \\
\hline Curitiba & 58 & 158 & $-0,036$ & 19,0 & 81,0 \\
\hline Recife & 30 & 114 & $-0,016$ & 48,5 & 51,5 \\
\hline Terezina & 47 & 194 & $-0,050$ & 37,1 & 62,9 \\
\hline Rio de Janeiro & 41 & 63 & $-0,087^{* *}$ & 58,8 & 41,2 \\
\hline Natal & 30 & 81 & $-0,071$ & 41,5 & 58,5 \\
\hline Porto Velho & 79 & 86 & $-0,103$ & 81,5 & 18,5 \\
\hline Boa Vista & --- & $170^{*+*}$ & 0,001 & 29,8 & 70,2 \\
\hline Porto Alegre & 30 & 66 & $-0,026$ & 40,5 & 59,5 \\
\hline Florianópolis & 13 & 74 & $-0,048$ & 46,8 & 53,2 \\
\hline Aracaju & 26 & 162 & 0,001 & -.. & 180,4 \\
\hline São Paulo & 40 & 120 & $-0,030$ & 40,3 & 59,7 \\
\hline
\end{tabular}

" $\mathrm{p} \leq 0,05 \quad *{ }^{* *} \mathrm{p} \leq 0,01 \quad{ }^{* *} \mathrm{p} \leq 0,002 \quad$ em branco: $p>0,05$

Nenhuma capital apresenta RME com significância estatística $(p \leq 0,002)$. Consequentemente, é possível afirmar que a intervenção médica contribui de forma pouco expressiva na definição do nível da 
mortalidade por colelitíase e colecistite nas capitais, seja porque não há declínio no periodo, seja porque a taxa estimada para 1992 não difere significativamente daquela esperada na ausência da intervenção médica.

6.21. Impacto da intervenção médica na mortalidade por nefrite e nefrose

A taxa padronizada de mortalidade por nefrite e nefrose (CID9 580-589) declina a 3,5\% aa., evoluindo de 5,82/100.000 para 3,68/100.000 no período de 1979 a 1992 no conjunto das capitais, quando ajustada por regressão loglinear (Tabela 2). A intervenção médica contribui com cerca de 33,5\% deste declínio em 1992. Como este efeito (-1,2\% aa.) não produz uma diferença significativa entre a taxa estimada e a esperada na ausência da intervenção ( $R M E=66,5 \quad p>0,05$ ), é possível afirmar que a intervenção médica contribui de forma pouco expressiva para o declínio da taxa de mortalidade por nefrite e nefrose no conjunto das capitais em 1992 (Tabela 6).

No período de 1979-1982, Belém $(\mathrm{RMP}=228 \mathrm{p} \leq 0,002)$ e São Luiz $(\mathrm{RMP}=248 \mathrm{p} \leq 0,002)$ apresentam nivel de mortalidade superior ao esperado. Neste período, Macapá ( $R M P=175$ ), Manaus $(\mathrm{RMP}=171)$ e Boa Vista (RMP=164) apresentam nível elevado de mortalidade. No período de 1989-1992, nenhuma capital apresenta nível de mortalidade diferente do esperado, apesar de Aracaju (RMP=240 $\mathrm{p} \leq 0,05)$ e Cuiabá (RMP=127 p $\leq 0,002)$ apresentarem níveis elevados (Tabela 27).

A análise de regressão revela que vinte e duas capitais têm coeficiente de regressão negativo e quatro capitais têm coeficiente de regressão positivo. Dentre as vinte e duas capitais com coeficiente de regressão negativo, apenas em Boa Vista $(\mathrm{RME}=16,4 \mathrm{p} \leq 0,002)$ a contribuição da intervenção médica de $83,6 \%$ da taxa de declínio da mortalidade por nefrite e nefrose produz uma diferença significativa entre a taxa estimada para 1992 e a esperada na ausência de intervenção médica (Tabela 27).

Nas demais capitais, a participação da intervenção médica na taxa de declínio, mesmo quando expressiva como em Macapá ( $\mathrm{PTD}=79,4 \%$ ), Florianópolis ( $\mathrm{PTD}=71 \%$ ) e Manaus $(\mathrm{PTD}=67,8 \%$ ), não gera um efeito capaz de produzir diferença significativa (ao nível de significância de $p \leq 0,002$ ) entre a taxa de mortalidade da estimada para 1992 e a esperada na ausência da intervenção médica (Tabela 27). Nas 
capitais com coeficiente de regressão positivo, a influência da assistência médica sobre a taxa de declínio da mortalidade não é mensurável pelo modelo de análise proposto.

Tabela 27. Razão de mortalidade padronizada (RMP), coeficiente de regressão loglinear, percentual da taxa de declínio da mortalidade devido à intervenção médica (PTD) e razão de mortalidade evitável $\left(\mathrm{RME}_{1992}\right)$ por nefrite e nefrose (CID9 580-589) nas capitais brasileiras.

\begin{tabular}{|c|c|c|c|c|c|}
\hline \multirow[b]{2}{*}{ Capital } & \multicolumn{2}{|c|}{ RMP } & \multirow{2}{*}{$\begin{array}{l}\text { Coeficiente } \\
\text { de } \\
\text { Regressão } \\
\text { (b) }\end{array}$} & \multirow{2}{*}{$\begin{array}{r}\text { PTD } \\
(\%)\end{array}$} & \multirow[b]{2}{*}{$\mathrm{RME}$} \\
\hline & 1979-1982 & $1989-1992$ & & & \\
\hline Rio Branco & $29^{* *}$. & 111 & $-0,011$ & 37,3 & 62,7 \\
\hline Maceió & 103 & 102 & $-0,019$ & 8,3 & 91,7 \\
\hline Macapá & 175 & 87 & $-0,103^{* *}$ & 79,4 & $20,6^{* *}$ \\
\hline Manaus & 171 & 86 & $-0,095^{* * *}$ & 67,8 & $32,2^{*}$ \\
\hline Salvador & 138 & 151 & $-0,029^{* *}$ & 16,4 & 83,6 \\
\hline Fortaleza & 129 & 100 & $-0,064^{* * *}$ & - & 118,3 \\
\hline Brasília & 86 & 76 & $-0,042^{* *}$ & 65,0 & 35,0 \\
\hline Vitória & 63 & 102 & 0,014 & -- & 108,1 \\
\hline Goiânia & 94 & 113 & $-0,020$ & 37,6 & 62,4 \\
\hline São Luiz & $248^{* * *}$ & 95 & $-0,140^{* * *}$ & 57,3 & 42,7 \\
\hline Belo Horizonte & 158 & 128 & $-0,056^{* * *}$ & 10,6 & 89,4 \\
\hline Campo Grande & 116 & 115 & $-0,018$ & 38,0 & 62,0 \\
\hline Cuiabá & 127 & $213^{*}$ & $-0,007$ & -- & 139,7 \\
\hline Belém & $228^{* *}$ & 211 & $-0,042^{* *}$ & 14,2 & 85,8 \\
\hline João Pessoa & 107 & 181 & 0,019 & -- & 150,4 \\
\hline Curitiba & 79 & 79 & $-0,041^{* *}$ & 24,1 & 75,9 \\
\hline Recife & 142 & 111 & $-0,054^{* *}$ & 68,2 & $31,8^{*}$ \\
\hline Terezina & 103 & 130 & $-0,030$ & 18,7 & 81,3 \\
\hline Rio de Janeiro & 67 & 67 & $-0,032^{* * *}$ & 15,7 & 84,3 \\
\hline Natal & 100 & 79 & $-0,060$ & 32,6 & 67,4 \\
\hline Porto Velho & 71 & 102 & 0,000 & 29,7 & 70,3 \\
\hline Boa Vista & 164 & 106 & $-0,111^{*}$ & 83,6 & $16,4^{* * *}$ \\
\hline Porto Alegre & 101 & 76 & $-0,059^{* * *}$ & 61,1 & 38,9 \\
\hline Florianópolis & 104 & 66 & $-0,095^{*}$ & 71,0 & 29,0 \\
\hline Aracaju & 124 & $240^{*}$ & 0,031 & -- & $264,7^{* *}$ \\
\hline São Paulo & 94 & 81 & $-0,052^{* * *}$ & 54,6 & 45,4 \\
\hline
\end{tabular}

${ }^{*} \mathrm{p} \leq 0,05 \quad{ }^{* *} \mathrm{p} \leq 0,01 \quad{ }^{* * *} \mathrm{p} \leq 0,002 \quad$ em branco: $\mathrm{p}>0,05$

6.22. Impacto da intervenção médica na mortalidade por complicações da gravidez, parto e puerpério 
A taxa padronizada de mortalidade por complicações da gravidez, parto e puerpério (CD9 630-639) declina a 8\% aa., evoluindo de 4,05/100.000 para 1,44/100.000 no período de 1979 a 1992 no conjunto das capitais, quando ajustada por regressão loglinear (Tabela 2). A intervenção médica contribui com cerca de $62,6 \%$ deste declínio em 1992 . Como este efeito ( $-5 \%$ aa.) não produz uma diferença significativa entre a taxa estimada e a esperada na ausência da intervenção ( $R M E=37,36 p>0,05$ ), é possível inferir que a intervenção médica contribui de forma pouco expressiva para o declínio da taxa de mortalidade por complicações da gravidez, parto e puerpério no conjunto das capitais em 1992 (Tabela 6).

No periodo de 1979-1982, João Pessoa ( $R M P=69 \mathrm{p} \leq 0,002)$ apresenta nível de mortalidade inferior ao esperado e São Luiz ( $R M P=851$ p $\leq 0,002)$, Porto Velho $(R M P=400$ p $\leq 0,002)$, Boa Vista (RMP=286 $\mathrm{p} \leq 0,002)$ e Recife $(\mathrm{RMP}=117 \mathrm{p} \leq 0,002)$ apresentam nível de mortalidade superior ao esperado. No período de 1989-1992, apenas João Pessoa ( $R M P=71 \mathrm{p} \leq 0,002)$ apresenta nível de mortalidade inferior ao esperado e nenhuma capital apresenta nível de mortalidade superior ao esperado, apesar de São Luiz (RMP=300 $\mathrm{p}>0,05)$, Manaus $(R M P=204 p>0,05)$, Aracaju $(R M P=169 p>0,05)$, Cuiabá $(R M P=168 p>0,05)$ e Belém $(\mathrm{RMP}=153 \mathrm{p}>0,05)$ apresentarem nível elevado de mortalidade (Tabela 28).

Dentre as vinte e cinco capitais com coeficiente de regressão negativo, treze apresentam tendência exponencial de declinio $(p \leq 0,002)$. Entre elas, estão Porto Velho $(\mathrm{RME}=6,7 \mathrm{p} \leq 0,002)$, Boa Vista $(R M E=11,7 p \leq 0,002)$ e Macapá ( $R M E=13,5 p \leq 0,002)$, cuja contribuição da intervenção médica no declínio da taxa de mortalidade produz uma diferença significativa entre a taxa estimada para 1992 e a esperada na ausência de intervenção médica. Nestas capitais, é possível afirmar que a intervenção médica contribui de forma expressiva para o declínio da taxa de mortalidade por complicações da gravidez, parto e puerpério no conjunto das capitais em 1992 (Tabela 28).

Nas demais capitais, a participação da intervenção médica na taxa de declínio, mesmo quando expressiva como em Terezina ( $\mathrm{PTD}=90,2)$, Rio Branco (PTD=86,6\%), Goiânia (PTD=85,6\%), Belém $(\mathrm{PTD}=83,3)$, Porto Alegre ( $\mathrm{PTD}=80,8 \%)$, São Luiz $(\mathrm{PTD}=75,6)$ e Manaus $(\mathrm{PTD}=67,1)$, não gera um efeito capaz de produzir diferença significativa (ao nível de significância de $p \leq 0,002$ ) entre a taxa de mortalidade da estimada para 1992 e a esperada na ausência da intervenção médica. Para Florianópolis 
$(b=0,075 \mathrm{p}>0,05$ ), capital com coeficiente de regressão positivo, a influência da assistência médica sobre a mortalidade não é mensurável pelo modelo de análise proposto (Tabela 28).

Tabela 28. Razão de mortalidade padronizada (RMP), coeficiente de regressão loglinear, percentual da taxa de declínio da mortalidade devido à intervenção médica (PTD) e razão de mortalidade evitável (RME $\left.{ }_{1992}\right)$ por complicação da gravidez, parto e puerpério (CID9 630-639) nas capitais brasileiras.

\begin{tabular}{|c|c|c|c|c|c|}
\hline \multirow[b]{2}{*}{ Capital } & \multicolumn{2}{|c|}{ RMP } & \multirow{2}{*}{$\begin{array}{l}\text { Coeficiente } \\
\text { de } \\
\text { Regressão } \\
\quad \text { (b) }\end{array}$} & \multirow{2}{*}{$\begin{array}{r}\text { PTD } \\
(\%)\end{array}$} & \multirow[b]{2}{*}{ RME } \\
\hline & $1979-1982$ & 1989-1992 & & & \\
\hline Rio Branco & 135 & 83 & $-0,130^{* *}$ & 86,6 & $13,4^{\circ}$ \\
\hline Maceió & 92 & 103 & $-0,072^{* *}$ & 53,9 & 46,1 \\
\hline Macapá & $271^{* *}$ & 115 & $-0,135^{* *}$ & 86,5 & $13,5^{* * *}$ \\
\hline Manaus & $236^{*}$ & 204 & $-0,094^{* * *}$ & 67,1 & $32,9^{*}$ \\
\hline Salvador & 62 & 77 & $-0,059^{* * *}$ & 43,9 & 56,1 \\
\hline Fortaleza & 181 & 76 & $-0,166^{* * *}$ & 68,7 & 31,3 \\
\hline Brasilia & 70 & 86 & $-0,062^{* *}$ & 72,8 & 27,2 \\
\hline Vitória & 124 & 82 & $-0,077$ & 66,7 & 33,3 \\
\hline Goiânia & 108 & 74 & $-0,132^{* * *}$ & 85,6 & 14,4 \\
\hline São Luiz & $851^{* * *}$ & 300 & $-0,183^{* * *}$ & 75,6 & $24,4^{* *}$ \\
\hline Belo Horizonte & 122 & 80 & $-0,125^{* * *}$ & 63,4 & 36,6 \\
\hline Campo Grande & 102 & 116 & $-0,064^{* *}$ & 65,8 & 34,2 \\
\hline Cuiabá & 151 & 168 & $-0,085^{* * *}$ & 49,3 & 50,7 \\
\hline Belém & 374 & 153 & $-0,168^{* * *}$ & 83,3 & $16,7^{* *}$ \\
\hline João Pessoa & $69^{* * *}$ & $71^{* * *}$ & $-0,094$ & 65,7 & 34,3 \\
\hline Curitiba & 75 & 121 & $-0,034$ & 17,4 & 82,6 \\
\hline Recife & $117^{* * *}$ & 126 & $-0,051^{* *}$ & 67,3 & 32,7 \\
\hline Terezina & 212 & 94 & $-0,193^{* * *}$ & 90,2 & $9,8^{* *}$ \\
\hline Rio de Janeiro & 60 & 88 & $-0,045^{* *}$ & 29,3 & 70,7 \\
\hline Natal & 71 & 124 & $-0,030$ & - & 100,1 \\
\hline Porto Velho & $400^{* * *}$ & 145 & $-0,181^{* * *}$ & 93,3 & $6,7^{* * *}$ \\
\hline Boa Vista & $286^{* * *}$ & 79 & $-0,137^{*}$ & 88,3 & $11,7^{* * *}$ \\
\hline Porto Alegre & 78 & 61 & $-0,113^{* * *}$ & 80,8 & 19,2 \\
\hline Florianópolis & 15 & 28 & 0,075 & - & 261,9 \\
\hline Aracaju & 206 & 169 & $-0,107^{* * *}$ & 56,2 & 43,8 \\
\hline São Paulo & 64 & 88 & $-0,050^{* * *}$ & 53,7 & 46,3 \\
\hline
\end{tabular}

$* \mathrm{p} \leq 0,05 \quad * \mathrm{p} \leq 0,01 \quad * * \mathrm{p} \leq 0,002 \quad$ em branco: $\mathrm{p}>0,05$ 
6.23. Impacto da intervenção médica na mortalidade por sintomas, sinais, e afeç̧ões mal definidas

A taxa padronizada de mortalidade por sintomas, sinais e afeç̧ões mal definidas (CID9 780-799) declina a 1,1\% aa., evoluindo de 25,20/100.000 para 21,87/100.000 no período de 1979 a 1992 no conjunto das capitais, quando ajustada por regressão loglinear (Tabela 2). A intervenção médica contribui com cerca de $8,6 \%$ deste declínio em 1992. Como este efeito ( $-0,09 \%$ aa.) não produz uma diferença significativa entre a taxa estimada e a esperada na ausência da intervenção ( $R M E=91,40 p>0,05$ ), é possível afirmar que a intervenção médica contribui de forma pouco expressiva para o declínio da taxa de mortalidade por sintomas, sinais e afeções mal definidas no conjunto das capitais em 1992 (Tabela 6).

No período de 1979-1982, Porto Alegre ( $R M P=15)$, Curitiba ( $R M P=23)$, Salvador e Brasília $(R M P=30)$ e São Paulo $(R M P=34)$ apresentam nível de mortalidade inferior ao esperado (p $\leq 0,002)$ e Fortaleza (RMP=1.224), João Pessoa (RMP=733), Cuiabá ( $R M P=487)$, Goiânia ( $R M P=309)$, Aracaju $(R M P=226)$, Macapá $(R M P=205)$ e Boa Vista $(R M P=187)$ apresentam nível de mortalidade superior ao esperado ( $\mathrm{p} \leq 0,002)$. No periodo de 1989-1992, Curitiba $(\mathrm{RMP}=21)$ e São Paulo $(\mathrm{RMP}=20)$ apresentam nível de mortalidade inferior ao esperado $(\mathrm{p} \leq 0,002)$ e Manaus ( $R M P=527)$, João Pessoa ( $R M P=306)$, Cuiabá $(\mathrm{RMP}=250)$, Aracaju $(\mathrm{RMP}=225)$, Fortaleza $(\mathrm{RMP}=202)$ e Vitória $(\mathrm{RMP}=187)$ apresentam nível de mortalidade superior ao esperado ( $\leq \leq 0,002$ ) (Tabela 29).

Dentre as dezenove capitais com coeficiente de regressão negativo, sete apresentam tendência exponencial de declínio $(\mathrm{p} \leq 0,002)$. Entre elas, estão Macapá $(\mathrm{RME}=12,3)$, Fortaleza $(\mathrm{RME}=23,8)$, Goiânia ( $\mathrm{RME}=29,5)$, Terezina $(\mathrm{RME}=32,2)$, Boa Vista $(\mathrm{RME}=48,6)$ e Cuiabá (RME=66,9), cuja contribuição da intervenção médica no declínio da taxa de mortalidade produz uma diferença significativa $(p \leq 0,002)$ entre a taxa estimada para 1992 e a esperada na ausência de intervenção médica. Nestas capitais, é possivel afirmar que a intervenção médica contribui de forma expressiva para o declínio da mortalidade por complicações da gravidez, parto e puerpério no conjunto das capitais em 1992 (Tabela 29).

Nas demais capitais, a participação da intervenção médica na taxa de declínio, mesmo quando expressiva como em Campo Grande (PTD=90), Brasília (PTD=60\%) e Recife (PTD=42,1\%), não gera um efeito capaz de produzir diferença significativa (ao nível de significância de $p \leq 0,002$ ) entre a taxa de 
mortalidade da estimada para 1992 e a esperada na ausência da intervenção médica (Tabela 29). Para as demais capitais com coeficiente de regressão positivo, a influência da assistência médica sobre a mortalidade não é mensurável pelo modelo de análise proposto.

Tabela 29. Razão de mortalidade padronizada (RMP), coeficiente de regressão loglinear, percentual da taxa de declínio da mortalidade devido à intervenção médica (PTD) e razão de mortalidade evitável $\left(\mathrm{RME}_{1992)}\right.$ por causas mal definidas (CID9 780-799) nas capitais brasileiras.

\begin{tabular}{|c|c|c|c|c|c|}
\hline \multirow[b]{2}{*}{ Capital } & \multicolumn{2}{|c|}{ RMP } & \multirow{2}{*}{$\begin{array}{l}\text { Coeficiente } \\
\text { de } \\
\text { Regressão } \\
\quad \text { (b) }\end{array}$} & \multirow{2}{*}{$\begin{array}{r}\text { PTD } \\
\text { (\%) }\end{array}$} & \multirow[b]{2}{*}{ RME } \\
\hline & 1979-1982 & 1989-1992 & & & \\
\hline Rio Branco & 91 & 219 & -0.020 & 44,2 & 55.8 \\
\hline Maceió & 91 & 87 & -0.007 & - & $106.9^{* * *}$ \\
\hline Macapá & $205^{* * *}$ & $42^{* *}$ & $-0.143^{* * *}$ & 87,7 & $12.3^{* * *}$ \\
\hline Manaus & 139 & $527^{* * *}$ & $0.118^{* * *}$ & -- & $514.4^{* * *}$ \\
\hline Salvador & $30^{* * *}$ & $42^{* *}$ & $0.034^{*}$ & - & $188.3^{*}$ \\
\hline Fortaleza & $1224^{* * *}$ & $202^{* * *}$ & $-0.187^{* * *}$ & 76,2 & $23.8^{* * *}$ \\
\hline Brasilia & $30^{* * *}$ & $23^{* *}$ & -0.032 & 60,0 & $40.0^{\circ}$ \\
\hline Vitória & $42^{* *}$ & $187^{* * *}$ & $0.145^{* * *}$ & - & $591.0^{* * *}$ \\
\hline Goiânia & $309^{* * *}$ & 140 & $-0.077^{* * *}$ & 70,5 & $29.5^{* * *}$ \\
\hline São Luiz & 80 & 95 & -0.008 & -- & $238.5^{* * *}$ \\
\hline Belo Horizonte & 97 & 64 & $-0.049^{* *}$ & 1,8 & 98.2 \\
\hline Campo Grande & 88 & 66 & -0.158 & 90,0 & 10.0 \\
\hline Cuiabá & $487^{* * *}$ & $250^{* * *}$ & $-0.064^{* * *}$ & 33,1 & $66.9^{* *}$ \\
\hline Belém & $44^{* *}$ & $36^{* *}$ & -0.031 & 1,5 & 98.5 \\
\hline João Pessoa & $733^{* * *}$ & $306^{* * *}$ & $-0.089^{* * *}$ & 63,3 & $36.7^{* * *}$ \\
\hline Curitiba & $23^{* * *}$ & $21^{* * *}$ & -0.011 & -- & 112.8 \\
\hline Recife & 60 & 60 & -0.007 & 42,1 & $57.9^{*}$ \\
\hline Terezina & 116 & $43^{* *}$ & $-0.101^{* * *}$ & 67,8 & $32.2^{* * *}$ \\
\hline Rio de Janeiro & $52^{\circ}$ & 100 & $0.056^{* *}$ &.- & $262.2^{* * *}$ \\
\hline Natal & $39^{* *}$ & $45^{* *}$ & 0.014 & -- & 177.4 \\
\hline Porto Velho & 100 & $148^{*}$ & 0.091 & -- & $230.0^{* * *}$ \\
\hline Boa Vista & $187^{* * *}$ & 139 & -0.027 & 51,4 & $48.6^{* * *}$ \\
\hline Porto Alegre & $15^{* * *}$ & $36^{* *}$ & 0.015 & - & 101.6 \\
\hline Florianópolis & 51 & 32 & $-0.055^{*}$ & 51,4 & 48.6 \\
\hline Aracaju & $226^{* * *}$ & $225^{* * *}$ & 0.011 & - & $203.0^{* * * *}$ \\
\hline São Paulo & $34^{* * *}$ & $20^{* * *}$ & $-0.052^{* * *}$ & 54,8 & 45.2 \\
\hline
\end{tabular}

$\mathrm{p} p \leq 0,05 \quad * \mathrm{p} \leq 0,01 \quad$ *** $\mathrm{p} \leq 0,002 \quad$ em branco: $\mathrm{p}>0,05$ 
CONCLUSÕES 


\section{Conclusōes}

A mortalidade por CICS declina exponencialmente (5,4\% aa.) de 1979 a 1992 e sua distribuição torna-se mais homogênea no conjunto das capitais ao final do periodo. A intervenção médica, quando medida pela Razão de Mortalidade Evitável, contribui de forma significativa $(p \leq 0,002)$ e abrangente $(85 \%$ das capitais) para este declínio (2,5\% aa. no conjunto, variando de $11,1 \%$ aa. em Fortaleza a $0,3 \%$ aa. em Vitória).

A intervenção médica é igualmente efetiva no declínio da mortalidade por CICS na maioria das capitais, seja quando interpretada pela freqüência de resultados significativos alcançados entre capitais de uma mesma macrorregião (Tabela 30), exceto para Boa Vista $\left(X^{2}=5,27 p=0,02165\right.$ ), onde o desempenho é superior ao das demais capitais da região, seja quando a comparação se faz entre todas as capitais (Tabela 31), exceto para Boa Vista $\left(X^{2}=9,84 p=0,00171\right)$ e Goiânia $\left(X^{2}=4,30 p=0,03815\right)$, ou mesmo entre as macrorregiões $\left(X^{2}=3,89 \mathrm{p}=0,42163\right)$ (Tabela 32). Portanto, se há diferença geográfica de efetividade da intervenção médica, ela não pode ser explicada pela proporção de causas de óbito evitável que têm parte importante de seu declínio devido à influência da intervenção médica.

A intervenção médica é mais freqüentemente efetiva nas capitais com nível de mortalidade por CICS (RMP) superior ao esperado. Esta comparação é tão válida para o periodo de 1979-1982 $\left(\mathrm{X}^{2}=19,92\right.$ $\mathrm{p}=0,00001)$ quanto para 1989-1992 $\left(\mathrm{X}^{2}=20,52 \mathrm{p}=0,00001\right)$ (Tabelas 32 e 33) e torna evidente a importância da intervenção médica para a maior homogeneidade da mortalidade por CICS entre as capitais $(s=23,34 p=0,5576)$, bem como para declínio do nivel de mortalidade: das sete capitais com RMP superior a esperada em 1979-1982, apenas Maceió ( $R M P=146 p \leq 0,002)$, João Pessoa $(R M P=156 p \leq 0,002)$ e Aracaju ( $R M P=153 \mathrm{p} \leq 0,002)$ encontram-se nesta situação em 1989-1992. Estes achados permitem supor que o declínio observado pode estar associado à introdução tardia de inovações na organização da oferta ou do acesso aos serviços de saúde. 
Tabela 30. Presença de RME significativa nas capitais por macrorregióes

Observado

Capitais por

Macrorregião
Sim Não Total (\%)
Esperado

Sim Não Total
$\mathrm{X}^{2}$
Norte

\begin{tabular}{|c|c|c|c|c|c|c|c|c|c|}
\hline Rio Branco & 4 & 10 & 14 & 29 & 4.30 & 9.70 & 14,00 & 0.0205 & 0.88606 \\
\hline Macapá & 5 & 13 & 18 & 28 & 5.52 & 12.48 & 18,00 & 0.0498 & 0.82334 \\
\hline Manaus & 2 & 16 & 18 & 11 & 5.52 & 12.48 & 18,00 & 2.2488 & 0.13372 \\
\hline Belém & 4 & 14 & 18 & 22 & 5.52 & 12.48 & 18,00 & 0.4208 & 0.51653 \\
\hline Porto Velho & 6 & 11 & 17 & 35 & 5.22 & 11.78 & 17,00 & 0.1173 & 0.73203 \\
\hline Boa Vista & 10 & 6 & 16 & 62 & 4.91 & 11.09 & 16,00 & 5.2738 & 0.02165 \\
\hline Total & 31 & 70 & 101 & 31 & 31.00 & 70.00 & 101.00 & 8.1310 & 0.14916 \\
\hline \multicolumn{10}{|l|}{ Nordeste } \\
\hline Maceió & 3 & 13 & 16 & 19 & 3.66 & 12.34 & 16,00 & 0.1191 & 0.73006 \\
\hline Salvador & 3 & 12 & 15 & 20 & 3.43 & 11.57 & 15,00 & 0.0542 & 0.81586 \\
\hline Fortaleza & 5 & 16 & 21 & 24 & 4.80 & 16.20 & 21,00 & 0.0080 & 0.92872 \\
\hline São Luiz & 4 & 17 & 21 & 19 & 4.80 & 16.20 & 21,00 & 0.1345 & 0.71378 \\
\hline João Pessoa & 3 & 9 & 12 & 25 & 2.75 & 9.25 & 12,00 & 0.0237 & 0.87773 \\
\hline Recife & 8 & 12 & 20 & 40 & 4.58 & 15.42 & 20,00 & 2.5637 & 0.10934 \\
\hline Terezina & 2 & 15 & 17 & 12 & 3.89 & 13.11 & 17,00 & 0.9175 & 0.33814 \\
\hline Natal & 5 & 13 & 18 & 28 & 4.12 & 13.88 & 18,00 & 0.1891 & 0.66369 \\
\hline Aracaju & 2 & 11 & 13 & 15 & 2.97 & 10.03 & 13,00 & 0.3189 & 0.57226 \\
\hline Total & 35 & 118 & 153 & 23 & 35.00 & 118.00 & 153.00 & 4.3287 & 0.82632 \\
\hline \multicolumn{10}{|l|}{ Sudeste } \\
\hline Belo Horizonte & 3 & 17 & 20 & 15 & 3.73 & 16.27 & 20,00 & 0.1440 & 0.70429 \\
\hline Vitória & 4 & 10 & 14 & 29 & 2.61 & 11.39 & 14,00 & 0.7358 & 0.39102 \\
\hline Rio de Janeiro & 1 & 19 & 20 & 5 & 3.73 & 16.27 & 20,00 & 2.0012 & 0.15718 \\
\hline São Paulo & 6 & 15 & 21 & 29 & 3.92 & 17.08 & 21,00 & 1.1037 & 0.29346 \\
\hline Total & 14 & 61 & 75 & 19 & 14.00 & 61.00 & 75.00 & 3.9847 & 0.26312 \\
\hline \multicolumn{10}{|l|}{ Sul } \\
\hline Curitiba & 2 & 16 & 18 & 11 & 3.24 & 14.76 & 18,00 & 0.4746 & 0.49089 \\
\hline Florianópolis & 3 & 14 & 17 & 18 & 3.06 & 13.94 & 17,00 & 0.0012 & 0.97264 \\
\hline Porto Alegre & 4 & 11 & 15 & 27 & 2.70 & 12.30 & 15,00 & 0.6259 & 0.42885 \\
\hline Total & 9 & 41 & 50 & 18 & 9.00 & 41.00 & $\mathbf{5 0 . 0 0}$ & 1.1017 & 0.57647 \\
\hline \multicolumn{10}{|l|}{ Centro-Oeste } \\
\hline Campo Grande & 3 & 13 & 16 & 19 & 4.36 & 11.64 & 16,00 & 0.4261 & 0.51389 \\
\hline Cuiabá & 2 & 17 & 19 & 10 & 5.18 & 13.82 & 19,00 & 1.9537 & 0.16218 \\
\hline Goiânia & 9 & 10 & 19 & 47 & 5.18 & 13.82 & 19,00 & 2.8134 & 0.09348 \\
\hline Brasilia & 4 & 8 & 12 & 33 & 3.27 & 8.73 & 12,00 & 0.1616 & 0.68767 \\
\hline Total & 18 & 48 & 66 & 27 & 18.00 & 48.00 & 66.00 & 5.3549 & 0.14758 \\
\hline Total (geral) & 107 & 338 & 445 & 24 & 107.00 & 338.00 & 445.00 & 22.9009 & 0.58335 \\
\hline
\end{tabular}


Tabela 31. Presença de RME significativa nas capitais

Observado

Capital
Sim Não Total (\%)
Esperado

Sim Não Total $X^{2}$

\begin{tabular}{lrrrrrrrrr} 
Rio Branco & 4 & 10 & 14 & 29 & 3 & 11 & 14 & 0.1193 & 0.72980 \\
Maceió & 3 & 13 & 16 & 19 & 4 & 12 & 16 & 0.1866 & 0.66580 \\
Macapá & 5 & 13 & 18 & 28 & 4 & 14 & 18 & 0.1043 & 0.74672 \\
Manaus & 2 & 16 & 18 & 11 & 4 & 14 & 18 & 1.2523 & 0.26312 \\
Salvador & 3 & 12 & 15 & 20 & 4 & 11 & 15 & 0.1021 & 0.74936 \\
Fortaleza & 5 & 16 & 21 & 24 & 5 & 16 & 21 & 0.0005 & 0.98245 \\
Brasília & 4 & 8 & 12 & 33 & 3 & 9 & 12 & 0.4306 & 0.51171 \\
Vitória & 4 & 10 & 14 & 29 & 3 & 11 & 14 & 0.1193 & 0.72980 \\
Goiânia & 9 & 10 & 19 & 47 & 5 & 14 & 19 & 4.2985 & 0.03815 \\
São Luiz & 4 & 17 & 21 & 19 & 5 & 16 & 21 & 0.2181 & 0.64049 \\
Belo Horizonte & 3 & 17 & 20 & 15 & 5 & 15 & 20 & 0.6805 & 0.40942 \\
Campo Grande & 3 & 13 & 16 & 19 & 4 & 12 & 16 & 0.1866 & 0.66580 \\
Cuiabá & 2 & 17 & 19 & 10 & 5 & 14 & 19 & 1.4441 & 0.22948 \\
Belém & 4 & 14 & 18 & 22 & 4 & 14 & 18 & 0.0249 & 0.87469 \\
João Pessoa & 3 & 9 & 12 & 25 & 3 & 9 & 12 & 0.0046 & 0.94621 \\
Curitiba & 2 & 16 & 18 & 11 & 4 & 14 & 18 & 1.2523 & 0.26312 \\
Recife & 8 & 12 & 20 & 40 & 5 & 15 & 20 & 2.1174 & 0.14563 \\
Terezina & 2 & 15 & 17 & 12 & 4 & 13 & 17 & 1.0662 & 0.30181 \\
Rio de Janeiro & 1 & 19 & 20 & 5 & 5 & 15 & 20 & 3.0169 & 0.08240 \\
Natal & 5 & 13 & 18 & 28 & 4 & 14 & 18 & 0.1043 & 0.74672 \\
Porto Velho & 6 & 11 & 17 & 35 & 4 & 13 & 17 & 0.8947 & 0.34421 \\
Boa Vista & 10 & 6 & 16 & 62 & 4 & 12 & 16 & 9.8402 & 0.00171 \\
Porto Alegre & 4 & 11 & 15 & 27 & 4 & 11 & 15 & 0.0429 & 0.83595 \\
Florianópolis & 3 & 14 & 17 & 18 & 4 & 13 & 17 & 0.2894 & 0.59061 \\
Aracaju & 2 & 11 & 13 & 15 & 3 & 10 & 13 & 0.4055 & 0.52426 \\
São Paulo & 6 & 15 & 21 & 29 & 5 & 16 & 21 & 0.1789 & 0.67228 \\
& & & & & & & & & \\
Total & 107 & 338 & 445 & 24 & 107 & 338 & 445 & 28.3807 & 0.29063 \\
& & & & & & & & & \\
\hline
\end{tabular}


Tabela 32. Presença de RME significativa nas macrorregiões

Observado

Macrorregião

Sim Não Total (\%)

Esperado

Sim Não Total

$X^{2}$

p

$24,29 \quad 76,72 \quad 101,00 \quad 1,8536 \quad 0,72980$

$\begin{array}{lllll}36,79 & 116,21 & 153,00 & 0,0871 & 0,76790\end{array}$

Nordeste

$\begin{array}{llll}35 & 118 & 153 & 23\end{array}$

18,03

$56,97 \quad 75,00 \quad 0,9008$

0,34257

Sudeste

$14 \quad 61$

$\begin{array}{ll}75 & 19\end{array}$

$\begin{array}{llll}12,02 & 37,98 & 50,00 & 0,7588\end{array}$

0,38370

Sul

$\begin{array}{llll}9 & 41 & 50 & 18\end{array}$

$15,87 \quad 50,13 \quad 66,00 \quad 0,2859$

0,59286

Centro-Oeste

$18 \quad 48$

$\begin{array}{ll}66 & 27\end{array}$

Total

$107 \quad 338$

$445 \quad 24$

$107,00 \quad 338,00 \quad 445,00 \quad 3,8862$

0,42163

* Palmas (Tocantins) não foi incluída no estudo porque foi criada pela Constituição de 1986

A intervenção médica não é igualmente efetiva $\left(X^{2}=70,42 \quad p=0,00000\right)$ quando seu impacto sobre a mortalidade é interpretado pela freqüência de resultados significativos alcançados nas diversas causas de óbito evitável (Tabela 34). O componente mais expressivo da influência da intervenção médica sobre a mortalidade por CICS é sua contribuição para tendência exponencial de declínio da mortalidade por doenças infecciosas intestinais: é a segunda maior taxa de mortalidade estimada em $1992\left(\mathrm{Y}^{\circ}=82 / 100.000\right)$, a intervenção médica é efetiva em $100 \%$ das capitais e contribui com $83,8 \%$ da taxa de declínio $(12,07 \%$ aa.) desta causa no conjunto das capitais.

As causas de óbito evitável podem ser classificadas em quatro grupos de acordo com frequêencia de resultados significativos alcançados nas capitais com declínio da mortalidade por CICS: quanto maior a proporção de capitais com RME significativa, maior a contribuição para o declínio da mortalidade por CICS no conjunto das capitais. Os resultados da Tabela 35 sugerem três grupos de causas cujo declínio é 
influenciado de modo significativo pela intervenção médica. Em um quarto grupo ficam as causas de óbito evitável que não sofrem influência significativa da intervenção médica.

Tabela 33. Presença de RME significativa de acordo com a RMP significativa das CICS (1979-1982)

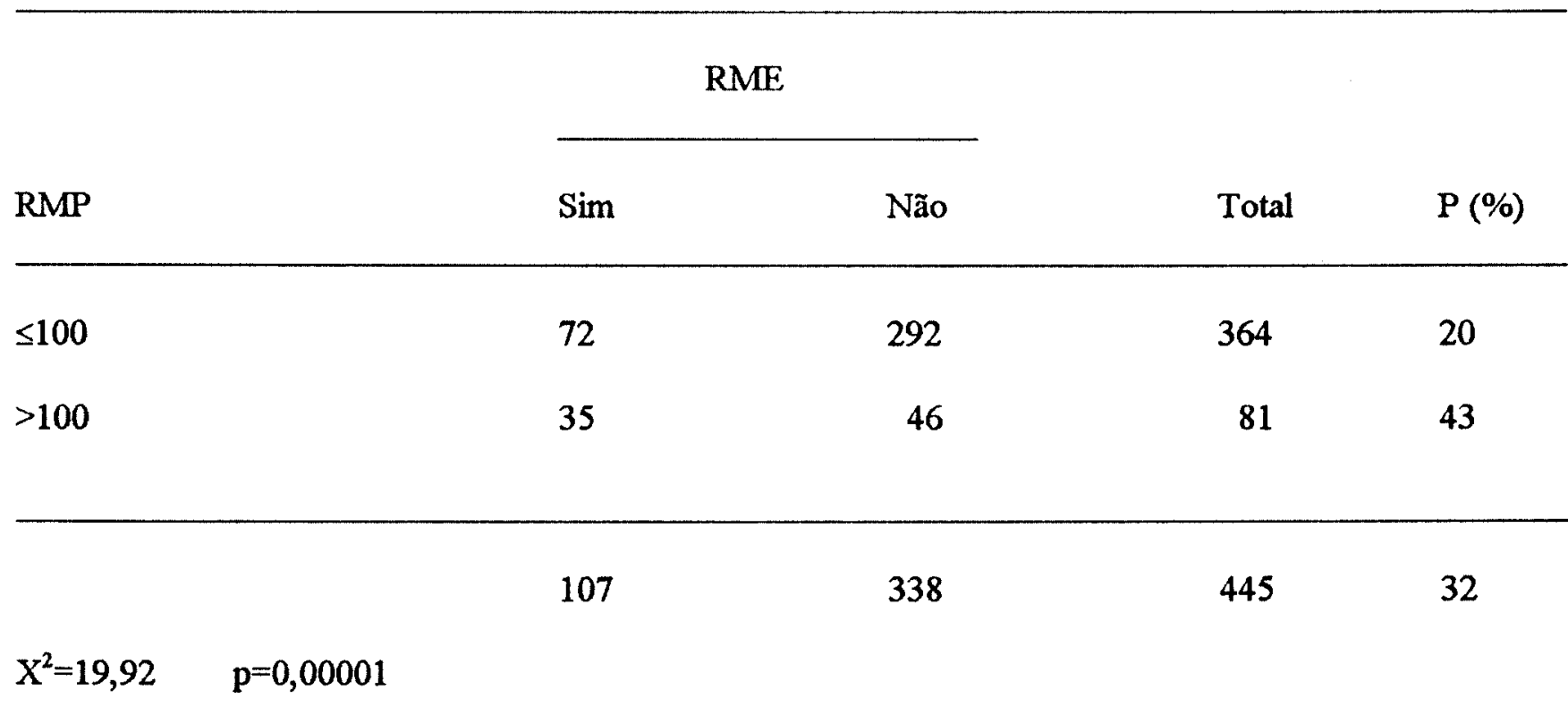

Tabela 34. Presença de RME significativa de acordo com a RMP significativa das CICS (1989-1992)

RME

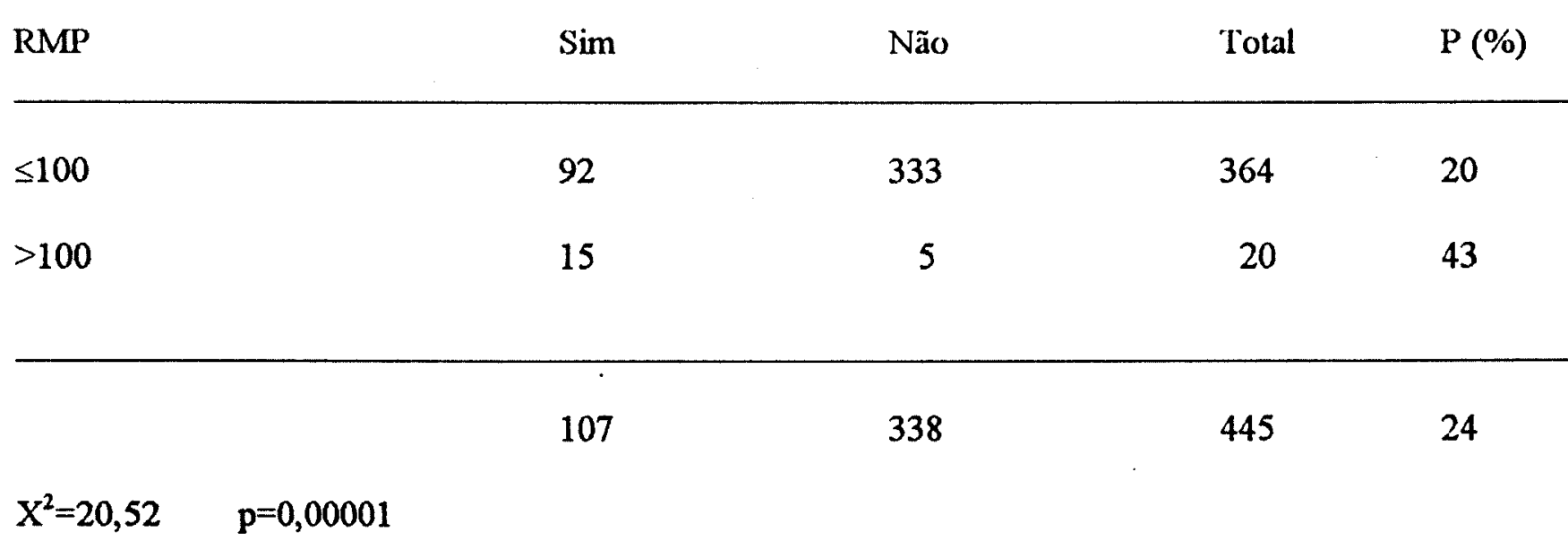


Causas de óbito (CICS)
Observado

Esperado

Sim Não Total (\%) Sim Não Total

$\mathrm{X}^{2}$

\begin{tabular}{|c|c|c|c|c|c|c|c|c|c|}
\hline Doenças infecciosas intestinais & 26 & 0 & 26 & 100 & 8,86 & 17,14 & 26,00 & 33,1589 & 0,00000 \\
\hline Septicemia & 13 & 6 & 19 & 68 & 6,47 & 12,53 & 19,00 & 6,5768 & 0,01033 \\
\hline Tuberculose & 4 & 22 & 26 & 15 & 8,86 & 17,14 & 26,00 & 2,6658 & 0,10253 . \\
\hline Diabetes mellitus & 1 & 5 & 6 & 17 & 2,04 & 3,96 & 6,00 & 0,5337 & 0,46506 \\
\hline Meningite & 10 & 10 & 20 & 50 & 6,82 & 13,18 & 20,00 & 1,4882 & 0,22250 \\
\hline Hipertensão arterial & 8 & 16 & 24 & 33 & 8,18 & 15,82 & 24,00 & 0,0039 & 0,95027 \\
\hline Doença cerebrovascular & 9 & 11 & 20 & 45 & 6,82 & 13,18 & 20,00 & 0,7003 & 0,40267 \\
\hline Infecções respiratórias agudas & 8 & 12 & 20 & 40 & 6,82 & 13,18 & 20,00 & 0,2059 & 0,64997 \\
\hline Pneumonia e gripe & 13 & 12 & 25 & 52 & 8,52 & 16,48 & 25,00 & 2,3569 & 0,12473 \\
\hline Mortes maternas & 3 & 22 & 25 & 12 & 8,52 & 16,48 & 25,00 & 3,5756 & 0,05864 \\
\hline Causas mal definidas & 6 & 10 & 16 & 37 & 5,45 & 10,55 & 16,00 & 0.0550 & 0,81453 \\
\hline Tumor maligno do útero (ne) & 1 & 18 & 19 & 5 & 6,47 & 12,53 & 19,00 & 4,6290 & 0,03144 \\
\hline Tumor maligno do colo do útero & 1 & 19 & 20 & 5 & 6,82 & 13,18 & 20,00 & 4,9620 & 0,02591 \\
\hline Doença pulmonar obstrutiva cr. & 3 & 23 & 26 & 12 & 8,86 & 17,14 & 26,00 & 3,8757 & 0,04899 \\
\hline Nefrite e nefrose & 1 & 21 & 22 & 5 & 7,50 & 14,50 & 22,00 & 5,6302 & 0,01765 \\
\hline Total & 107 & 207 & 14 & 34 & 107,00 & 207,00 & 314,00 & 70,4179 & 0,00000 \\
\hline
\end{tabular}

Os grupos de causas de óbito evitável por intervenção médica, são os seguintes (Quadro 9):

1. Causas de óbito evitável que mais contribuem para o declínio da mortalidade por CICS: doenças infecciosas intestinais $\left(X^{2}=33,16 p=0,00000\right)$ e septicemia $\left(X^{3}=6,58 p=0,01033\right)$;

2. Causas que menos contribuem para o declínio da mortalidade por CICS: tumor maligno de útero não especificado $\left(X^{2}=4,63 p=0,03144\right)$, tumor maligno de colo de útero $\left(X^{2}=4,96 p=0,02591\right)$, doença pulmonar obstrutiva crônica $\left(X^{2}=3,88 p=0,04899\right)$ e nefrite e nefrose $\left(X^{2}=5,63 p=0,01765\right)$; 
Quadro 9. Classificação das CICS baseada na efetividade da intervenção médica

CID9 Causas Indicadoras de Cuidados de Saúde - CICS

Causas que mais contribuem para o declínio da mortalidade por CICS

001-009 Doenças infecciosas intestinais

$038 \quad$ Septicemia

Causas que contribuem o esperado para o declínio da mortalidade por CICS

$\begin{array}{ll}010-018 & \text { Tuberculose } \\ 250 & \text { Diabetes melito } \\ 320-322 & \text { Meningite bacteriana } \\ 401-405 & \text { Hipertensão arterial } \\ 430-436 & \text { Doença cerebrovascular } \\ 460-466 & \text { Infeções respiratórias agudas } \\ 480-487 & \text { Pneumonia e gripe } \\ 630-639 & \text { Complicações da gravidez, parto e puerpério } \\ 780-789 & \text { Sinais, sintomas e afeç̧ões mal definidas }\end{array}$

Causas que menos contribuem para o declínio da mortalidade por CICS

491-492 Doença pulmonar obstrutiva crônica

580-589 Nefrite e nefrose

179 Tumor maligno do útero não especificado

180 Tumor maligno do colo do útero

Causas que não contribuem para o declínio da mortalidade por CICS

172 Melanoma maligno de pele

201 Doença de Hodgkin

393-398 Doença reumática crônica do coração

493 Asma

531-534 Úlcera gástrica, duodenal e jejunal

540-543 Apendicite

550-553 Hérnia abdominal

574-575 Colelitíase e colecistite 
3. Causas que contribuem o esperado para o declínio da mortalidade por CICS: tuberculose $\left(X^{2}=2,67\right.$ $p=0,10253)$, diabetes melito $\left(X^{2}=0,5337 \quad p=0,46506\right)$, meningite $\left(X^{2}=1,49 \quad p=0,22250\right)$, hipertensão arterial $\left(X^{2}=0,0039 p=0,95027\right)$, doença cerebrovascular $\left(X^{2}=0,70 \quad p=0,40267\right)$, infeç̧ões respiratórias agudas $\left(X^{2}=0,2059 \mathrm{p}=0,64997\right)$, pneumonia e gripe $\left(X^{2}=2,36 \mathrm{p}=0,12473\right)$, complicações da gravidez, parto e puerpério $\left(X^{2}=3,58 \quad p=0,05864\right)$ e sintomas, sinais e afeç̧ões mal definidas $\left(X^{2}=0,055\right.$ $\mathrm{p}=0,81453$ ).

A velocidade de declínio da taxa de mortalidade por CICS $(5,4 \%$ aa.; $\mathrm{p} \leq 0,002)$ é 2,2 vezes aquela das demais causas de óbito $(2,4 \%$ aa., $\mathrm{p} \leq 0,002)$ no período de 1979 a 1992 . Três suposições podem ser formuladas para explicar esta tendência: (i) o padrão pode refletir a diminuição da incidência dessas doenças e, conseqüentemente dos óbitos delas decorrentes, (ii) pode estar associado a melhorias nas condições gerais de vida, ou (iii) pode ser devido a uma significativa contribuição da intervenção médica.

O estudo supõe e produz evidências sobre a possivel contribuição da intervenção médica para o declínio da mortalidade evitável. O processo que tornou essa suposição uma hipótese de trabalho, capaz de orientar a produção de dados empiricos e sua refutação, implicou numa série de simplificações do modelo de análise, inicialmente explicitadas nos pressupostos assumidos, nos ajustes estatísticos empregados para o cálculo das tendências e sua significância e, finalmente, nas conclusões baseadas na interpretação dos resultados obtidos. Algumas considerações finais são necessárias para um melhor julgamento da relevância dos achados epidemiológicos.

Inicialmente, deve-se destacar que não há certeza de que todos os óbitos por CICS poderiam ter sido evitados por intervenção médica adequada. Conseqüentemente, subestima-se o efeito observado, quando é ignorado o grau de severidade alcançado pela doença no momento da intervenção médica.

Parece implausível supor que a varią̧ão temporal da aplicação das técnicas de classificação das causas nas declarą̧ões de óbito não influenciam a mensuração do nível da mortalidade especifica. Pode ser citado como exemplo do que ocorre, o declínio da taxa de mortalidade por septicemia, que a rigor não deve ser considerada como causa básica de óbito, como decorrente do aprimoramento no preenchimento da declaração de óbito. 
O declínio da mortalidade por CIPSS pode ser um parâmetro insatisfatório de mensuração da influência dos fatores de prevenção primária de caráter socioeconômico, independentes da ação médica. As causas de óbito que compõem o grupo não são totalmente independentes da intervenção médica, apesar da preponderância das medidas de ordem social para sua prevenção eficaz. Nesta circunstância como na anterior, ocorre subestimação do impacto da intervenção médica no declínio da taxa de mortalidade evitável.

O declínio da mortalidade por CIPSS pode não ser representativo do que ocorreria na ausência de intervenção médica. Ao aplicar o inexpressivo coeficiente de regressão da mortalidade por CIPSS observado para a maioria das capitais, bem como para seu conjunto, para estimar a taxa de mortalidade por CICS em 1992 e retratar o nível da mortalidade evitável na ausência de intervenção médica, é possível que a RME superestime o seu impacto sobre o declínio da mortalidade.

Finalmente, é inegável que grande parte do efeito observado é devido ao expressivo declínio da mortalidade por doenças infecciosas intestinais, um componente importante da mortalidade infantil, no qual a intervenção médica muitas vezes é coadjuvante de medidas de prevenção primária, como o saneamento básico. Portanto, os resultados apresentados devem ser acolhidos com reserva, e novos estudos com outros parâmetros de análise devem ser aguardados para um julgamento mais convicto sobre a importância da intervenção médica no declínio da mortalidade evitável. 
BIBLIOGRAFIA 


\section{BIBLIOGRAFIA}

1. ARMITAGE P.; BERRY G. Statistical methods in medical research. London, Blackwell Scientific Publications, 1987.

2. BAUER R.; CHARLTON J. Area variation in mortality from diseases amenable to medical intervention: the contribution of differences in morbidity. Int $J$ Epidemiol, 15: 408$412,1986$.

3. CARR-HILL R.; HARDMAN G.; RUSSEL I. Variations in avoidable mortality and variations in health care resources. Lancet, april 1987. p. 789-792.

4. CHARLTON J.; HARTLEY R.; SILVER R.; ROLAND W. Geographical variation in mortality from conditions amenable to medical intervention in England and Wales. Lancet march 26, 1983.

5. CHARLTON J;; VELEZ R. Some international comparison of mortality amenable to medical intervention. BrMed J, 292: 295-301, 1986.

6. CHARLTON J.; HARTLEY R.; SILVER R.; HOLLAND W. Geographical variation in mortality from conditions amenable to medical intervention in England and Wales. Lancet, $\operatorname{march} 26,1983$.

7. DIEHR P.; CAIN K.; CONNEL F.; VOLINN E. What is too much variation? The null hypothesis in small area analysis. Health Serv Res, 24: 741-771, 1990.

8. GAIZAUSKIENË A; GUREVICIUS R. Avoidable mortality in Lithuania. $J$ Epidemiol and Community Health, 49: 281-284, 1995. 
9. GIL L.; RATHWELL T. The effect of health services on mortality: amenable and nonamenable causes in Spain. Int J Epidemiol, 18: 652-657, 1989.

10. HOLE D.; LAMONT D. Problems in the interpretation of small area analysis of epidemiological data: the case of cancer incidence in the West of Scotland. $J$ Epidemiol and Comunity Health, 46: 305-310, 1992.

11. HOLLAND W. Commission of the European Communities. European Community atlas of "avoidable death". Health Services Research, Series no.6, Vol 1. Oxford: Osford Medical Publications, 1991.

12. HUMBLET P.; LAGASSE R.; MOENS G. et al. La mortalite evitable en Belgique. Soc Sci Med, 25: 485-493, 1987.

13. MACKENBACH J.; LOOMAN C.; KUNST A.; HABBEMA J. Post-1959 mortality trends and medical care: gains in life expectancy due to decline in mortality from conditions amenable to medical intervention in the Netherlands. Soc Sci Med, 9: 889-894, 1988.

14. MACKENBACH J.; LOOMAN C.; KUNST A.; HABBEMA J. Regional differences in mortality from conditions amenable to medical intervention in the Netherlands: a comparison of four time periods. $J$ Epidemiol and Comunity Health, 42: 325-332, 1988.

15. MACKENBACH J.; BOUVIER-COLLE; JOUGLA E. "Avoidable" mortality and health services: a review of aggregate data studies. $J$ Epidemiol and Comunity Health, 44: 106-111, 1990.

16. MACKENBACH J.; LOOMAN C.; STRONKS K.; KUNST A. The contributions of medical care to inequalities in health: differences between socio-economic groups in decline 
of mortality from conditions amenable to medical intervention. Soc Sci Med, 3: 369-376, 1989.

17. MACKENBACH J.; LOOMAN C.; KUNST A.; HABBEMA J. Regional differences in decline of mortality from selected conditions: the Netherlands, 1969-1984. Int J Epidemiol, 17: $821-829,1995$.

18. MALCOLM M.; SALMOND C. Trends in amenable mortality in New Zeland 19681987. Int J Epidemiol, 22: 468-474, 1993.

19. MORGENSTERN H. Uses of ecologic analysis in epidemiologic research. $A J P H, \mathbf{7 2 :}$ 1336-1344, 1982.

20. PAMPALON R. Avoidable mortality in Quebéc and its regions. Soc Sci Med, 37: 823$831,1993$.

21. POIKOLAINEN K.; ESKOLA J. The effect of health services on mortality: decline in death rates from amenable and non-amenable causes in Finland, 1969-81. Lancet january 1986. p. 199-202.

22. POIKOLAINEN K.; ESKOLA J. Health services resources and their relation to mortality from causes amenable to health care interventions: a cross-national study. Int $J$ Epidemiol 17: 86-89, 1988.

23. RUTSTEIN D.; BERENSBERG W.; THOMAS C. et al. Measuring the quality of medical care. A clinical method. New Engl J Med march 1976. 
24. XAVIER A.; BAYO A.; ALFONSO J.; CORTINA P.; CORELLA D.. The effectivness of health system in Valencia, Spain, 1975-1990. J Epidemiol and Comunity Health; 50: 320-325, 1996.

25. WESTERLING R.; SMEDBY B. The European community 'avoidable death indicators ' in Sweden 1974-1985. Int J Epidemiol, 21: 502-510, 1992.

26. WESTERLING R. Trends in "avoidable" mortality in Sweden 1974-1985. J Epidemiol and Comunity Health, 46: 489-493, 1992.

27. WESTERLING R. Systematic small-area variation in mortality for malignant neoplasms in Sweden. Int J Epidemiol, 24: 1086-1093, 1995.

28. WESTERLING R. Can regional variation in 'avoidable' mortality $\mathrm{b}$ explained by deaths outside hospital? A study from Sweden, 1987-90. J Epidemiol and Comunity Health, 50: 326-333, 1996.

29. WESTERLING R. Components of small area variation in death rates: a method applied to data from Sweden. J Epidemiol and Comunity Health, 49: 214-221, 1995. 
ANEXO 1

\section{ANAÁLISE EXPLORATÓRIA}

DA DISTRIBUIÇÃO DE FREQUUÊNCIA DA VARIÂNCIA 
Tabela 1. Análise descritiva da distribuiçåo de frequência da variância dos óbitos por causas evitáveis (CICS) nas capitais (1979-1982 e 1989-1992)

Causas indicadoras de cuidados de saúde - CICS

\begin{tabular}{|c|c|c|c|c|c|c|c|c|c|c|c|c|c|c|c|c|c|c|c|c|c|c|}
\hline \multirow[b]{2}{*}{$\begin{array}{l}\text { Medida } \\
\text { descritiva }\end{array}$} & & & & & & & & & & & & & & & & & & & & & & \\
\hline & Al & A2 & B1 & B2 & $\mathrm{C}_{1}$ & $\mathrm{C}_{2}$ & $\mathrm{D}_{1}$ & D2 & E1 & E2 & $F_{1}$ & $F_{2}$ & G1 & $\mathbf{G} 2$ & $\mathrm{H} \mathbf{l}$ & $\mathrm{H} 2$ & I1 & I2 & $\mathbf{J}_{1}$ & $J_{2}$ & L1 & L2 \\
\hline Média & 1,45 & 1,15 & 1,56 & 0,70 & 0,97 & 0,96 & 4,13 & 2,47 & 5,56 & 2,56 & 2,41 & 1,42 & 1,02 & 0,80 & 0,96 & 0,79 & 0,85 & 0,84 & 0,91 & 1,19 & 1,26 & 0,72 \\
\hline Mediana & 1,04 & 0,86 & 1,15 & 0,66 & 0,69 & 0,88 & 3,60 & 2,26 & 3,60 & 2,09 & 1,72 & 1,06 & 0,97 & 0,75 & 0,83 & 0,71 & 0,73 & 0,73 & 0,89 & 1,22 & 1,08 & 0,69 \\
\hline Moda & 0,85 & 0,80 & 1,12 & 0,62 & 0,64 & 0,75 & 2,96 & 2,08 & 3,22 & 1,96 & 1,50 & 0,98 & 0,00 & 0,66 & 0,81 & 0,68 & 0,60 & 0,65 & 0,84 & 1,12 & 1,03 & 0,69 \\
\hline Valor minimo & 0,16 & 0,21 & 0,22 & 0,19 & 0,12 & 0,14 & 0,84 & 0,38 & 0,56 & 0,65 & 0,44 & 0,26 & 0,00 & 0,00 & 0,25 & 0,32 & 0,16 & 0,09 & 0,00 & 0,00 & 0,50 & 0,22 \\
\hline Valor máximo & 5,34 & 3,25 & 7,08 & 1,58 & 3,28 & 3,19 & 9,33 & 6,06 & 16,54 & 5,88 & 14,60 & 7,73 & 2,29 & 1,82 & 2,41 & 1,51 & 2,63 & 2,12 & 2,65 & 3,49 & 2,48 & 1,41 \\
\hline Intervalo & 5,18 & 3,05 & 6,86 & 1,39 & 3,16 & 3,05 & 8,49 & 5,68 & 15,97 & 5,33 & 14,16 & 7,47 & 2,29 & 1,82 & 2,17 & 1,19 & 2,46 & 2,03 & 2,65 & 3,49 & 1,98 & 1,19 \\
\hline Quartil inferior & 0,45 & 0,39 & 0,79 & 0,44 & 0,47 & 0,56 & 2,09 & 1,57 & 2,39 & 1,44 & 1,01 & 0,82 & 0,71 & 0,49 & 0,62 & 0,59 & 0,55 & 0,51 & 0,38 & 0,47 & 0,81 & 0,45 \\
\hline Quartil superior & 2,02 & 1,79 & 2,20 & 0,89 & 1,36 & 1,06 & 6,37 & 3,30 & 7,21 & 3,90 & 2,49 & 1,51 & 1,46 & 0,97 & 1,22 & 0,98 & 1,21 & 1,12 & 1,19 & 1,56 & 1,74 & 1,04 \\
\hline Intervalo interquartil & 1,56 & 1,40 & 1,41 & 0,46 & 0,88 & 0,50 & 4,28 & 1,72 & 4,82 & 2,46 & 1,48 & 0,69 & 0,75 & 0,49 & 0,60 & 0,40 & 0,65 & 0,61 & 0,80 & 1,09 & 0,93 & 0,58 \\
\hline Assimetria & 1,55 & 0,97 & 2,87 & 0,71 & 1,66 & 1,76 & 0,52 & 0,91 & 1,21 & 0,74 & 3,53 & 3,74 & 1,14 & 0,60 & 1,25 & 0,80 & 1,35 & 0,97 & 0,88 & 0,87 & 0,73 & 0,45 \\
\hline
\end{tabular}

Legenda:

Al e A2 - Doenças infecciosas intestinais, 1979-1982 e 1989-1992, respectivamente

B1 e B2 - Tuberculose, 1979-1982 e 1989-1992, respectivamente

C1 \& C2 - Septicemia, 1979-1982 e 1989-1992, respectivamente

D1 e D2 - Melanome maligno da pele, 1979-1982 e 1989-1992, respectivamente

E1 e E2 - Tumor maligno do útero náo especificado, 1979-1982 e 1989-1992, respectivamente

F! — F2 - Tumor maligno do colo do útero, 1979-1982 e 1989-1992, respectivemente

G1 e G2 - Doença de Hodgkin, 1979-1982 e 1989-1992, respectivamente

H1 e H2 - Diabetes melito, 1979-1982 e 1989-1992, respectivamente

Il e I2 - Meningites, 1979-1982 e 1989-1992, respectivarnente

J1 e J2 - Doença reumática crónica do coracto, 1979-1982 e 1989-1992, respectivamente

L1 e L2 - Hipertensáo arterial, 1979-1982 e 1989-1992, respectivamente 
Tabela 2. Análise descritiva da distribuição de frequência da variância dos óbitos por causas evitáveis (CICS) nas capitais (1979-1982 e 1989-1992)

Causas indicadoras de cuidados de saúde - CICS

Medida

descritiva

$\begin{array}{llll}\mathbf{M}_{1} & \mathbf{M}_{2} & \mathbf{N} 1 & \mathbf{N} 2\end{array}$

o1

$\mathbf{P}_{1} \quad \mathbf{P}_{2}$

$\mathbf{Q}_{2}$

Q2 $\quad R_{1}$

R2

si

$\mathrm{T} 1$

T2

U2

$v_{1} \quad v_{2} \quad x_{1}$

$\mathrm{X}_{2}$

22

Média

Mediana

Moda

Valor minimo

Valor máximo

Intervalo

Quartil inferior

Quartil superior

Intervalo interquartil

Assimetria

\begin{tabular}{|c|c|c|c|c|c|c|c|c|c|c|c|c|c|c|c|c|c|c|c|c|c|c|c|}
\hline 20 & 77 & 60 & 66 & 87 & 0,69 &, 41 & 74 & 25 & 63 & 37 & 75 & 38 & 75 & 52 & 83 & 15 & 85 & 46 & 97 & 07 & 94 & 07 & 04 \\
\hline 10 & 79 & 0,39 & 63 & 77 & 0,68 & 12 & 64 & 16 & 57 & 1,04 & 72 & 98 & 73 & 1,21 & 63 &, 92 & 78 &, 30 & 90 &, 35 &, 76 & .02 & 0,58 \\
\hline 16 & 73 & 0,34 & 0,54 & 0,69 & 0,66 & 00 & 0,55 & 0,00 & 00 & 1,01 & 72 & 0,93 & 71 & 1,02 & 00 & 0,88 &, 77 & 1,26 & 88 &, 27 & ,69 &, 92 & 51 \\
\hline & 30 &, 06 &, 00 & 26 & 0,35 & 45 & 24 &, 00 & 00 & 0,58 & 34 & 0,00 & 34 & .00 & 00 & 0,00 & 00 & 56 & 33 & 18 & 24 & 17 & 89 \\
\hline 56 & 1,29 & 2,56 & 2,18 & 1,89 & 1,05 & 3,90 & 1,95 & 4,14 &, 67 & 4,25 & 1,78 & 4,60 &, 78 & 5,46 & 1,86 & 2,79 & 1,69 & 3,07 & 2,11 & 10,38 & 2,54 & 3,62 & 4,49 \\
\hline 30 & 0,99 & 2,49 & 2,18 & 1,62 & 0,70 & 3,45 & .71 & 4,14 & 67 & 3,67 & ,44 & 4,60 & 1,44 & 5,46 & 1,86 & 2,79 & 1,69 &, 51 & 1,77 & 10,20 & 2,30 & 3,46 & 4,41 \\
\hline 86 & 0,63 & 0,17 & 0,21 & 0,60 & 0,51 & 0,78 & 0,48 & 0,55 & 35 & 0,89 & 57 & 0,73 & ,56 & 0,76 &, 41 & 0,67 & 0,53 & 1,11 & 0,68 & 86 & 0,61 &, 44 & 0,33 \\
\hline 31 & 0,94 & 0,79 & 0,89 & 1,08 & 0,82 & 1,76 & 0,98 & 1,85 & .87 & 1,61 & 1,90 & 1,65 & 89 & 1,84 & 1,31 & 1,65 & 1,27 & 1,66 & 1,01 &, 55 & 1,24 & 2,38 & 1,64 \\
\hline 49 & 0,31 & 0,63 & 0,67 & 0,47 & 0,31 & 0,99 & 0,50 & 1,30 & 52 & 0,72 & 0,33 & 0,92 & 0,33 & 1,09 & 0,90 & 0,98 & 0,74 & 0,55 & 0,33 & 1,70 & 0,64 & 1,94 & 1,31 \\
\hline 50 & $-0,06$ & 1,79 & 1,18 & 0,96 & 0,24 & 1,35 & 1,39 & 1,05 & 0,73 & 2,05 & 1,53 & 1,67 & 1,47 & 1,82 & 0,58 & 0,86 & 0,13 & 1,05 & 1,21 & 2,78 & 1,43 & 2,83 & 1,85 \\
\hline
\end{tabular}

Legeada:

M1 e M2 - Doença cerebrovascular, 1979-1982 e 1989-1992, respectivamente

N1 e N2 - Infeç̧סes respiratórias aqudas, 1979-1982 e 1989-1992, respectivemente

O1 \& O2 - Pneumonia e gripe, 1979-1982 e 1989-1992, respectivamente

P1 e P2 - Doença pulmoner obstrutiva crónica, 1979-1982 e 1989-1992, respectivemente

Q1 e Q2 - Asms, 1979-1982 e 1989-1992, respectivamente

R1 e R2 - Úlcera gastrica, duodenal e jejunal , 1979-1982 e 1989-1992, respectivamente

S1 e S2 - Apendicite, 1979-1982 e 1989-1992, respectivamente

T1 e T2 - Hemia da cavidade abdominal, 1979-1982 e 1989-1992, respectivamente

U1 e U2 - Colelitfase e colecistite, 1979-1982 e 1989-1992, respectivamente

$\mathrm{V} 1$ e V2 - Nefrite e nefrose

X1 e X2 - Complicą̧lo de gravidez, parto e puerptrio, 1979-1982 e 1989-1992, respectivamente

$Z 1$ e Z2 - Sintomas, sinais e afeç̧бes mal definidas, 1979-1982 e 1989-1992, respectivernente 